\title{
Clarifying Resource Dependence: A Multi-Dimensional Approach to Dependence and Autonomy in Entrepreneurial Firms
}

\author{
Curtis R. Sproul
}

Follow this and additional works at: https://researchrepository.wvu.edu/etd

\section{Recommended Citation}

Sproul, Curtis R., "Clarifying Resource Dependence: A Multi-Dimensional Approach to Dependence and Autonomy in Entrepreneurial Firms" (2017). Graduate Theses, Dissertations, and Problem Reports. 6705. https://researchrepository.wvu.edu/etd/6705

This Dissertation is protected by copyright and/or related rights. It has been brought to you by the The Research Repository @ WVU with permission from the rights-holder(s). You are free to use this Dissertation in any way that is permitted by the copyright and related rights legislation that applies to your use. For other uses you must obtain permission from the rights-holder(s) directly, unless additional rights are indicated by a Creative Commons license in the record and/ or on the work itself. This Dissertation has been accepted for inclusion in WVU Graduate Theses, Dissertations, and Problem Reports collection by an authorized administrator of The Research Repository @ WVU.

For more information, please contact researchrepository@mail.wvu.edu. 


\title{
Clarifying Resource Dependence: A Multi-Dimensional Approach to Dependence and Autonomy in Entrepreneurial Firms
}

\author{
Curtis R. Sproul \\ Dissertation submitted \\ to the College of Business and Economics \\ at West Virginia University \\ in partial fulfillment of the requirements for the degree of \\ Doctor of Philosophy in Business Administration \\ Concentration in Management \\ David D. Dawley, Ph.D., Chair \\ Abhishek Srivastava, Ph.D. \\ Miles A. Zachary, Ph.D. \\ Amanda Ross, Ph.D. \\ Matthew R. Marvel, Ph.D., Outside Committee Member \\ Department of Management
}

Morgantown, West Virginia

2017

Keywords: Entrepreneurship, Resource Dependence, Autonomy, Remedies Copyright 2017, Curtis R. Sproul 


\section{ABSTRACT \\ Clarifying Resource Dependence: A Multi-Dimensional Approach to Dependence and Autonomy in Entrepreneurial Firms}

\section{Curtis R. Sproul}

Entrepreneurial firms face dependence on other firms in the external environment to access resources critical for the development and survival of the firm. While substantial research has examined resource dependence and how firms may remedy such dependencies, the literature often fails to acknowledge key factors that can predict and explain firm behavior and outcomes in such situations. Firms are shown to enter into inter-organizational relationships in order to remedy resource dependencies, but studies typically evaluate such relationships according to their structure, rather than the resource being sought. Research also frequently ignores the role of autonomy in resource dependence. As gaining autonomy is the primary goal of resource dependence remedies, studies thus often assume autonomy is gained or may fail to consider the social complexity of the environment. Resource dependence remedies are also shown to vary in terms of their relationship to performance, creating additional questions within the literature. This dissertation seeks to shed light on these issues by considering the type of resource sought during a dependence remedy, the role of autonomy in dependence remedies, and how remedies relate to firm performance. 


\section{TABLE OF CONTENTS}

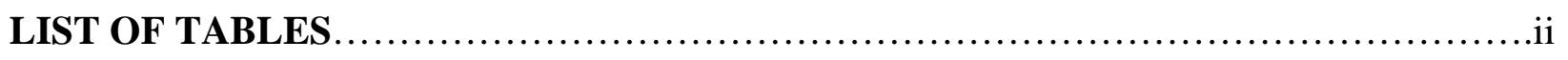

CHAPTER I: INTRODUCTION..................................................

CHAPTER II: LITERATURE REVIEW ........................................ 11

CHAPTER III: HYPOTHESES DEVELOPMENT ................................. 54

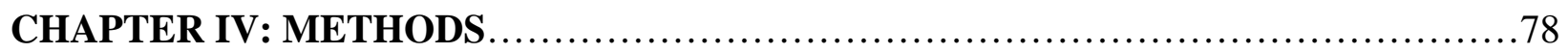

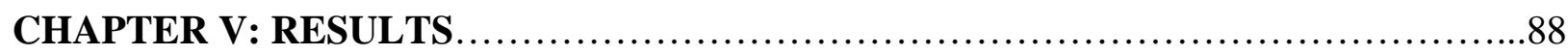

CHAPTER VI: DISCUSSION................................................ 94

CHAPTER VII: CONCLUSION............................................. 109

REFERENCES............................................................... 110 


\section{LIST OF TABLES}

Table 2.1. Results of review focused on resource dependence in entrepreneurial firms.........127

Figure 3.1. Model.............................................................. 135

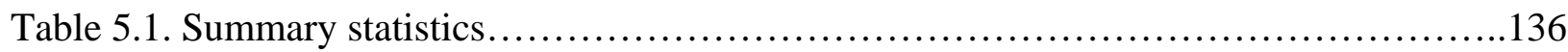

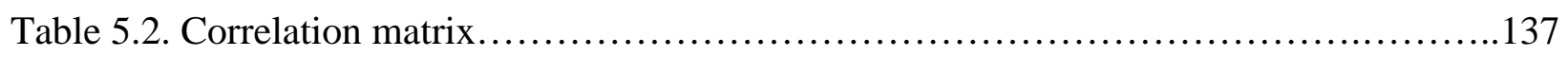

Table 5.3. Mixed-effects regression analysis.........................................138

Table 5.4. Sobel-Goodman mediation analysis....................................139

Table 5.5. Sobel-Goodman mediation analysis......................................140

Table 5.6. Sobel-Goodman mediation analysis......................................141

Table 5.7. Mixed-effect regression analysis for moderation..............................142

Table 5.8. Mixed-effects binomial regression......................................143

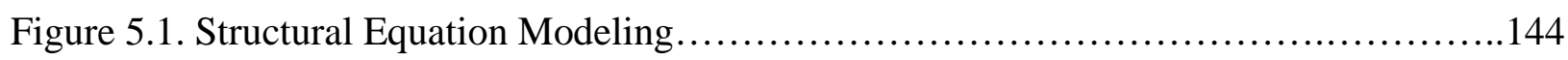

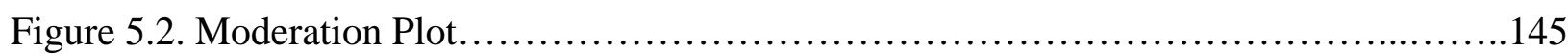




\section{CHAPTER I: INTRODUCTION}

Resource dependence theory (RDT) (Pfeffer, 1972a; Pfeffer, 1972b; Pfeffer, 1972c;

Pfeffer \& Salancik, 1978) explains how organizations are influenced by their external environment and what actions may be taken to manage the environment. The theory suggests that organizations are embedded in social relationships and interdependent networks with other organizations that may have differing goals. These social relationships and networks are influenced by power, causing some organizations to be dependent on other organizations for critical resources. Dependence on other organizations creates circumstances in which the survival and success of the focal organization are uncertain (Pfeffer, 1987).

Considerable attention is devoted to the question of how firms alleviate their dependencies on other firms, referred to in this dissertation as dependence remedies. Researchers discuss many remedies, often focusing on inter-organizational relationships (IORs) such as joint ventures (e.g., Pfeffer \& Nowak, 1976), alliances (e.g., Xia, 2011), mergers and acquisitions (e.g., Finkelstein, 1997), as well as the board of directors (Hillman, Cannella, \& Paetzold, 2000). Researchers also examine how remedies lead to outcomes such as firm performance (e.g., Lavie, 2007), the likelihood of a merger (e.g., Wang \& Zajac, 2007), and alliance outcomes (e.g., Hoang \& Rothaermel, 2005). These antecedents and outcomes may vary in detail, but each represents a specific action by a firm in conjunction with another firm and that action's outcome, taken in an attempt to remedy dependence. This dissertation examines such antecedents and outcomes by focusing specifically on inter-organizational relationships (IORs) such as joint ventures, alliances, mergers and acquisitions, as well as the board of directors' composition. Firms frequently utilize these remedies, providing an opportunity to more carefully examine the relationship between resource dependence remedies and their outcomes. 
Firms taking action to remedy dependence are seeking autonomy. Autonomy is a firm’s freedom to make decisions regarding its internal resources without external influence (Oliver, 1991a). Pfeffer (2003) explains that autonomy is a critical concept for achieving desired outcomes in RDT. Further, autonomy considers actors and concepts beyond customers and products that were the primary focus of organizational research before RDT (Pfeffer, 2003). Suppliers, government firms, and other actors in the environment that can affect the resources of a firm may be considered when examining a firm’s autonomy (Pfeffer, 2003). As such, autonomy is a critical component of RDT research.

RDT provides a strong theoretical lens for examining firms because it recognizes that firms exist within a larger social environment comprised of other firms that may have differing goals, and that those firms may exercise power and control over a focal firm by constraining its resources (Wry, Cobb, \& Aldrich, 2013). Additionally, firms are unable to meet all of the various demands arising from the environment (Pfeffer \& Salancik, 1978). RDT’s recognition of power as an important aspect of IORs helps explain what demands a firm chooses to meet and may explain what otherwise appears to be irrational behavior (Pfeffer, 1987). At the same time, RDT may consider more rationally sought outcomes such as firm performance (e.g., Kor \& Leblebici, 2005). By looking beyond efficiency-based reasons for IORs, RDT provides a more holistic approach to understanding strategic firm choices and their consequences (Pfeffer, 2003).

\section{Problematic Issues in Resource Dependence Research}

While resource dependence research has made considerable empirical and theoretical advancements (Cascario \& Piskorski, 2005), unexplored and unanswered questions remain. This dissertation explores four specific problems that prevent researchers from completely explaining and predicting firm actions and outcomes: (1) inadequate explanation of how different specific 
resource needs are remedied, (2) a lack of theoretical and empirical work regarding autonomy, (3) failure to consider how different remedies for dependence relate to different types of performance, and (4) failure to consider how firms may prevent new dependencies from developing when firms take action to reduce dependence. Discussion of these problems continues in greater detail in the following paragraphs.

First, RDT often explores remedies for dependence according to the structure of the remedy, rather than the resource being sought. To better understand these remedies, more focus should be given to the initial dependencies that firms face. While some research has examined different types of dependence (e.g., Gabrielsson, 2007), a thorough understanding of the differences between resource dependence remedies and their outcomes does not exist (Drees \& Heugens, 2013; Hillman, Withers, \& Collins, 2009). By having a clearer understanding of the specific dependencies that firms face, research in RDT can better explain how firms can remedy such dependencies and capture additional benefits. For example, the success of joint ventures (e.g., Das \& Teng, 2003), acquisitions (e.g., Moatti, Ren, Anand, \& Dussauge, 2015), or the appointment of a specific type of director to the board (e.g., Lester, Hillman, Zardkoohi, \& Cannella, 2008) typically dominate the literature. While these avenues of study are important to the understanding of firms, they often ignore the type of resource sought by the firm. For example, firms seeking manufacturing resources are likely to enter into IORs with corporations, while firms seeking marketing resources are not (Katila, Rosenberger, \& Eisenhardt, 2008). Research ignoring the type of dependence may thus be overlooking an important explanatory characteristic.

Second, studies using a resource dependence lens often overlook autonomy as a distinct construct of material importance. Originally conceived as an industry-level construct (Burt 1979; 
1980), autonomy has also been used at the firm-level to measure the ability to deal with payment problems and independence from government (Peng \& Luo, 2000), subunit power (Galang \& Ferris, 1997), cash on hand (Uzzi, 1999), and management (as opposed to ownership) controlled firms (Stearns \& Mizruchi, 1986). Broadly speaking, autonomy has been shown to mediate the relationship between IORs and performance (Drees \& Heugens, 2013). However, scholars lack a sufficient conceptual understanding of autonomy. The limited development of the autonomy construct has led to a multitude of operationalizations, which further complicates the understanding of resource dependence and the outcomes firms seek through dependence remedies. Furthermore, research suggests that autonomy is multifaceted. For example, Drees and Heugens (2013) find that autonomy differs when IORs are ownership-based and non-ownershipbased. Given that autonomy mediates the relationship between actions that remedy dependence and performance, a clearer understanding of the construct, as well as what types of autonomy may exist may provide evidence that further explains the remedies that firm pursue in their attempts to reduce dependence, and how those attempts relate to firm performance.

Third, RDT is not a consistent predictor of firm performance (Drees \& Huegens, 2013). Pfeffer and Salancik (1978) argue and Pfeffer (2003) conspicuously states that remedies for dependence are sometimes successful. Additionally, RDT does not assume that firm actions are taken with conscious, economically beneficial factors in mind, nor does it exclude such actions (Pfeffer \& Salancik, 1978; Pfeffer, 1987). Burt (1983) addresses one aspect of mixed performance results and uncertain drivers of dependence remedies, suggesting that cooptive IORs are maintained as long as they are beneficial to both firms, therefore producing little variance in outcomes. Burt's (1983) reasoning, though, focuses only on the exercise of power. Indeed, RDT produces both positive (e.g., Lavie, 2007) and negative (e.g., Koka \& Prescott, 
2008; Hayward, 2003) relationships with firm performance. Additionally, no specific link between remedy and performance type has been investigated. Understanding differences in performance outcomes and what performance types are likely to arise from specific remedies can significantly advance the resource dependence literature.

Finally, Pfeffer (1987) suggests that remedies for resource dependence are likely to produce new sets of dependencies, leaving firms in new but still dependent situations. For example, firms may appoint a new board member from a financial institution in an attempt to remedy a need for capital, only to become dependent on the financial institution for survival and thus influenced by the new board member (Mizruchi, 1996). In contrast, IORs involving a degree of cooperation or that provide complementary resources in addition to the exchanged resources may create a set of conditions that lead to mutual benefit for both firms (Oliver, 1990). Oliver (1990) suggested that IORs could exist due to reciprocity, efficiency, or stability. IORs that do exist for these reasons, rather than coercion, may bring benefits to the firm instead of new dependencies that require remedies.

\section{Dissertation Goals and Specific Research Questions}

This dissertation addresses the above problems by examining the IORs of entrepreneurial firms. Firms engage in IORs to gain access to resources that they currently lack (e.g., Meyer, Estrin, Bhaumik, \& Peng, 2009). Entrepreneurial firms are especially likely to be dependent upon others for critical resources needed for survival and growth as they are often unable to create or acquire such resources organically (Daily, McDougall, Covin, \& Dalton, 2002). For example, access to outside capital leads to growth, as firms gain the flexibility to hire additional employees or increase R\&D spending (Baum \& Silverman, 2004; Columbo \& Grilli, 2010). Additionally, entrepreneurial firms rarely possess all the resources required for operations (Katila 
et al., 2008). For example, manufacturing facilities are very costly and typically take multiple years to build (Park, Chen, \& Gallagher, 2002). Such facilities are critical resources for entrepreneurial firms, as manufacturing resources allow for greater control over the manufacturing process (Park et al., 2002) and lead to higher firm performance (Zahra \& George, 1999). Entrepreneurial firms may also lack marketing resources, which provide the ability to enter new markets (Koka \& Prescott, 2008), or access to additional brands and products (Kalaignanam, Shankar, \& Varadarajan 2007). Resources such as these are shown to not be interchangeable (Ozmel, Robinson, \& Stuart, 2013), suggesting that entrepreneurial firms may seek any or all of them depending on their specific dependencies.

In order to contribute to theory that explains and predicts the relationship between dependence remedies, autonomy, and firm performance, this dissertation examines how types of resource dependence are remedied and the outcomes of such remedies. Overall, this dissertation seeks to better explain and predict the relationship between resource dependence remedies and firm performance by investigating IORs that grant access to different types of resources, how those varied resources provide autonomy to the firm, and how that autonomy affects firm performance. Additionally, the ability of complementary resources to provide benefits in IORs, as opposed to creating new dependences (Pfeffer, 1987) is evaluated. In doing so, contributions and clarification are provided to resource dependence theory.

Considering the different types of resources, remedies, and characteristics of autonomy previously discussed, research questions relating to how entrepreneurial firms remedy dependencies will now be developed. Each research question follows the previous arguments regarding problems present in resource dependence theory. The first question focuses on types of resource dependence. Firms facing dependencies utilize several different strategies to remedy 
dependence and (Pfeffer \& Salancik, 1978). For example, firms utilize joint ventures (Pfeffer \& Nowak, 1976), mergers and acquisitions, (Pfeffer, 1972b), alliances (Barringer \& Harrison, 2000), and the board of directors (Pfeffer, 1972c) in attempts to reduce dependence. However, research has primarily focused on the strategies themselves, rather than the resources being sought. While some scholars examine dependencies based on alliance types (Das, Sen, \& Sengupta, 1998) and resources types (Katila et al., 2008), little theoretical development of specific types of dependence has occurred. The need for such examination is apparent, as outcomes have been shown to differ depending on the type of resource sought (Katila et al., 2008) and the manner in which the resource is acquired (Das et al., 1998). Therefore, the first research question asks:

1: How are different resource dependencies remedied?

The next research question seeks to further explain the varying relationship between resource dependence remedies and firm performance (Drees \& Huegens, 2013). Entrepreneurial firms require resources for growth and survival (Daily et al., 2002) and thus are likely to seek remedies that lead to performance. However, RDT suggests that firm attempts to remedy dependencies are not guided by rational decision processes, and so may or may not result in the intended consequence (i.e., higher performance) (Pfeffer, 1987). Indeed, research finds both positive (e.g., Luo \& Park, 2004) and negative (e.g., Koka \& Prescott, 2008) relationships between remedies and firm performance. This begs the question of how different types of dependence remedies are related to performance. Thus, the second research question asks: 
2: How are different resource dependence remedies related to performance?

Autonomy is considered a key construct in RDT (Pfeffer \& Salancik, 1978) and IORs in general (Oliver, 1991a). However, research has failed to develop autonomy in a meaningful way. Oliver (1991a) proposed that autonomy has a positive relationship with firm performance, stemming from three distinct sources. Autonomy allows a firm to (1) meet the demands of multiple external actors simultaneously, (2) respond to unforeseen contingencies, and/or (3) avoid opportunistic behavior on the part of other parties. Scholars have investigated autonomy in a wide variety of contexts, such as network effects (Uzzi, 1999), avoiding dependence on powerful actors (Peng \& Luo, 2000), and internal control of the firm (Stearns \& Mizruchi, 1986). These varying uses of autonomy suggest a lack of consensus regarding an important theoretical construct. As previously discussed, resource dependence is proposed to possess different characteristics depending on the type of resource being sought. It is unlikely that such differences will lead to autonomy in similar manners. Given the various treatments of autonomy in the literature, autonomy also appears likely to possess different characteristics depending on the resource sought by the firm. These largely unexplored differences in autonomy lead to the third research question.

3. How does autonomy affect the relationship between dependence remedies and performance?

Assumptions in RDT suggest that firms undertaking dependence remedies will also create new dependencies, effectively trading one set of dependencies for another (Pfeffer, 1987). 
However, firms may instead be able to create joint dependence, causing firms to work together for mutual benefit rather than attempting to impose their will on each other (Gulati \& Sytch, 2007). Given that such IORs may be characterized by joint dependence insofar as both parties are mutually dependent on each other, it begs the fourth research question, which asks:

4: How can dependence remedies prevent new, negative dependencies, from forming?

\section{Organization of Dissertation}

This dissertation consists of seven (7) chapters. This introduction serves as the first chapter. Chapter I has presented and overview of the problematic issues facing research in resource dependence and firm performance, explained the goals of the dissertation and specifically stated research questions relating to resource dependence remedies, autonomy, and

firm performance. Chapter II reviews relevant literature in the areas of RDT in general, including power, dependence types, IORs, autonomy, and performance. Chapter II seeks to present the seminal work in RDT, evaluate the current state of the literature, and identify areas in need of further research.

Chapter III builds on the literature review in Chapter II, integrates theory on the role of complementary resources in IORs, and develops specific hypotheses that test the relationship between dependence remedies, autonomy, firm performance, and complementary resources. Nine hypotheses are developed based on the research questions expressed in Chapter I.

Chapter IV discusses the methodology of the dissertation. It presents the research design, data sources, variables, operationalizations, and empirical analysis used for testing. Next, 
Chapter V presents the results of the hypotheses given in Chapter III based on the methods detailed in Chapter IV.

Chapter VI discusses the results of the analysis, their implications for management scholars, and the contributions of the dissertation. Limitations are also discussed. Finally, Chapter VII contains the overall conclusion. 


\section{CHAPTER II}

\section{LITERATURE REVIEW}

While research in resource dependence has been prolific and expanded well beyond the original theory (Pfeffer \& Salancik, 1978), many core ideas related to resource dependence theory are often overlooked in the literature. This development has caused one of the original authors of the theory to remark that it has been reduced to a “...metaphorical statement about organizations” (Pfeffer, 2003, p. xvi). Wry et al. (2013) examine this claim and review the overall impact and contributions of the original theory, as well the phenomenon investigated. Overall, results show that many scholars fail to consider issues related to the external environment and interactions between firms (Wry et al., 2013). Several unanswered questions remain regarding how firms remedy dependence.

First, the autonomy of a firm is an important consideration (Oliver, 1991b). Firms facing power disadvantages lack autonomy, which constrains the actions they may take and causes dependence (Pfeffer, 1987). The extent of a firm's dependence is related to the importance of the resource to the focal firm, the extent to which the resource provider has authority over resource distribution, and the availability of alternative substitute resources (Pfeffer \& Salancik, 1978). Autonomy is shown to be a critical component in the relationship between resource dependence remedies and firm performance (Drees \& Heugens, 2013), but is often overlooked in the literature (Wry et al., 2013).

Second, research examining remedies for dependence often focus on the structure of the inter-organizational relationship (IOR) used as a remedy, while ignoring the type of resource sought. For example, studies examine joint ventures (e.g., McCann, 1991) or the board of directors (e.g., Lynall, Golden, \& Hillman, 2003). A focus on the structure of the IOR is relevant, 
but there are important issues related to the type of resource sought. Katila, Rosenberg, and Eisenhardt (2008) find that the scarcity of a resource and level of commitment required to obtain it produces different decisions by firms regarding how to access such resources. Examination of the commitment and type of resource sought may help shed additional light on the relationship between resource dependence remedies and performance.

Finally, entrepreneurial firms may be especially vulnerable to resource dependency (Daily, McDougall, Covin, \& Dalton, 2002). As entrepreneurial firms tend to be younger and smaller, they likely lack the resources needed to grow and succeed (Lynall, Golden, \& Hillman, 2003). Firms seek resources from other firms in the external environment (e.g., Baum \& Silverman, 2004) to overcome such a liability of smallness (Aldrich \& Auster, 1996). However, a lack of resources creates situations in which entrepreneurial firms may lack bargaining power, making it difficult to overcome resource dependencies. Indeed, firms seeking remedies may simply trade one dependency for another (Pfeffer, 1987), face power disadvantages that reduce firm performance (e.g., Gulati \& Sytch, 2007), or control by IOR partners (e.g., Mizruchi, 1996).

This chapter progresses as follows. First, this chapter presents an overview of theories that are frequently used in the literature to predict and explain firm behavior and outcomes related to environmental dependence and remedies. Second, the literature on environmental dependence and the remedies for such dependence will be reviewed. The purpose of this review is to evaluate the existing research and identify potential research deficiencies that deserve future study.

\section{Theoretical Explanations}

\section{Resource Dependence Theory}

Resource dependence theory was developed to explain how organizations influence other organizations in the external environment, and what may be done to manage the environment 
(Pfeffer \& Salancik, 1978). Pfeffer (1987) explicitly presented the underlying assumptions for resource dependence. First, organizations are the fundamental units of analysis in the study of intercorporate relations and society. Second, organizations are constrained by environments comprised of interdependent organizations, causing a lack of autonomy. Third, organizational survival and success are uncertain due to the unforeseeable actions of interdependent organizations. Fourth, organizations will seek to reduce or remedy interdependencies. However, these actions are likely to create new interdependent situations, suggesting that some level of interdependence will always be present. Lastly, dependence and interdependence dictate both inter-organizational and intra-organizational power. This power then affects the actions of the organization. The integration of theory about interdependent organizations and power allows for predictions about organizational responses (Wry, Cobb, \& Aldrich, 2013).

Based on these assumptions, Pfeffer and Salancik (1978) explain the task of organization management as the management of a coalition that ensures the survival of the organization. The coalition is made up of actors both inside and outside the focal organization. Interdependence between the coalition and focal organization can be beneficial when actors work together for mutual benefit but is difficult when there are conflicting and competing demands from coalition members (Pfeffer \& Salancik, 1978). These demands can cause dependence, which is a factor of three things: the importance of the resource to the focal firm, the extent to which the resource provider has authority over resource distribution, and the availability of alternative substitute resources (Pfeffer \& Salancik, 1978). These ideas build upon earlier work in power (Emerson, 1962) and organizational environments (Thompson, 1967) that describe interactions between actors. 
Emerson's (1962) theory of power relations incorporated power, authority, legitimacy, and power structures into one theory. Emerson defines power as the amount of resistance by actor B that actor A can overcome. The relational aspect of each actors' power over the other makes the insight novel for its time. Emerson notes that the power of A over B does not necessarily cancel out the power of B over A, as this power may not be balanced. For example, a business owner and key employee may have power over the other. However, the relationship may be unbalanced if the employee has made threats to leave the business without notice and the owner has no viable alternative to replace the employee.

Thompson (1967) continued research in power by raising the level of analysis to the organization. Organizations aim to shield or insulate a technical "core" from uncertainty in the environment. By instituting systems that control resources, organizations can effectively create contingencies for uncertainty and optimally exploit their technological advantage. Thompson (1967) explains the process of managing external contingencies as 'bridging” and suggests that alliances, joint ventures, mergers, and cooptation are some of the available tools for managing such contingencies. Indeed, many of these tools are used by Pfeffer and colleagues to explain remedies for resource dependence (Pfeffer 1972b; Pfeffer \& Nowak, 1976; Pfeffer \& Salancik, 1978).

Pfeffer also contributed early empirical results and theoretical development to power issues stemming from three separate types of interdependence (1972b; 1972c). First, symbiotic interdependence exists between firms in a buyer and supplier relationship. In this case, interdependence causes uncertainty related to necessary inputs and maintaining important customers. Second, competitive interdependence exists between two firms engaged in similar businesses and competing for the same customers. Uncertainty then stems from the competition 
present in their environment, as firms are unsure about the actions of their rivals. Lastly, firms may diversify to move away from previous interdependencies.

The primary focus of the RDT literature is investigating action taken by organizations to remedy dependence. One remedy involves utilizing the board of directors to bring various benefits to the firm. Pfeffer and Salancik (1978) propose that directors bring four benefits to an organization that can help remedy dependence. First, directors bring valuable information in the form of advice and counsel related to firm activities (e.g., Hillman \& Dalziel, 2003). Second, directors provided access to information external to the organization through their personal relationships (e.g., Hillman, 2005). Third, the same relationships could bring preferential access to resources (e.g., Mizruchi \& Stearns, 1994). Finally, directors could add legitimacy to an organization (e.g., Certo, Daily, \& Dalton, 2001).

Firms may also remedy dependencies by utilizing alliances and joint ventures to gain access to resources (Bae \& Gargiulo, 2004). Alliances help firms avoid uncertainty present in the external environment, seek out cooperation (Steensma, Marino, Weaver, \& Dickson, 2000), and reduce interdependence (Gulati \& Gargiulo, 1999). In general, firms prefer the lower commitment level of a joint venture or alliance, compared to the higher commitment required for a merger or acquisition (Folta, 1998). However, higher commitments are sometimes required to access scarce resources. Mergers and acquisitions also allow firms to access needed resources but require a higher commitment than the more temporary nature of alliances or joint ventures. Pfeffer (1972b) began work in mergers through the lens of resource dependence, finding that interdependence between firms is likely to lead to a merger, which then reduces interdependence (Pfeffer, 1972b). Mergers are used to reduce symbiotic interdependence resulting from buyer- 
supplier relationships, competitive interdependence resulting from the actions of rival firms, and for diversification purposes (Pfeffer, 1972b; Finkelstein, 1997).

\section{Resource-Based Theory}

The resource-based view (RBV) of the firm states that firms gain a competitive advantage when the resources they control are valuable, rare, inimitable, and non-substitutable (Barney, 1991). The RBV proposes that resources are developed internally (Barney, 1991), but resources can also be accessed externally through various types of alliances (Das \& Teng, 2000). Entrepreneurial firms, which typically lack the internal resources required for firm growth and survival, are especially likely to seek necessary resources externally (Alvarez \& Busenitz, 2001). Firms whose resources are immobile and non-substitutable are more likely to seek out other necessary resources through alliances (Das \& Teng, 2000). Das and Teng (2000) further propose that firms seeking resources from alliances benefit when resources match in a particular way. Alliances between firms with similar resources, or with dissimilar resources that are complementary to each other are proposed to increase performance (Das \& Teng, 2000).

While early research in the RBV (Barney, 1991) focused on strategic management and used entrepreneurship mostly as a context, additional research demonstrates that the RBV can provide a clear lens to predict and explain how entrepreneurs and their firms create heterogeneous resource bundles (Alvarez \& Busenitz, 2001). Alvarez and Busenitz (2001) explain that the RBV applies to entrepreneurship by defining the opportunity-seeking behavior and resource organization capabilities of firms as resources. Applying the RBV to entrepreneurial firms seeking external remedies for dependence can explain how resources are involved in the formation of such remedies. Firms possessing complementary resources are more likely to create economic value (Alvarez \& Barney, 2001). However, the RBV may overlook the relational aspect of the remedies (Alvarez \& Barney, 2001). For example, the size difference 
between large, established firms and entrepreneurial firms can result in unenforceable contracts and the exploitation of the entrepreneurial firm by the larger firm (Lu \& Beamish, 2006). Firms whose resources are rare, valuable, inimitable, and non-substitutable are less to face highly dependent situations, as they already possess critical resources needed for survival. However, firms seeking such resources may face dependence, as options for accessing such resources are likely to be limited, and firms controlling them are likely to have strong bargaining power. Alvarez and Barney (2001) succinctly describe the benefit of resource acquisition and the potential drawbacks associated. One interviewed firm, near bankruptcy, entered into an agreement worth $\$ 5$ million dollars in revenue from a large partner, saving the firm. Conversely, another firm described how their larger partner gained access to their technology and commercialized it without them, leaving their employees out of work and the firm bankrupt (Alvarez \& Barney, 2001). While these issues are ignored in some RBV studies, another stream of the literature focuses on the relational aspects of resources.

Dyer and Singh (1998) explain how firms may gain a competitive advantage by working together in IORs to generate relational rent. Relational rent represents returns from the use of a production factor that is greater than the next-best use of that factor (Peteraf, 1994). Trading partners are more likely to generate relational rents when they possess relation-specific assets, utilize knowledge-sharing routines, identify and access complementary resources between firms, and engage in effective governance (Dyer \& Singh, 1998). Lavie (2006) expands on this relational view by considering firms in alliance networks. In addition to the relational rent described by Dyer and Singh (1998), firms may benefit from inbound spillover rent gained through opportunistic behavior toward an alliance partner. More specifically, firms may seek to understand the advantages possessed by an alliance partner and use that knowledge for their 
gain. Firms may also lose outbound spillover rent when alliance partners behave in such ways towards the focal firm (Lavie, 2006). The concept of relational rents runs counter to some assumptions and recommendations of resource dependence theory, as they infer that all firms may not have conflicting goals and that the primary goal of firms may not be to increase the dependence of other firms. In such cases, firms may successfully remedy dependence by correctly identifying IOR partners that will also seek relational rents and work for the benefit of both firms. However, spillover rents suggest that opportunism remains, that dependence may still occur and that both positive and negative outcomes of IORs are possible.

\section{Institutional Theory}

Institutional theory is largely concerned with legitimacy, whereby firms adopt the formal structures and norms of other firms in the environment (Meyer \& Rowan, 1977). Such structures and norms are typically accepted as necessary without consideration regarding their effect on the operations of a firm. As these structures and norms are backed by public opinion, a lack of legitimacy that can be a threat to the survival of the firm (Meyer \& Rowan, 1977), and young firms may lack legitimacy due to a liability of newness (Stichcombe, 1965). Pfeffer and Salancik (1978) suggest that a lack of legitimacy is one form of dependence and that firms seeking to remedy a lack of legitimacy may do so by entering into IORs with other firms.

Firms can gain legitimacy by entering into an IOR with other firms that are already considered legitimate (Barringer \& Harrison, 2000). However, such legitimizing processes can be a drain on financial resources, as a larger partner granting legitimacy may lower the profitability of an IOR. These costs then only make overall operations more difficult (Lu \& Beamish, 2006).

Second, the environment in which a firm operates can play a role in the legitimacy of the firm. For example, firms expanding internationally may suffer from a liability of foreignness 
stemming from a lack of knowledge about the firm from individuals and groups in the local environment, causing a lack of legitimacy (Kostova \& Zaheer, 1999). A liability of foreignness is made up of all costs associated with doing business in a foreign country (Zaheer, 1995), suggesting that there are both direct expenses and indirect costs involved. One remedy for this lack of legitimacy is to partner with a domestic firm in the host country (Lu \& Beamish, 2006), thereby gaining legitimacy by associating with an already legitimate firm (Barringer \& Harrison, 2000). Firms also may or may not be granted legitimacy from the institutional environment in which they operate. For example, foreign firms may be considered legitimate by potential investors when their home country has strong legal protections in place (Bell, Moore, \& Filatotchev, 2012). Such legitimacy may improve the success of a remedy for dependence on financial resources.

Research suggests that legitimacy may improve or hinder firm performance. Legitimacy gained through IORs may reduce real costs (Zaheer, 1995), suggesting that it may improve performance. Conversely, such IORs may also be costly (Lu \& Beamish, 2006), suggesting that performance may suffer. Overall, legitimacy is not found to be a factor in the relationship between resource dependence remedies and performance (Drees \& Heugens, 2013). Legitimacy may perhaps be related to the effectiveness of remedies, rather than a remedy itself (e.g., Bell et al., 2012).

\section{Agency Theory}

Agency theory (Jensen \& Meckling, 1976) broadly describes the relationship between principals, who own firms, and agents, who manage them. The relationship is further described as being contractual in nature, and agency theory thus defines the firm as a nexus of contracts (Jensen \& Meckling, 1976). Agency theory attempts to remedy two issues relating to the principal-agent relationship. First, the goals of principals and agents may not always coincide, 
and the principal typically has imperfect information available to monitor the agent. Second, risk plays a key role, as principals and agents may have different levels of risk tolerance. Agency theory specifies that these problems can be remedied through the efficient use of contracts between principals and agents (Jensen \& Meckling, 1976). While agency theory may often describe remedies for the aforementioned principal-agent problem, it also describes relationships between the board of directors and the firm when the board is utilized to remedy dependence on financial resources.

Agency theory describes aspects of financial remedies brought upon by IORs between firms and financial institutions. Firms are shown to appoint members of financial institutions to the board of directors to gain access to financing (Mizruchi \& Steans, 1994). This is especially true for firms seeking financing from venture capital firms, as firms exchange equity and board of director positions for financing that can be used to grow and develop the firm (Park \& Steensma, 2014). In either instance, these board members may provide monitoring or additional resource provision through their advice and counsel (Hillman \& Dalziel, 2003).

Like institutional theory, agency theory's role in resource dependence often reflects aspects of a remedy that effect the success of the remedy. For example, some studies find that boards engaging in monitoring the firm may have no effect or even lower firm performance (Kroll, Walters, \& Le, 2007; Wijbenga, Postma, \& Stratling, 2007). However, another proposes that monitoring has an inverted-U shaped relationship with performance (Garg, 2013). Each of these studies examines the role of directors who are appointed as part of a remedy for financial dependence. 


\section{Signaling Theory}

Signaling theory describes how information about ambiguous or difficult to observe characteristics can be communicated through visible external signals (Spence, 1973). Signals are sent from parties with more information to other parties with less information when those parties are involved in a transaction of some kind (Spence, 2002). When a signal is successfully sent and received it can work to minimize information asymmetry between people or groups, and ideally identifies the signaling party as higher in quality or superior to parties that do not signal (Spence, 2002). For example, in Spence's (1973) original study, job seekers signaled their quality by obtaining a college education and reporting it to firms as they sought employment. Signals themselves do not necessarily remedy dependence but convey information to other parties that influence the effectiveness of a dependence remedy.

Signals are often sent by firms to potential investors in an attempt to improve the outcome of financial remedies. For example, signals are used by firms and prospective investors to determine the value of the firm (Certo, Daily, \& Dalton, 2001). The presence of outside members on the board of directors or board leadership that is separate from firm leadership signals firm quality to potential investors, which may increase the effectiveness of financial dependence remedies (Certo et al., 2001). Additionally, independent boards of directors are shown to help attract key stakeholders by signaling that board monitoring is taking place (Deutsch \& Ross, 2003). Signals can also be in the form of IORs, such as how Park and Mezias (2005) describe alliance announcements as signals about actual firm action, as opposed to rumors, to investors. However, signals may not always be effective. As signals are not a standard or clear form of communication, issues may arise with their use. Park and Mezias (2005) also show that signals can vary regarding their strength and their meaning, possibly creating 
additional confusion or information asymmetry rather than clarifying uncertainty regarding firm survival.

Firms may also use relationships with prestigious organizations to signal a strong reputation and access to resources (Honig, Lerner, \& Raban, 2006). Signaling in such a way can increase a firm’s ability to secure outside investors and to increase performance (Honig et al., 2006). In this manner, signaling theory is similar to institutional theory, in that signals are attempting to relay legitimacy (Certo, 2003). In a similar manner to affiliations with legitimate firms (Honig et al., 2006), a prestigious board of directors may signal the quality of the firm (Certo et al., 2001). Indeed, a prestigious board described by signaling theory and affiliations with legitimate firms described by institutional theory may be used to describe the same phenomenon: the appointment of prestigious outside board members to the board of a firm seeking legitimacy.

\section{Transaction Cost Economics}

Transaction Cost Economics’ (TCE) focuses on transactions between organizations, and how the costs associated with such transactions varies across different types of organizational forms (Williamson, 1975). Williamson explains that cost minimization drives the manner in which firms handle transactions (1991). As such, firms may choose transactions through market, hybrid, or hierarchal governance forms. Market transactions are arms-length transactions. Firms engaging in market transactions are not dependent on one another, as the transaction is likely easily made and multiple alternatives are likely available. Hybrid forms of transaction governance involve commitments between firms, as contracts are used to bind the behavior of firms. These agreements also describe what ranges of divergence from the specific agreement can be remedied, what information must be disclosed, and typically utilizes arbitration to settle 
disagreements rather than the court system. Hierarchy governance refers to the internalization of the transaction. Rather than engaging with another firm to secure a resource, firms decide to produce the resource themselves, sometimes through the acquisition of another firm.

Acquisitions eliminate the need for contract law or the use of courts, as internal firm rules and procedures can be used to dictate the terms of production (Williamson, 1985; Williamson, 1991).

Firms choose a form of transaction governance based on three characteristics relating to the transaction (Williamson, 1991). First, the asset specificity of the transaction describes the flexibility of assets used in the transaction. Specifically, assets that are only usable for one specific transaction are considered highly specific, while assets that may be used for numerous transactions are considered to have low asset specificity. Second, uncertainty plays a role in the choice of governance form but does so according to the level of asset specificity required. Williamson (1985) explains that low asset specificity likely leads to market governance regardless of the uncertainty since firms can easily find new transaction partners if necessary. However, when a significant level of asset specificity is coupled with uncertainty, firms are likely to choose hybrid or hierarchy governance in order to reduce the risk involved with market transactions that can vary substantially from traction to transaction (Williamson, 1985). The very highest levels of uncertainty, however, are likely to produce either market or hierarchal governance. In this case, market-based governance allows for greater flexibility, and hierarchy allows for decisions to be made without other firms. Market and hierarchy are thus better suited for situation characterized by high uncertainty, as hybrid forms are not likely to provide either the flexibility to adapt or certainty that firms seek (Williamson, 1991). Lastly, the frequency of the transaction can also determine governance forms much like uncertainty. Transactions that frequently occur, coupled with asset specificity, push firms to hierarchy governance, as 
monitoring costs may otherwise by too high. Infrequent transactions are likely to lead to market governance, as forming hierarchal governance is likely to be very costly (Williamson, 1985).

Overall, the theories outlined above seek to explain the actions of firms seeking remedies for dependence on various resources. Some approaches, such as resource dependence theory (Pfeffer \& Salancik, 1978), relational aspects of RBV (Lavie, 2006), and TCE approaches that consider opportunism (e.g., Joshi \& Stump, 1999) offer mechanisms with which to explain the social aspect of IORs that seek to remedy dependence. Other theories typically focus more on the overall value and importance of the resource acquired, such as the traditional RBV (Barney, 1991). Institutional theory (Meyer \& Rowan, 1977) tends to recognize the social aspect of IORs when considering legitimacy, but often ignores the quality of the IOR or any tangible resource acquired. Signaling theory offers explanations regarding why some remedies may be more successful than others, but may not consider if the remedy being sought is the best strategy for the firm. Agency theory (Jensen \& Meckling, 1976) sheds light on how IORs built through the board of directors can incentivize actions that benefit the firm, but makes various assumptions regarding the behavior of directors that are challenged by other scholars (e.g., Core, Holthausen,

\& Larcker, 1999). To best understand the potential contributions of each of these theories and the overall literature addressing remedies for resource dependence, autonomy, and performance, a systematic review of the literature is conducted.

\section{Review of Dependence Remedies, Autonomy, and Performance}

Extensive research, utilizing numerous theories as described above, examines resource dependence, remedies for dependence, autonomy, and performance outcomes since Pfeffer and colleagues brought mainstream attention to the subject in the 1970s. However, uncertainty still exists regarding the relationship between dependence remedies, autonomy, and performance 
(Drees \& Heugens, 2013). Additionally, entrepreneurial firms are known to face challenges relating to a lack of resources necessary for the survival of the firm, but questions remain regarding the potential rewards and drawbacks to seeking resources in the external environment (e.g., Hallen et al., 2014). To assess the overall findings on dependence remedies, autonomy, and performance in entrepreneurship, the review process of other published entrepreneurship reviews is followed (e.g., Busenitz et al., 2003; Shepherd, Williams, \& Patzel, 2015; Marvel, Davis, \& Sproul, 2016). Articles included meet the following criteria: (1) publication in a top-tier management journal or entrepreneurship-specific journal. Management journals include Academy of Management Journal, Academy of Management Review, Administrative Science Quarterly, Journal of Management, Journal of Management Studies, Journal of International Business Studies, Management Science, Organization Science, and Strategic Management Journal. Entrepreneurship journals include Entrepreneurship Theory and Practice, Journal of Business Venturing, Journal of Small Business Management, Strategic Entrepreneurship Journal, Small Business Economics, and Entrepreneurship and Regional Development; and (2) Keywords include one of: entrepreneur(s), entrepreneurial, entrepreneurship, founder(s), opportunity, opportunities, (new) venture, start-up, or startup, AND any of the keywords alliance(s), merger(s), acquisition(s), joint venture(s), board(s) of directors, director interlock(s), board composition, inter-organizational relationship, or bridging, AND any of the keywords autonomy, performance, or success. Following Shepherd et al. (2015), the term "small business" is not included, as small businesses may be entrepreneurial, but being a small business does not necessarily make the firm entrepreneurial (Shane \& Venkataraman, 2000). Using ABI/Inform Complete, this search produces 275 articles. To best understand the theoretical and empirical contributions to the literature, teaching cases, editorials, review articles, meta-analyses, and 
spurious results are removed. A majority of studies found in the search results do not relate to the specific literature being reviewed due to certain keywords being used in multiple literatures, producing numerous results dealing with established firms or unrelated phenomena. ${ }^{1}$ This reduces the total number of articles to 93.

\section{Remedies, Autonomy, and Outcomes in Table 2.1}

Table 2.1 contains all the articles reviewed and the material relevant to the research questions presented in Chapter I of this dissertation, including the basis and structure of the remedy used for dependence, the classification and treatment (if any) of autonomy, and the theoretical lens of the study. Examining these issues provides an overall understanding of the literature in environmental dependence and uncovers several key findings. The next sections present a more detailed discussion of the findings in Table 2.1 and progress as follows. First, remedies for dependence will be discussed according to the structure of the remedy and then the type of remedy. Second, the literature describing the relationship between remedies and performance is presented. Finally, the role of autonomy in dependence remedies and the relationship between autonomy and performance will be discussed.

\section{Joint Ventures and Alliances}

Firms engage in joint ventures and alliances with other firms to gain access to resources in the external environment and attempt to remedy dependencies (Pfeffer \& Salancik, 1978). However, early research on alliances between firms finds little to no benefit accruing to firms in

\footnotetext{
${ }^{1}$ Use of the term "venture" produces numerous articles about joint ventures that are irrelevant for this review and otherwise absent in the search results. Including the term is necessary, though, to capture many relevant studies. For example, the phrase "new high-tech ventures" would otherwise be omitted from results, but is relevant for this review. Additionally, the terms "success" and "opportunity" produces several articles that are otherwise unrelated to the review (e.g., CEO succession), but are necessary to capture relevant studies. One retracted study is also eliminated (Ernst, Lichtenthaler, \& Vogt, 2011). Finally, studies focusing on established businesses are also excluded (many of these also fall into the irrelevant results produced by the terms "venture" and "opportunity"). This is in line with published reviews of entrepreneurship as well as the description of entrepreneurship as exploiting opportunities and involving decisions about the value of resources (Shane \& Venkatraman, 2000).
} 
the alliance. While alliances and joint ventures are found to be most frequently used for accessing new markets and distribution channels (McCann, 1991), research also finds no relationship between IORs and performance (Golden \& Dollinger, 1993) and that new ventures outperform joint ventures (Woodcock, Beamish, \& Makino, 1994). Bantel (1998) also examines firms utilizing alliances as a form of strategy, finding very few positive results. Firms utilizing alliances as the main component of their strategy are found to compete in mature product markets, produce low levels of growth and market development, and are inefficient. Overall, Bantel (1998) finds these firms lacking in a clear strategy and having poor prospects. However, early non-findings and negative findings are contradicted by additional research that demonstrates benefits accruing to entrepreneurial firms engaging in alliances.

Entrepreneurial firms must typically focus on specific goals or possess certain characteristics to benefit from alliances or joint ventures. For example, Larson (1991) finds that entrepreneurial firms partnering together benefit from information exchange, joint forecasting, collaborative R\&D, and improved innovation. Alliances providing such benefits to entrepreneurial firms are considered to be highly salient resources for the development of the firm (Lichenstein \& Brush, 2001). Multiple studies examine one or more of these aspects of alliances. Baum and Silverman (2004) examine several firm characteristics and their relationship with the firm's ability to acquire venture capital. Results suggest that firms engaging in alliances, as well as possessing higher levels of human capital, increase the likelihood of acquiring venture capital (Baum \& Silverman, 2004). Alliances are also shown to improve financial performance. For example, social capital in the form of linkages between entrepreneurs and the Israeli military defense leads to higher sales revenue (Honig et al., 2006). Firms also seek alliances to remedy several internal and external challenges. Firms with less financial slack, lower numbers of 
products in their pipeline, lower quality scientific teams, weaker patent positions, higher competitive environments, or less attractive financing environments seek of alliances to overcome these challenges (Patzelt, Shepherd, Deeds, \& Bradley, 2008).

Entrepreneurial firms may also participate in multiple alliances simultaneously. Alliance networks constitute all current firm alliances and research finds numerous benefits related to alliance networks. Baum, Calabrese, and Silverman (2000) investigate the scope and efficiency of alliance networks present at firm founding. Results suggest that efficiently organized networks provide inexpensive and easier access to information and capabilities. Firms seeking alliances with rivals may also gain additional learning opportunities and reduce potential future threats (Baum et al., 2000). Indeed, Koka and Prescott (2008) show that entrepreneurial alliance networks based on information brokerage and access to diverse information outperform prominent alliance networks consisting of affiliations with other prominent firms after regulatory change. Alliance networks also provide access to resources, as firms may also be able to access new markets provided by an alliance partner (Koka \& Prescott, 2008), or reduce the time to IPO when a larger network is present (Sea, 2004).

Firms in alliance networks may also influence other firms due to their position in the network. Scholars examining network position often focus on structural holes. Structural holes are network positions that allow for the brokerage of resources between other members of the network (Burt, 1997). Entrepreneurial teams that reside in structural holes of their network are shown to lead to venture performance, and can also be a complement for functional diversity (Vissa \& Chacar, 2009). Lechner and Leyronas (2012) also examine structural holes present in alliance networks. Results suggest that firms can utilize structural holes to access the resources present in a regional cluster, leading to firm performance. Relatedly, firms located in central 
network positions also receive benefits from their network position. Network centrality is shown to have a positive and direct effect on new product performance (Soh, 2003), and to moderate the relationship between EO and firm performance (Stam \& Elfring, 2008). In this context, repeated partnerships are also positively related to new product performance (Soh, 2003), and bridging ties also moderate the relationship between EO and firm performance (Stam \& Elfring, 2008). In related work, Ozcan and Eisenhardt (2009) examine firm networks, showing that firms can take a proactive approach to reducing dependence by organizing around key industry structures. Firms able to stake out a central location in a network and create multiple ties around uncertainty in an industry create better performing individual ties (Ozcan \& Eisenhardt, 2009).

Entrepreneurial firms also seek alliances in international contexts. Some early research on joint ventures and alliances examine these IORs in transition and developing countries. Artisien and Buckley (1985) conduct an exploratory study of firms entering into joint ventures in Yugoslavia. Results show that Western firms partnering with Yugoslavian firms sought growth and profits, but did not report the realization of profits. D’Souza and McDougall (1989) present one possible explanation for the achievement of growth but not profits. Joint ventures in developing countries are said to lead to performance when there is fit between the needs of the country and the resource advantages of the entering firm (D’Souza \&McDougall, 1989). International alliances can also lead to growth in transition economies, but in this case, domestic firms experience growth when they can produce low-cost and high-quality products (Malo \& Norus, 2009). Performance in transition economies is also shown to require commitment and cooperation between firms that have not traditionally engaged in such behaviors (Fink \& Harris, 2012). Research often finds that international alliances are beneficial when knowledge is obtained. For example, international alliances with local partners can provide the local 
knowledge needed to remedy a lack of resources and capabilities when expanding internationally (Lu \& Beamish, 2001). The host country experience of local partners helps firms overcome a liability of foreignness and increases profitability in international joint ventures, but decreases their longevity as the international partner gains their local knowledge (Lu \& Beamish, 2006). Acquiring new knowledge in the form of technical skills, managerial skills, or knowledge of product or market development is shown to lead to overall firm performance in international outsourcing arrangements (Li, Wei, \& Liu, 2010). Entrepreneurial orientation also benefits firm performance in specific foreign markets, particularly when firm capabilities match the resource sought in the alliance (Brouthers, Nakos, \& Dimitratos, 2014). However, not all international alliances are productive. Firms seeking product innovation are shown to experience negative performance when engaging in a strategic alliance for product development, as international partners from transition economies likely lack the experience to capitalize on such a relationship (Li \& Atuahene-Gima, 2001).

\section{Mergers and Acquisitions}

Firms entering into alliances or joint ventures to secure resources may also choose to acquire resources by acquiring or merging with other firms. While entrepreneurial firms are less likely to acquire other firms simply due to their size and lack of resources, mergers and acquisitions are still notable phenomena. In an examination of causes of firm growth, Fusser and Willard (1990) find that high-growth firms are more likely to have originated in business incubators and that high and low growth firms do not differ in making acquisitions. While entrepreneurial firms may not acquire many firms, they are often targets of acquisitions. These acquisitions produce synergies that may otherwise be unavailable due to the size and scope of entrepreneurial forms (Brush, 1996). Acquired firms are likely to increase their market share as 
they gain operational synergy with their acquirer. If acquired firms are also able to gain financial synergies, those synergies are likely to create greater value than operational synergies (Brush, 1996). Further, synergies are likely to be found when firm resources are complementary, rather than similar (Harrison, Hitt, Hoskisson, \& Ireland, 2001). The combination of complementary resources may create valuable and unique synergy, opportunities for learning, the development of new capabilities, and sustainable competitive advantages (Harrison et al., 2001).

\section{Board of Director Interlocks and Composition}

Entrepreneurial firms often remedy financial dependence by exchanging equity and board of directors seats in exchange for funding needed to grow the firm (Nelson, 2003). This phenomenon receives considerable attention from scholars seeking to understand the effects of funding and the additional resources that can be utilized through such relationships. While early research simply sought to determine the role of boards in venture capital backed firms, finding that such boards are more likely to be involved in the formation and evaluation of the firm (Fried, Bruton, \& Hisrich, 1998), research quickly advanced to more specific topics.

Board size, which receives considerable attention in the strategy literature (e.g., Dalton, Daily, Johnson, \& Ellstrand, 1999), is also studied in the entrepreneurial context. Daily and Dalton (1993) find that firms with more directors overall and more outside directors' experience higher sales revenue and growth, as these directors bring access to resources in the external environment. Board size is also associated with IPO performance, as larger boards signal firm quality and help to prevent IPO underpricing (Certo et al., 2001).

The composition of the board of directors also affects and is affected by several firm characteristics. Powerful CEOs are proposed to appoint board members for resource needs, while financiers are proposed to appoint members for institutional or agency reasons. As such, board 
composition can be heavily influenced by the firm's situation at founding, reflecting the goals of powerful actors in the firm (Lynall, Golden, \& Hillman, 2003). The presence of original top management team (TMT) members can also produce positive outcomes that may remedy financial dependence. Post-IPO firms are shown to experience higher market performance when original TMT members are present and external board members can provide advice and counsel (Kroll, Walters, \& Le, 2007). Additional research suggests that boards should have a specific range of original TMT members on the board. Original TMT members on the board of post-IPO firms have an inverted-U shaped relationship with stock market returns, such that returns increase substantially as membership rises from 50-75\%, but then decreases (Walters, Kroll, \& Wright, 2010).

Boards of directors are also tasked with monitoring the firm. While monitoring is not typically a remedy for dependence, the relationship between monitoring and performance is unclear and at least one study suggests that monitoring may be a resource. Kroll et al. (2007) find that monitoring by board members does not increase performance, but Garg (2013) argues for a more precise relationship. Boards with venture capital appointments in place are proposed to substitute for the resource provision task of directors, bringing experience and skills in monitoring that improves performance. An inverted-U shaped relationship between venture board monitoring and performance is proposed (Garg, 2013).

Finally, boards play a key role in family firms as well. The presence of nonfamily board members provides access to external resources and sources of information that allow a family firm to expand (Arregle, Naldi, Nordqvist, \& Hitt, 2012). Family firms seeking international expansion benefit from nonfamily board members, as nonfamily board representation has a positive relationship with the scale and scope of family firm internationalization (Arregle et al., 
2012). The board can also assist with difficult leadership transitions in family firms. Outside board members can assist in leadership transitions by providing resources and information that can alleviate constraints brought about by the family tradition associated with the firm (Yoo, Schenkel, \& Kim, 2014). Specific results show that non-first-son successors to family firms that interact with outside board members experience positive firm performance from doing so (Yoo et al., 2014).

Overall, research finds various positive outcomes accruing to firms that engage in IORs to remedy dependence. As described above, significant research examines IORs and their outcomes in terms of the structure of the IOR. While the board of directors is frequently used to acquire financial resources (e.g., Daily \& Dalton, 1993), alliances, joint ventures, and acquisitions are all used to acquire various types of non-financial resources. However, there can be significant differences between types of non-financial resources. For example, Cai, Hughes, and Yin (2014) examine the purchase, attraction, and development of resources and the effect of each on performance. However, firms in the sample are widely distributed in industries such as manufacturing, construction and real estate, computer service and software, and biology (Cai et al., 2014). Clearly, the purchase, attraction, or development of resources within each of those industries varies greatly. For example, developing real estate involves entirely different factors than developing computer software. Others utilize a specific industry to draw a sample (e.g., Gabrielsson, 2007; Zahra \& Hayton, 2008; Raymond, Marchand, St-Pierre, Cadieux, \& Labelle, 2013), giving varying degrees of attention to the specific nature of the industry or resource. Ignoring the specific nature of resources being developed, acquired, or purchased by firms creates a potential problem, as different resource types in each of these industries can be 
substantially different. The next section reviews the literature that examines resource dependence remedies according to the type of resource being sought.

\section{Remedies for Specific Resource Dependencies}

The first column of interest in Table 2.1 considers the various types of dependence remedies explored in extant research. Katila et al. (2008) categorize dependencies based on the type of resource required by a firm. Financial resources are described as access to capital by newer firms that allow a firm to prosper (Katila et al., 2008). Complementary resources are necessary operational resources possessed by established firms, but lacking in entrepreneurial firms. Complementary resources are also non-financial resources not typically provided by investors such as venture capital or private equity firms. Additionally, results suggest that complementary resource dependence remedies vary in their level of commitment. In this case, commitment refers to the scarcity and inimitability of the resource being sought. Higher commitment complementary remedies describe resources such as manufacturing capabilities or R\&D, which are costly, difficult to develop, and not widely available. Conversely, lower commitment complementary remedies describe resources such as marketing resources, human resource services, or basic supply agreements. Accordingly, the type of remedy examined within a particular article was classified as either (1) financial, (2) high commitment complementary, or (3) low commitment complementary.

High commitment resource dependence remedies. Entrepreneurial firms often lack the resources necessary to fully commercialize their products (Teece, 1986). Forming alliances to access high commitment resources, such as manufacturing resources, can thus remedy this dependence and allow firms to grow and develop. Firms are proposed to perform best in manufacturing alliances when working to utilize their strengths. D’Souza and McDougall (1989) 
propose that smaller firms entering into manufacturing joint ventures may do well by seeking partners in developing countries. The existence of fit between the focal firm and the needs of the developing country and firm should lead to success for the focal firm. Joint ventures in developing countries may also be attractive to smaller firms as a lack of cutting-edge technology may not hinder the ability to find venture partners or experience success (D’Souza \& McDougall, 1989).

However, empirical results do not offer an entirely clear explanation of the outcomes of manufacturing alliances. Partnerships between entrepreneurial firms can be a substitute for vertical integration, granting access to $R \& D$ and manufacturing resources that may otherwise be out of reach (Larson, 1991), but such results of such partnerships may be difficult to understand. Golden and Dollinger (1993) examine IORs between small manufacturing firms, finding no relationship between IORs and firm performance. Indeed, in some instances, profit margins decrease due to IORs. The authors speculate that IORs may be used as a form of satisficing, whereby partners accept a lower level of performance in exchange for higher levels of certainty (Golden \& Dollinger, 1993). Inkpen and Crossan (1995) offer some possible explanation for non-findings related to IORs, finding that organizational learning in joint ventures is often hindered by inflexible managerial beliefs. Management that can identify gaps in knowledge and also adjust current beliefs when presented with new evidence is more likely to learn and benefit from IORs in manufacturing contexts (Inkpen \& Crossan, 1995). McGee, Dowling, and Megginson (1995) examine similar cooperative agreements, shedding some light on other uncertain findings. Results show that cooperative arrangements for manufacturing and $R \& D$ benefit firm performance most when the founding team has manufacturing experience. 
Manufacturing alliances are also studies in international contexts, as many emerging countries offer the opportunity to manufacture quality products at low prices (Malo \& Norris, 2009). Examining alliances from the view of manufacturing firms, Malo and Norris (2009) find that manufacturers based in transition economies are successful when forming previously unavailable international alliances allowing for the sale of low-cost, high-quality products. Li et al. (2010) also examine firms in emerging countries, focusing on manufacturers that perform outsourcing for firms from developed countries. As more advanced processes are outsourced these firms have the opportunity to learn from their foreign partners and improve performance. Results show that high market orientation and EO lead to knowledge acquisition, and that knowledge acquisition leads to firm performance (Li et al., 2010).

Overall, while entrepreneurial firms do in fact obtain high commitment resources via IORs, the success of such IORs remain in question. Issues related to management beliefs (Inkpen \& Crossan, 1995), experience (McGee et al., 1995), and the type of economy in which a firm resides (Li et al., 2010) all effect outcomes of IORs for high commitment resources. This wide range of specific contextual factors creates a challenge for understanding the general phenomenon.

Low commitment resource dependence remedies. Low commitment resources represent resources that are important to the development of the firm but are more readily available and easy to access, thus requiring a lower level of commitment to be secured. One such resource frequently examined in the literature is marketing resources. Marketing alliances provide specific resources to entrepreneurial firms, typically assisting with access to new markets or channels of distribution that were otherwise unavailable, creating the potential for growth (McCann, 1991). Baum et al. (2000) describe similar resources being available through 
downstream marketing alliances, such as market access and distribution infrastructure. Access to markets and means to distribute to those markets provides opportunities for the growth and development of the firm. Accessing such resources through marketing alliances is likely to increase revenue growth as well as employment and R\&D spending (Baum et al., 2000). Brouthers et al. (2014) examine international performance stemming from marketing alliances. While marketing alliances improve performance in general, results show that the capabilities possessed by the firm play a large role in the success of a particular alliance. Firms possessing marketing capabilities increased performance when engaging in marketing alliances, more so than firms without marketing capabilities. The same relationship is found for firms with research capabilities engaging in research alliances (Brouthers et al., 2014).

One study also examines marketing relationships between local development agencies and entrepreneurs in their area (Izquierdo, Carrion, \& Gutierrez, 2008). Relational exchange between agencies and entrepreneurs represents a form of social capital. In this study, firms assist with economic development goals in exchange for relationships with other key stakeholders, such as government agencies and other groups. Relational exchange with entrepreneurs is shown to promote the goals of local development agencies and increases firm competitiveness and managerial efficiency (Izquierdo et al., 2008). Ozcan and Eisenhardt (2009) find that strong ties between an entrepreneurial firm and a large firm reduce uncertainty and provide access to distribution channels that can be critical to success. Further, achieving success is found to create opportunities for additional alliances that access new distribution channels (Ozcan \& Eisenhardt, 2009).

Compared to high commitment resources, research on low commitment resources appears to present a clearer picture of the relationship between acquiring such resources and 
performance. Firms acquiring access to marketing resources are often available to increase revenues (McCann, 1991), and may find additional opportunities through the building of relationships (Izquierdo et al., 2008). Growing firm revenues may also allow for further development of the firm in other areas, such as R\&D spending (Baum et al., 2000).

Financial resource dependence remedies. Some firms can reduce the need for external financial resources through internal actions. For example, Levitas and McFayden (2009) find that patent activity and exploitation alliances decrease the need for capital. These activities tend to maximize profits, making firms less likely to seek financing (Levitas \& McFayden, 2009). However, most entrepreneurial firms do require access to external capital at some point, and many scholars have investigated how firms attract and acquire funding.

One stream of research studies the characteristics or actions of firms that make them more likely to obtain external financing. One study finds straightforward results, suggesting that simply offering better terms to venture capitalists and investigating numerous options improves the possibility of acquiring funding (Hustedde \& Pulver, 1992). However, the resources and actions of firms rightfully receive more attention. Human capital is found to support venture capital, although Baum and Silverman (2004) find that venture capitalists may over-value human capital, as founding team human capital is shown to have a negative or non-significant relationship with outcomes such as revenues and R\&D expenditures (Baum \& Silverman, 2004). Human capital is not found, however, to increase the odds of securing funding through crowdfunding sources (Ahlers, Cumming, Gunther, \& Schweizer, 2015). Technical knowledge, though, is found to contribute to the acquisition of venture capital. Honig et al. (2006) find that firm knowledge gained through spillovers increases the chances of receiving venture capital, and Baum and Silverman (2004) find a similar relationship when a firm possesses patents. 
Research examining the relationship between alliances and the acquisition of venture capital also finds conflicting results based on the type of financing sought. Baum and Silverman (2004) find that engaging in downstream or horizontal alliances increases the likelihood of acquiring venture capital. However, Ahlers et al. (2015) find that alliance capital in the form of non-executive board members does not increase the possibility of obtaining equity crowdfunding.

Entrepreneurial firms further advanced in the firm life cycle may have the option of conducting an Initial Public Offering (IPO) to remedy financial dependence. Several studies examine the success of IPOs in specific contexts. First, independent boards may be beneficial to family firms after an IPO. Family firms often underperform the market post-IPO, but governance from an independent board reduces the negative performance (Ehrhardt \& Nowak, 2003). Second, the ethnic proximity of VCs to their funded firms is positively related to successful IPOs, acquisitions, and net profits after IPO (Hegde \& Tumlinson, 2014). Finally, firms seeking an IPO in a foreign country benefit from the advice and counsel of an independent board, leading to a more successful IPO (Bell et al., 2012).

While not as common as venture capital-related research, some studies examine financial dependence remedies in conjunction with other important events. For example, public firms are shown to occasionally exit public markets (Zahra, 1995). Firms exiting public markets eliminate the scrutiny attached to the market, but must utilize alternative financial remedies to do so. By utilizing leveraged buyouts, firms can increase corporate entrepreneurship and firm performance (Zahra, 1995). Entrepreneurs also use financial remedies to exit their firms entirely. Entrepreneurial age and human capital lead to different types of intended exit by the entrepreneur (DeTienne \& Cardon, 2012). Older entrepreneurs are more likely to choose family succession or 
liquidation, compared to a more traditional financial remedy such as an IPO or exit after acquisition (DeTienne \& Cardon, 2012).

\section{Remedies and Performance}

A recent meta-analysis by Drees and Heugens (2013) supports the idea that resource dependence remedies are positively related to firm performance. However, some contradictory findings exist (e.g., Koka \& Prescott, 2008), and among positive results, not all remedies are shown to produce equal performance outcomes (Drees \& Heugens, 2013). To help clarify the findings present in the literature, this section reviews the relationship between dependence remedies and performance. Relevant summaries are shown in the last column of Table 2.1.

\section{Board of Director Interlocks, Composition, and Performance}

Several studies examine performance relating to the board of directors. As boards are often associated with venture capital research and financial remedies, the boards' effect on IPO performance is often a topic of investigation. Board independence is shown to lead to foreign IPO success (Bell et al., 2012), and board size helps prevent IPO underpricing (Certo et al., 2001). Firms that have recently completed an IPO experience positive stock market returns when original TMT members are present on the board and receive advice from outside members (Kroll et al., 2007). The ratio of original TMT members on the board also affects post-IPO stock market returns. Returns are highest when the original TMT holds a majority of seats (over 50\%), but not an overwhelming majority (under 75\%) (Walter et al., 2010).

Boards also assist with financial performance. Daily and Dalton (1993) find that board size and higher numbers of outside directors leads to sales revenue and growth. One study examines financial performance as an antecedent to board behavior (i.e., Gabrielsson, 2007). Contrary to expected findings, strong past performance has a negative relationship with 
monitoring and resource provision by the boards of directors. Results suggest that boards may avoid becoming involved when performance is strong, but feel they should intervene when performance is weak (Gabrielsson, 2007). Additionally, Garg (2013) proposes that venture boards, boards with venture capital appointments in place, can be a substitute for the resource provision task of directors as they may bring experience and skills in monitoring that improve performance. Thus, an inverted-U shaped relationship between venture board monitoring and performance is proposed (Garg, 2013). Finally, outside directors can also assist firms in leadership transitions, providing advice to non-first-son successors in family businesses that then leads to performance (Yoo et al., 2014). Overall, findings suggest that skilled and experienced board members with the intent to improve firm performance are likely to succeed at doing so.

Researchers also examine non-financial performance brought on by the board of directors. For example, industrial firms that may pollute the environment may be dependent on public opinion and regulatory issues related to their operations. Boards comprised of legal experts and active CEOs are shown to improve the environmental performance of industrial firms by lowering the overall pollution emitted by plants in populated areas (de Villiers, Naiker, \& van Staden, 2011). Non-profit organizations concerned with improving social performance may benefit from entrepreneurial orientation (EO) provided by the board of directors. EO is found to increase market-based funding of the NPO as well as social performance of the organization (Coombes, Morris, Allen, \& Webb, 2011).

\section{IORs and Performance}

Reviewing the literature in entrepreneurship and IORs produces several themes about how such IORs lead to performance. Firm performance in international settings is frequently examined separately from domestic settings, as firms entering new foreign markets or 
working with new foreign partners often exhibit a liability of foreignness. Despite this liability, research finds numerous ways in which firms can be successful in international settings. First, one study suggests that expanding internationally is best done via new ventures (Woodcock, Beamish, \& Makino, 1994). New ventures are shown to outperform joint ventures for such expansion, and both new ventures and joint ventures are shown to outperform acquisitions (Woodcock et al., 1994). Other studies suggest that factors beyond the structure of foreign entry influence performance. Firms with local joint venture partners that possess experience in the host country can increase their profitability, but decreases the survival of the joint venture (Lu \& Beamish, 2006). As firms gain the local knowledge of their partner, the necessity of the joint venture decreases, leading to a higher likelihood of it dissolving (Lu \& Beamish, 2006). Zahra and Hayton (2008) also find that learning plays a critical role in international contexts, demonstrating that absorptive capacity positively influences the relationship between international alliances and firm performance. International opportunities are also present for firms in transition economies (Malo \& Norris, 2009). By forming international alliances to manufacture low-cost products, transition economy firms experience performance in sales growth (Malo \& Norris, 2009).

While some early research on IORs in entrepreneurial settings found no relationship between IORs and performance (e.g., Golden \& Dollinger, 1993), the majority of studies find a positive relationship (e.g., Certo et al., 2001). Baum et al. (2000) find that marketing alliances lead to revenue growth, and alliances with organizations such as universities or research institutes improve patenting and R\&D performance (Baum et al., 2000). Other studies also find a positive relationship between alliance networks and performance. Koka and Prescott (2008) examine the nature of alliance networks, finding that entrepreneurial networks outperform 
prominent networks in terms of sales per employee even during times of incremental change. A positive relationship also holds in transition economies, where cooperation and self-commitment lead to performance (Fink \& Harris, 2012). Alliance entrepreneurship, defined as pro-actively seeking and evaluating alliance opportunities, leads to market share, sales growth, market development, and product development. (Sarkar, Echambadi, \& Harrison, 2001). Small firms in uncertain environments experience even greater performance when engaging in alliance entrepreneurship (Sarkar et al., 2001). These pro-active, thought-out processes to creating alliance networks are demonstrated in the qualitative study by Ozcan and Eisenhardt (2009). Firms in the emerging wireless gaming industry performed best when they created alliance networks throughout the industry, strategically creating numerous partners and to avoid dependence on any one alliance (Ozcan \& Eisenhardt, 2009).

Fit and performance. Studies also examine the relationship between firm resources and those of their alliance partners. D’Souza and McDougall (1989) find that fit between firm advantages present at multiple levels and the needs of their joint venture partners in developing countries leads to higher performance. This relationship is also found in the fit between management experience and the type of alliance formed by a firm (McGee, Dowling, \& Megginson, 1995). For example, marketing alliances produce higher performance when firm management possesses marketing experience (McGee et al., 1995). Finally, in a related concept, Harrison et al. (2001) find that complementary resources between firms are critical to the success of alliances and acquisitions.

Network position and performance. Network position is also shown to lead to performance. Network centrality is shown to lead to new product development performance (Soh, 2003) and also to moderate the relationship between EO and firm performance (Stam \& 
Elfring, 2008). Vissa and Chacar (2009) also find positive outcomes stemming from a firm's network position, as structural holes are shown to lead to increases in revenue. Firms also experience higher performance when they conduct network brokerage as part of participation in industry events (Stam, 2010). Firms filling structural holes in their networks are also often able to leverage their position for positive performance. Lechner and Leyronas (2012) find that structural holes are important for clustered firms and lead to higher revenue.

Learning and performance. Learning and knowledge are also key factors in performance related to alliances. Knowledge spillovers taking place during alliances have a positive relationship with alliance performance and firm performance (Honig et al., 2006; Shu, Liu, Gao, \& Shanley, 2014). Knowledge acquisition resulting from cross-border outsourcing leads to firm performance (Li et al., 2010). Learning capabilities mediate the relationship between resource acquisition types and performance (Cai et al., 2014). Managers must be willing to accept that some of their current knowledge may be wrong to learn from JV partners (Inkpen \& Crossan, 1995).

Innovation and product performance. Innovation is a sought-after goal of many entrepreneurial firms (e.g., Sampson, 2007), and alliances can help firms seeking innovation. Larson (1991) finds that entrepreneurial firms can improve innovation performance when partnering together and sharing information. However, this result is not consistently found. Jones, Lanctot, and Teegan (2001) find that external technology acquisition has a negative relationship with product and financial performance. Li and Atuahene-Gima (2001) also find negative financial performance to be the outcome when firms enter alliance for innovation and product development. 
Overall, the relationship between IORs and performance suggests that firms benefit from engaging in relationships with other firms. However, as described above, some mixed results exist. One explanation for mixed results suggests that autonomy is a key construct in IORs, but is often ignored (Drees \& Huegens, 2013). The next section discusses autonomy, the mechanisms that provide autonomy, and the relationship between autonomy and performance.

\section{AUTONOMY}

Autonomy is an organization's freedom to make decisions regarding its internal resources without external influence (Oliver, 1991a). A lack of autonomy causes firms to dedicate resources to meet demands brought on by external organizations, and firms are ultimately seeking autonomy through resource dependence remedies (Pfeffer \& Salancik, 1978). Oliver (1991a) describes autonomy as having three distinct mechanisms. First, autonomy allows a firm to meet the demands of multiple external actors simultaneously, preventing resources from being constrained. Second, autonomy is the ability of a firm to respond to contingencies, insulating them from unforeseen events that may constrain the flow of resources (Oliver, 1991a). Third, organizational relationships may create the possibility for opportunistic behavior on the part of a resource provider that leads to benefits for the resource provider and negative outcomes for the focal firm (Oliver, 1991a). The next paragraphs review the studies that consider autonomy according to each of these mechanisms. A summary of how autonomy is treated by articles in this literature review is contained in Table 2.1.

\section{Mechanisms of Autonomy}

Meeting multiple demands simultaneously. Firms seeking autonomy in this way are attempting to secure other options for access to resources. Lechner and Leyronas (2012) discuss autonomy in terms of structural holes in the firm's network. Like Oliver's (1991a) description of 
autonomy, structural holes are proposed to grant preferential access to resources, bargaining power, and the ability to change. Structural holes, and thus autonomy, are shown to lead to firm performance (Lechner \& Leyronas, 2012).

Ozcan and Eisenhardt (2009) do not discuss autonomy explicitly but describe a similar relationship by explaining how firms create alliance networks to reduce dependence that can exist in dyadic alliances. The performance of individual ties in the portfolio is then stronger as firms organize around key industry structure, locate centrally, and make ties around uncertainty.

Responding to contingencies. Patzelt et al. (2008) describe firms being dependent on alliances, suggesting that these firms lack autonomy. This situation arises due a lack of organizational slack for alliance formation, causing firms to continue to remain committed to underperforming alliances. While other research examines firms in situations that may allow for investigation regarding this type of autonomy, no other studies in this review proposed such a relationship in theory or tested one empirically.

Avoiding opportunistic behavior. Some studies approach autonomy from a very simplistic viewpoint. Gales and Blackburn (1990) consider the perceived autonomy of retailers dealing with suppliers. While suppliers may have control over critical resources, frequent communication between suppliers and retailers leads to retailers perceiving autonomy (Gales \& Blackburn, 1990). Kanter, Richardson, North, \& Morgan (1991) touch upon autonomy in their study of Eastman Kodak. Proposed projects arising from within the firm were required to function autonomously, without the need for the manufacturing or other resources currently controlled by Eastman Kodak (Kanter et al., 1991). In a very simplistic view, Fink and Harris (2012) consider firms to have autonomy is they are legally independent organizations. 
Multiple studies consider autonomy in terms of the interdependence present between firms. Lichenstein and Brush (2001) propose that interdependence arises from resource salience. As their findings show that the salience of resources changes over time in entrepreneurial firms, interdependence can also shift from one resource provider to answer. Koka and Prescott (2008) view interdependence as beneficial to firms in cooperative alliances, as it leads to higher quality exchange. Developing from a high level of resource commitment, interdependence enables effective transactions between partners and fosters the flow of information (Koka \& Prescott, 2008). In a contrary approach, Benghozi and Salvador (2014) assume that autonomy is lost during traditional partnerships between firms.

\section{Autonomy and Performance}

Meta-analysis finds that resource dependence remedies are likely to increase firm performance through the mediating mechanism of autonomy (Drees \& Huegens, 2013). This section discusses articles found in the literature review search results that investigate that relationship. A summary of the results of each study, whether or not autonomy is considered, is found in the last column of Table 2.1.

Gales and Blackburn (1990) examine the relationship between autonomy and various operational performance outcomes. While the authors initially argued that frequent and intense communication between retailers and supplier would lead to less autonomy, results show that such communication may reduce uncertainty in the relationship and preserve retailers' ability to act. Autonomy then leads to increases in planning, advertising, promotional activity, and decreases in uncertainty (Gales \& Blackburn, 1990).

Lechner and Leyronas (2012) examine the autonomy of a firm in a network. Like Gales and Blackburn (1990), Lechner and Leyronas (2012) argue that autonomy is related to accessing 
valuable information. Additionally, autonomy provides preferential access to resources that then lead to firm performance (Lechner \& Leyronas, 2012). Fink and Harris (2012) also find that autonomy is one aspect of alliance commitment that leads to an index of firm performance measures, including employee performance, sales performance, and customer satisfaction. It should be noted, though, that autonomy was only one of 17 items in the questionnaire measuring alliance commitment (Fink \& Harris, 2012).

A small number of studies examine the relationship between autonomy and performance, demonstrating its importance to the literature on resource dependence remedies. However, autonomy is found to mediate the relationship between resource dependence remedies and firm performance (Drees \& Heugens, 2013), making it a key concept in the literature. The lack of substantial research that considers the role of autonomy in IORs that seek to remedy dependence is problematic for the understanding of such relationships, as it may potentially explain negative or non-findings in the literature, or add further explanatory power to the reasons and conditions that lead firms to seek IORs to remedy dependence.

\section{CONCLUSION}

Research examining dependence, autonomy, and remedies for dependence in entrepreneurial firms is deep in some areas, such as financial remedies mostly relating to venture capital and alliances seeking out critical resources. However, it is shown to be lacking in other areas, especially regarding the study of autonomy. As resource dependence is shown to be especially relevant to entrepreneurial settings (Daily et al., 2002) and firms seeking to remedy dependence are ultimately seeking autonomy (Pfeffer \& Salancik, 1978), the lack of studies considering autonomy represents a large deficiency in the literature. This is especially true given that entrepreneurial firms often lack required resources and must engage in various IORs to 
access financial and complementary resources needed for the development of the firm (Katila et al., 2008). Entering into these relationships creates a situation ripe for the creation of dependence by the more powerful firm. Additionally, results of some studies report contradictory relationships between remedies and performance, suggesting that further research is needed to better predict and describe the phenomenon. Lastly, while some studies consider resources by type, others strictly investigate remedies in terms of their structure. Understanding how firms acquire specific resources and the outcomes of doing so may also shed light on some contradictory findings. The next chapter presents additional relevant literature covering resource dependence, autonomy, remedies, and performance. Hypotheses are also developed and presented. 


\section{CHAPTER III: HYPOTHESES DEVELOPMENT}

\section{Resource Dependence}

Resource dependence describes a situation in which a firm heavily relies upon another firm in its external environment to supply critical inputs (Pfeffer, 1972b; Pfeffer \& Salancik, 1978; Gulati \& Gargiulo, 1999; Bae \& Gargiulo, 2004). These social situations are characterized by interdependencies between firms that limit possible actions and threaten firm survival (Pfeffer, 1987). Power is a key dynamic underlying these social situations (Pfeffer \& Salancik, 1978). Stemming from seminal work in power relations by Emerson (1962) and Thompson (1967), resource dependence recognizes that firms may have different amounts of power over each other and that this power may not cancel out (Emerson, 1962). Indeed, Pfeffer (1981) claims that firms should minimize their dependence on other firms and maximize the dependence of other firms on them (Pfeffer, 1981). Questions regarding this prescription remain, though, as implementing coercive strategies can remove any incentive that the dependent firm may have to work for the mutual benefit of both firms (Gulati \& Sytch, 2007). Such coercion can lead to negative performance for the powerful organization (Gulati \& Sytch, 2007), rather than the theorized positive outcomes (Pfeffer, 1981).

\section{Types of Resource Dependence Remedies}

As Wry et al. (2013) describe in their review of the resource dependence literature, prolific empirical evidence supports the idea that firms remedy dependence through IORs. However, changes in the environment from the 1970s to today suggest that firms consider remedies beyond those traditionally studied, leading Davis and Cobb (2010) to suggest that the traditional remedies, such as joint ventures and acquisitions, need to be updated. Relatedly, studies often examine IORs in terms of the relationship structure (e.g., joint ventures or 
acquisitions) without considering the specific resource being exchanged in the IOR. These issues are further discussed, and hypotheses are developed below.

Firms frequently seek external resources by engaging IORs with other firms (e.g., Baum \& Silverman, 2004). Given the often public and easily observed nature of IORs such as joint ventures, acquisitions, and board of director interlocks, it is understandable that scholars often examine resource dependence by evaluating the outcomes of these IORs. However, research suggests that firms seek resources in different manners based upon the type of resource being sought (Katila et al., 2008). Following this line of research, resource dependence remedies are considered in terms of access to financial resources or complementary resources. Financial resources represent access to capital and are fungible in nature. Complementary resources represent operational resources that are necessary for the continued development of the firm and not typically provided by financial resource providers. For example, venture capital firms provide financial resources but are unlikely to provide direct access to manufacturing or marketing resources. The next sections present arguments regarding remedies for financial resource dependence and complementary resource dependence and develop hypotheses.

\section{Financial Resource Dependence Remedies and Performance}

Financial dependence represents the need for outside cash to sustain and grow the firm (Katila et al., 2008). Few, if any, resources are more crucial to firm survival than access to capital. This is reflected in both traditional approaches to resource dependence that focus on large firms and board interlocks (e.g., Pfeffer, 1972c), and more modern approaches involving entrepreneurial firms and alternatives sources of financing (e.g., Gabrielsson, 2007). The fungible nature of financial resources delineates financial resource dependence as a unique type 
of resource dependence. This dissertation follows Katila et al. (2008) and defines financial resource dependence as a lack of financial resources necessary to sustain and grow the firm.

Empirical support for firms requiring financial resources is abundant. Pfeffer (1972c) shows that firms with higher needs for financial resources are more likely to create linkages with financial institutions through board of director interlocks to acquire financing. Similarly, Lang and Lockhart (1990) find that firms whose financial dependence increases respond by increasing the number of board of director interlocks with financial institutions. These interlocks are widely used to acquire financial resources, as results show that the simple presence of financial representation on a board makes a firm more likely to borrow than firms without financial representation (Mizruchi \& Steans, 1994).

However, the traditional focus on director interlocks as a remedy for financial resource dependence is challenged by observations that anti-trust and banking regulations on modern firms may prevent such IORs from forming (Drees \& Heugens, 2013). Indeed, Davis (1996) notices a steep decline in bank interlocks in U.S. firms after regulatory changes. These environmental changes suggest that some traditional resource dependence remedies are in need of updates (Davis \& Cobb, 2010). Venture capital is described by Rosenbusch, Brinckmann, and Muller (2013) as a formal investment (Bruton, Chahine, \& Filatotchev, 2009) by professional investors (Gompers \& Lerner 2001) who take an active role in the firm (Sahlman, 1990) and seek high returns (Dimov, Shepherd, \& Sutcliffe, 2007). Firms exchange equity and board of director seats for cash that can be used to further the goals of the firm (Rosenstein, 1988). The use of venture capital in addition to and in place of traditional financing has played a role in this change, as the amount of venture capital available increased substantially over a recent 25-year period (Puri \& Zarutskie, 2012). Indeed, firms often elect the use of venture capital even when 
capital markets may provide the necessary funding (Hoehn-Weiss \& Barden, 2014). Younger, smaller firms are especially likely to seek financing from venture capital firms or similar alternatives, as financing through formal financial institutions is typically not available (Aldrich \& Auster, 1996). While the mechanism for acquiring financial resources may differ for young firms compared to the director interlock-assisted borrowing often utilized by established firms, dependence on such resources remains (Hillman et al., 2009).

Research examining remedies for financial resource dependence has not failed to notice the use of venture capital, as numerous empirical studies investigate phenomena associated with venture capital financing. Venture capitalists are shown to target industries with high growth (Zacharakis, McMullen, \& Shepherd, 2007), and specific firms demonstrating high potential, such as a skilled and experienced founding team (Baum \& Silverman, 2004). Additionally, as venture capital provides an infusion of cash to a firm that is by definition in need of such resources, firms have the opportunity to improve performance by utilizing this cash for development of the firm. Firms may hire additional employees, acquire assets, launch a product, or continue potentially valuable R\&D after accessing financial resources (Baum \& Silverman, 2004). As any remedy for dependence is a means to an end, research frequently examines the relationship between acquiring venture capital and firm performance. This relationship is shown to exist in several studies.

Financial resources in the form of venture capital may be acquired in a different manner than traditional financing, but boards of directors still play a role, as entrepreneurial firms are often required to appoint outside board members from the venture capital firm as part of any funding round (Rosenstein, 1988). These directors may also bring benefits to the firm. Daily and Dalton (1993) study the composition of boards of directors and the effects of outside board 
members. Outside directors are more likely to work in the best interests of the firm and avoid decisions that may hamper performance, such as golden parachutes or policies that entrench management. Results show that outside directors lead to higher sales revenue and growth (Daily \& Dalton, 1993). Fried et al. (1998) also suggest that active boards in venture capital backed firms experience higher performance.

Additional empirical findings also support a positive relationship between acquiring venture capital and growth (Carlsson, 2002). Indeed, a primary reason firms seek financial resources is to provide the flexibility needed for growth (Columbo \& Grilli, 2010). Venture capitalists providing financing also typically have screening and monitoring capabilities that allow for the selection of firms that are more likely to grow (Columbo \& Grilli, 2010). Venture capitalists may also provide strong contractual incentives for firms to work toward growth (Gompers, 1995; Kaplan \& Stromberg, 2004). Overall, research suggests that venture capital leads to increases in growth as venture capitalists select promising firms (e.g., Columbo \& Grilli, 2010) and also add value to the firm through their expertise (e.g., Dimov \& Shepherd, 2005). Venture capitalists may also create value through the services provided to funded firms (Wijbenga et al., 2007). By providing assistance when entrepreneurial firms face challenges, such as cost overruns or lower sales, venture capitalists are likely to improve the financial performance of the firm (Wijbenga et al., 2007).

Despite the advantage associated with venture capital, some studies fail to find a relationship between venture capital and firm performance (Busenitz et al., 2004; Jain, Jayaramen, \& Kini, 2008). These divergent results may be the result of evaluating performance outcomes that are not sought after in the realm of venture capital. As previously stated, venture capitalist focus on high growth industries (Zacharakis et al., 2007) and many studies find results 
supporting a relationship between venture capital and growth, as previously discussed. Growth is also found more often than other performance outcomes such as profitability (Rosenbusch et al., 2013).

Thus, firms seeking venture capital as a financial dependence remedy will have success when focusing on sales growth.

H1: Financial resource dependence remedies in the form of venture capital funding will have a positive relationship with sales growth.

\section{Complementary Resource Dependence Remedies}

The successful commercialization of products or services by a firm typically requires complementary resources, consisting of non-financial resources beyond those directly needed for the product or service itself (Teece, 1986). These resources may require various levels of investment and commitment depending on the particular resource being sought, as well as by industry or firm (Katila et al., 2008). For example, a start-up firm that has successfully designed and patented a new medical device will require the resources needed to produce the device as well as a sales force tasked with selling the product to doctors, hospitals, and other medical providers. Conversely, a firm producing a new bottled energy drink will require distribution and mass marketing resources. The precise list of possible complementary resources a firm will seek is vast, but resources may be classified according to the level of commitment required for their acquisition. Following Katila et al. (2008), who find that manufacturing and marketing resources differ in how they are obtained due to their scarcity and the commitment required by a firm to 
obtain them, this dissertation classifies complementary resources as either high commitment or low commitment. Hypotheses for each are now developed.

High commitment complementary resource dependence remedies. Complementary resources requiring high levels of commitment are characterized by higher levels of scarcity relative to other resources and are typically more difficult to access. For example, Katila et al. (2008) describe manufacturing resources as having large capital requirements, scarce availability, and high commitment levels. The level of commitment is especially high for young firms (Katila et al., 2008). Similarly, Das et al. (1998) also state that acquiring access to manufacturing resources may be characterized by high fixed costs and also lack alternatives, creating high levels of commitment. High commitment levels from young firms can create dependent situations as firms may be locked in and unable to secure manufacturing from an alternative provider in the short-term. Indeed, manufacturers seeking to reduce their uncertainty related to the success of products may seek long-term contracts from firms seeking their services (Gerwin, 1993).

Despite the costs associated with accessing high commitment resources such as manufacturing, firms continue to engage in IORs to access manufacturing due to the possible benefits. For example, firms experienced in $R \& D$ tend to realize increased firm performance when entering into alliances to secure R\&D resources (McGee et al., 1995). Additionally, the high fixed costs associated with alliances may be reduced due to economies of scale and scope, transaction costs may be reduced, and smaller partners in manufacturing alliances are found to receive greater benefits than the larger partner (Das et al., 1998). Alliances that are strategically important and provide access to complementary resources are also found to lead to firm growth (Lunnan \& Haugland, 2008). As such alliances provide access to previously unavailable 
resources that can be immediately utilized, performance quickly results (Lunnan \& Haugland, 2008). Manufacturing alliances, in particular, are likely to be strategic for young or start-up firms, as they allow for greater control of the manufacturing process (Park et al., 2002). Finally, non-corporate ventures seeking manufacturing resources are also likely to experience higher growth when acquiring the resources via an alliance, as opposed to vertical integration (Zahra \& George, 1999). Thus:

H2: Firms that enter into IORs that grant access to high commitment complementary resources will have a positive relationship with sales growth.

Low commitment complementary resource dependence remedies. Katila et al. (2008) describe the nature of marketing resources as one specific low commitment complementary resource. Marketing resources are typically available in greater numbers or amounts than high commitment resources such as manufacturing (Das et al, 1998) and are thus unlikely to require large capital investments up-front or high levels of commitment. Such low commitment resources are thus available without entering into a high commitment IOR (Katila et al., 2008).

One low commitment resource, marketing resources, is shown to create value for firms in alliances in three ways (Swaminathan \& Moorman, 2009). First, firms may be able to access new markets provided by an alliance partner (Koka \& Prescott, 2008), creating the possibility for additional growth. Second, firms may be able to utilize brands or products that were previously unavailable, granting the opportunity to widen markets in which the firm is already active (Kalaignanam, Shankar, \& Varadarajan 2007). Finally, firms may be accessing resources that they previously lacked (Rindfleisch \& Heide, 1997). For example, technology firms that have 
focused purely on product development may have no internal resources available for marketing that product. Accessing such resources may lead to lower costs and increase cash flow compared to developing such resources internally (Swaminathan \& Moorman, 2009). Chatterjee (2004) explains that accessing such resources is especially relevant to entrepreneurial firms, who otherwise may not be able to access new markets or reach economies of scale.

However, empirical results supporting a link between low commitment resource dependence remedies and performance are not universal. Das et al. (1998) find no relationship between marketing alliances and performance measured as the cumulative abnormal stock returns in the period following a marketing alliance announcement. However, stock market reactions and other studies that evaluate the perceived benefits of alliances (e.g., Kale et al., 2002) fail to capture the actual business-level outcomes that result from alliances and the utilization of resources (Das et al., 1998).Overall, low commitment resources are likely to facilitate the development of the firm in a manner that allows for the full commercialization of a product or service (Teece, 1986), which is likely to lead to the growth of the firm (Das et al., 1998). Thus:

H3: Firms that enter into IORs that grant access to low commitment complementary resources will have a positive relationship with sales growth.

\section{Autonomy as Mediation}

Research in resource dependence does not exclusively examine organizational outcomes through a profit-seeking lens (Oliver, 1991b), although many studies have taken such an approach (e.g. Pfeffer, 1972b; Villalonga \& McGahan, 2005; Weitz \& Shenhav, 2000). By 
assuming a profit-seeking motive by organizations, RDT aligns itself with strategic management in attempting to explain differences in performance outcomes (Oliver, 1991b). Autonomy is thus a critical construct in resource dependence research, as it is shown to mediate the relationship between dependence remedies and performance (Drees \& Heugens, 2013).

Firms seeking remedies for dependence are ultimately seeking autonomy (Pfeffer \& Salancik, 1978). Autonomy is an organization's freedom to make decisions regarding its internal resources without external influence (Oliver, 1991a). A lack of autonomy causes organizations to dedicate resources to meet demands brought on by external organizations (Pfeffer \& Salancik, 1978). Thus, firms seek out autonomy through environmental management. Oliver’s (1991a) broad definition of autonomy coincides with the treatment autonomy has received in the literature. However, various treatments of autonomy in the literature suggest that it also appears likely to possess different characteristics depending on the resource sought by the firm. Oliver (1991a) describes autonomy as having three mechanisms that could lead to a positive relationship with firm performance. Each of these mechanisms is discussed below, and hypotheses relating to each are developed.

\section{Responding to Contingencies}

One mechanism underlying autonomy is the ability for a firm to respond to contingencies, insulating it from unforeseen events that may constrain the flow of resources (Oliver, 1991a). Successfully responding to contingencies allows an organization to maintain relationships that become strained due to changes in the environment. For example, Beekun and Ginn (1993) find that hospitals adjust their linkages with other organizations in order to maintain resources that matched their strategy, based on environmental uncertainty. The changing demands of a key stakeholder may also produce contingencies. Ingram and Simons (1995) find 
that firms respond to the demand for work-family considerations when other organizations also responded, or when female managers at the firm demand change.

Contingencies can also take a simpler form. Firms that sell products or services on credit to buyers must deal with the uncertainty that arises from collecting payments that are owed. The constant management of cash flow creates an ongoing contingency, whereby a firm must make decisions based on its customers' ability and willingness to pay. Possessing the flexibility to adjust terms of payment is then critical in such contingent situations (Peng \& Luo, 2000). In a similar financial context, research shows that having cash on hand can reduce dependence on creditors who may or may not feel an obligation to firms seeking credit (Uzzi, 1999).

Firms can never truly prepare for all contingencies. However, possessing discretionary financial resources creates a great deal of flexibility (George, 2005). One treatment of autonomy is in the form of cash on hand or other financial flexibility that allows a firm to operate in the manner it desires. Peng and Luo (2000) find that firms with favorable terms of payment experience higher performance. The ability to collect accounts receivable, along with favorable terms for accounts payable maximizes the amount of cash in the firms at all time, granting greater flexibility. Peng and Luo (2000) find that such payment terms produce gains in market share. Uzzi (1999) also suggests that a similar measure of autonomy produces benefits for the firm. Firms with cash on hand sufficient to fund the operations of the firm in the short-term experienced less dependence on creditors in the form of a lower cost of capital. As higher costs of capital are expenses with no attached benefit, such expenses are likely to limit the firm’s autonomy and reduce any expected growth (Peng \& Luo, 2000).

In sum, financial autonomy stemming from discretionary resources provides flexibility (Peng \& Luo, 2000; George, 2005) that may grant multiple benefits. Financial autonomy assists 
firms working to meet the changing demands of the environment, (Beekun \& Ginn, 1993;

Ingram \& Simons, 1995), and reduces dependence on others (Uzzi, 1999). These benefits then lead to the growth of the firm (Rosenbusch et al., 2013; Peng \& Luo, 2000; Columbo \& Grilli, 2010). Thus:

H4: Financial autonomy in the form of discretionary cash resources will mediate the relationship between financial dependence remedies and sales growth.

\section{Avoiding Opportunistic Behavior}

The second mechanism of autonomy allows a firm to avoid opportunistic behavior on the part of other parties (Oliver, 1991a). Opportunistic behavior may take place within an IOR by a resource provider, leading benefits for the resource provider and negative outcomes for the focal firm (Oliver, 1991a). However, some evidence also suggests that firms using their power to control other firms in such IORs experience lower firm performance (Gulati \& Sytch, 2007). In this case controlling tactics may cause the less powerful firm to operate less efficiently and make less of an effort. Instead of working together to produce a larger pie, the more powerful firm simply gains a larger share of a smaller pie (Gulati \& Sytch, 2007).

Firms seeking resources that require a great deal of commitment may be more likely to encounter opportunistic behavior from an IOR partner. For example, manufacturing resources are capital intensive, scarcely available, and may require equity transfers or other substantial commitments (Katila et al., 2008). Such commitments may then prevent firms from seeking alternative resources, causing autonomy to depend on the interactions taking place within the IOR. Additionally, the relatively scarce nature of such resources may prevent firms from having 
alternative choices when choosing a resource provider. Firms being abused by such powerful trading partners may seek to maneuver around those partners to reduce dependence (Ketchen \& Hult, 2007), but such maneuvers may be unavailable given the lack of alternatives and the high levels of commitment required to secure the resource. Indeed, Gerwin (1993) finds that manufacturing firms tend to seek long-term commitments from those seeking their services in order to reduce the risk related to the failure of the manufactured product. Firms offering valuable high commitment resources may also seek to avoid their IOR partners having other partners that provide the same resource, as opportunistic behavior may be more likely (Nohria \& Garcia-Pont, 1991). For example, a pharmaceutical firm may avoid entering into an R\&D alliance with a firm that is already engaged in a similar alliance with their direct competitor.

Firms are also unlikely to terminate alliances that are considered strategically important (Lunnan \& Haugland, 2008). In addition to the formal commitment made by partners in a high commitment alliance, large investments are unlikely to be abandoned quickly as firms make escalations of commitment (Sleesman et al., 2012). For example, a firm launching a new product is likely to begin by outsourcing some tasks, but then later enter into an alliance to secure manufacturing (Marion et al., 2015). Overall, firms are likely to secure high commitment resources from only one alliance partner and to be committed to that partner for some time.

High commitment resource dependence may continue throughout the life of an IOR as well. Wasti and Liker (1999) explain how constraints in the manufacturing services available to a firm effect the overall design of a product, suggesting that dependence on manufacturing resources may also be present during and after product development. While firms may prefer certain specifications for products, such preferences may not be commercially or technologically realistic. Such issues may come to light after manufacturing alliances have been formed, leading 
to a suboptimal situation with few or no available alternatives (Wasti \& Liker, 1999). Firms attempting to maintain control over innovations may also be concerned when securing manufacturing resources for products. Manufacturing is likely to be secured through a larger firm with excess capacity (Pisano, 1990), and in such circumstances, a manufacturer's interests may not align with the interests of its customer. Rather than simply providing manufacturing, the opportunity to misappropriate any valuable product design or innovation is a possibility (Santos \& Eisenhardt, 2005; Hallen et al., 2014). This possible opportunistic behavior only creates additional dependence on the choice and acquisition of manufacturing resources by smaller firms.

Firms with autonomy can avoid opportunistic behavior from IOR partners that grant access to high commitment resources (Oliver, 1991a). One manner in which firms may do so is to avoid entering into relationships that allow firms to engage in such behavior with little to no consequences for doing so. Firms may succeed in this endeavor if they can enter into IORs to secure resources with as little commitment as possible, as a lower commitment level suggests that firms possess other options to secure the resource. Nohria and Garcia-Pont (1991) explain that IORs such as distribution agreements or those that do not require equity to be transferred represent lower levels of commitment than IORs such as independent joint ventures or acquisitions. Additionally, accessing strategic resources via IORs is typically less costly than internal development and creates an easier path to reverse course if necessary (Porter \& Fuller, 1986). Within IORs, commitment level is higher when equity transfers are involved (Nohria \& Garica-Pont, 1991), which also works to prevent change once decisions are made to enter into such an IOR. 
Firms prefer lower commitment IORs to higher commitment IORs, as IOR partners are more likely to offer cooperation and assistance that allows the resource provided to be beneficial (Nohria \& Garcia-Pont, 1991). Similar relationships are found in the literature describing mutual dependence and complementary resources. Mutually dependent firms are more likely to work together toward common goals and is empirically shown to increase alliance performance (Xia, 2011; Xia \& Li, 2013). Mutual dependence may also lead to the growth of the firm as it emphasizes joint action and trust, which may drive the growth of the firm (Grewel, Iyer, Javalgi, \& Radulovich, 2011). Thus:

H5a: Complementary resource autonomy will mediate the relationship between high commitment complementary resource dependence remedies and sales growth, such that lower commitment levels will positively mediate the relationship between IORs and sales growth.

\section{Meeting Multiple Demands}

Oliver (1991a) also describes autonomy as allowing a firm to meet the demands of multiple external actors simultaneously, preventing resources from being constrained. Hambrick, Finkelstein, Cho, and Jackson (2005) further theorize about dealing with multiple external actors simultaneously. An increase in legitimate business models combined with less government influence and more diverse managerial backgrounds helps create increased heterogeneity among firms in an industry. Working together, these factors suggest that organizations have a wide variety of dependence reduction remedies at their disposal, but also likely means that organizations must be able to meet the differing demands created by a more heterogeneous 
external environment. The ability to meet multiple or differing demands simultaneously suggests that an organization can successfully deal with multiple external actors at once, either by meeting their demands, or choosing alternative options that produce more favorable outcomes for the focal organization. Hambrick et al. (2005) also posit that environmental conditions are now more favorable for firms seeking autonomy. Through a combination of reduced government oversight, an increase in the diversity of the task-backgrounds of managers, and a rise in the number of viable business models, firms possess a multitude of options for acquiring necessary resources and reducing dependence. Forming relationships with new partners indeed provides additional access to resources and thus possible solutions to problems. Firms facing environmental uncertainty are more likely to undertake such action (Beckman et al., 2004).

Ahoni, Maimon, and Segev (1981) examine the effects of multiple competing demands. Managers often face heterogeneous pressures, but some pressures are complementary. That is, by satisfying one set of pressures managers can simultaneously reduce another set, suggesting that multiple demands can be met simultaneously. David, Bloom, and Hillman (2007) also find evidence to support this mechanism of autonomy. Firms seeking to satisfy activist investors and shareholders are often able to appease both parties or overcome demands when in a position to do so. Firms are found to either challenge investor petitions in court, ignore them and allow a shareholder vote, or compromise with the activist in order to pacify the demand and simultaneously continue to pursue the firm’s intended goals (David et al., 2007). Empirical support also exists showing that firms can utilize or create additional options to secure external resources. In their seminal study of the United Way, Provan, Beyer, and Kruytbosch (1980) show how ties with third parties can affect the dyadic relationship between two organizations. Resources are obtained not just through power and influence over one party, but through a 
network of relationships between organizations. Similarly, Gargiulo (1993) demonstrates that autonomy can be created by creating a relationship with a third party in order to assert influence over or alleviate pressure from another party. Seeking these new relationships can reduce uncertainty by granting access to a wider range of resource providers (Beckman, Haunschild, \& Phillips, 2004), likely increasing autonomy.

New firms are also shown to benefit from access to a large and heterogeneous group of resource providers, resulting in reduced dependence on any given partner. Firms may gain access to novel solutions, overcome a lack of knowledge, and identify the best partners available as the business continues to develop (Sullivan \& Ford, 2014). New firms with multiple alliances are shown to see an increase in sales growth, and a diverse set of alliances leads to both sales growth and increases in market share (Pangarka \& Wu, 2013).

Overall, firms seeking low commitment complementary resources are likely to gain autonomy when access to multiple resource providers is present. In such instances, a lower commitment level should be required to access such resources, as low commitment resources are more readily available. Successfully doing so will then lead to an increase in firm performance (Drees \& Heugens, 2013).

H5b: Complementary resource autonomy will mediate the relationship between low commitment complementary resource dependence remedies and sales growth, such that lower commitment levels will positively mediate the relationship between IORs and sales growth. 


\section{Preventing New Dependencies}

Pfeffer (1987) notes that attempts to remedy resource dependence are not likely to be completely successful and that any action taken is likely to produce a new and different set of dependencies than previously existed. This is further supported by the narrative review work of Hillman et al. (2009), who find that attempts to restore autonomy are not often fully successful, and often cause new sets of dependencies to emerge. This assumption fits within the logic of resource dependence theory. A focal firm seeking resources from another firm is unlikely to gain access to those resources without giving up something of value in exchange. The exchange partner is also influenced by its external environment and acts with self-interest (Pfeffer, 1972b), making it unlikely to give up its own autonomy without benefit. Pfeffer (1981) also assumes that organizations work to secure resources that cause other organizations to become dependent on them. However, some evidence suggests that using such power may result in poor performance for the firm as less powerful firms have no incentive to improve performance when benefits will simply accrue to more powerful firms (Gulati \& Sytch, 2007).

In contrast, IORs involving a degree of cooperation, or that provide complementary benefits in addition to the resources being exchanged may create a set of conditions that lead to mutual benefit for both organizations. Madhok and Tallman (1998) find that alliance value is embedded within inter- and intrafirm relationships, which drive the collection of rents and provide an incentive to maintain the relationship. The formation of such relationships may also prevent the creation of new dependencies as firms instead work toward mutual goals and benefits. 


\section{Boards of Directors and Financial Autonomy}

Daily and Schwenk (1996) explain that resource dependence requirements influence the composition of the board of directors, as firms use outside directors to establish relationships with other organizations in the external environment. One such relationship that may induce the cooperation needed to achieve mutual goals exists within the board of directors of venture capital-backed firms. In such instances venture capital firms appoint members to the board of directors as part of a funding agreement (Kaplan \& Stromberg, 2004), and those members are likely to provide advice, counsel, and information (Hillman \& Dalziel, 2003) with the intent of achieving firm growth (Zacharakis et al., 2007). This suggests that the board capital of venture capital-appointed directors, represented as the sum of human and social capital (Hillman \& Dalziel, 2003) may help prevent new dependencies from forming. From a resource dependence perspective, board capital is proposed to lead to resource provision. Board members' human capital is proposed to provide advice and counsel regarding the strategy and direction of the firm, while social capital provides access to various types of information.

The human and social capital of board members that makes up board capital are studied throughout the literature. Hillman et al. (2009) suggest that the types of human and social capital present within the board of directors should be parsed to understand precisely what types are needed to provide the benefits listed by Pfeffer and Salancik (1978). Indeed, different types of human capital provide access to different types of resource provision. Hillman, Cannella, and Paetzold (2000) propose a taxonomy of directors using a resource dependence lens, categorizing them according to the resources provided by their expertise. Business experts possess expertise on competition, assist in decision making, and offer alternative viewpoints on problems facing the firm. They are likely to be current and former executives or directors at other large firms. 
Support specialists provide specialized expertise in areas such as law and banking. They could also provide access to critical resources (e.g., financial, legal), and bring social capital that provided communication with powerful external organizations or the government. Support specialists are likely to be lawyers, bankers, or PR experts. Finally, influential community members provide perspectives on and represent interests outside of the profit-seeking goals of the organization. They can influence powerful groups in the community, and may be political leaders, university faculty, or leaders of community organizations. (Hillman et al., 2000). Overall, directors may bring different types of expertise to the firm that provide benefits in specific ways, and the overall relationship between resource provision and performance has empirical support throughout the literature as well.

Within the context of entrepreneurship, Unger et al. (2011) also demonstrate that different types of human capital lead to performance. Human capital outcomes, such as knowledge and skills, are more beneficial than human capital investments such as education. Human capital related to entrepreneurial tasks also has a stronger relationship with performance than human capital related to non-entrepreneurial tasks. While this study focuses on the human capital of the entrepreneur rather than the board of directors (Unger et al., 2011), the entrepreneurial context seems likely to match well to the resource provision that directors engage in, especially directors of smaller, private firms who may have valuable entrepreneurial experience.

Empirical evidence demonstrating the relationship between board capital and performance exists in several contexts. In one study that examines differences in board capital, Lester, Hillman, Zardkoohi, and Cannella (2008) investigate the human and social capital of former government officials as it applies to resource provision. Findings suggest that the tenure 
and position of the official influences the likelihood of being appointed to a board of directors. Additionally, utilizing the taxonomy of Hillman et al. (2000), Kroll, Walters, and Le (2007) show that post-IPO firms are likely to benefit from certain types of directors. After delineating business experts into those that provided advice and counsel and those that provided monitoring, results show that business expert directors providing advice and counsel lead to higher market returns (Kroll et al., 2007).

While boards are shown to assist in performance in many circumstances (e.g., Dalton et al., 1999; Lynall et al., 2003), small firms are often faced with decisions regarding dependencies and ownership control, which may threaten autonomy. Indeed, entrepreneurs are often faced with decisions to accept critical financial resources from providers that may usurp their own valuable resources (Hallen, Katila, \& Rosenberger, 2014; Katila et al., 2008). Additionally, some research finds that owners seek to protect their control of the firm. Daily and Dalton (1993) show that founder-led firms have smaller boards and fewer independent directors, as founders seek to maintain control of their firms. Fiegener et al. (2000) further demonstrate that owner-led firms are likely to appoint board members dependent on the owner, insulating the owner's control of the firm, while non-majority owners are more likely to appoint independent directors to help with resource provision. However, a founder's decision to insulate himself or herself can be detrimental as smaller, less independent boards are associated with lower firm performance (Daily \& Dalton, 1993). Indeed, as entrepreneurs are required to provide board seats (Kaplan \& Stromberg, 2004) in exchange for financial resources, choosing not to do so in order to insulate control may prevent firms from experiencing the benefits that accrue from venture capital (e.g., Baum \& Silverman, 2004). Evidence suggests that some entrepreneurs do work to appoint board members that may bring benefits to the firm. 
Clarysse, Knockaert, and Lockett (2007) examine board composition in start-up firms in terms of the human capital present on the board. Differences in external equity holders are found to lead to different types of human capital on the board. More specifically, public research organizations with equity stakes are more likely to add complementary human capital, while venture capitalists with equity stakes and autonomous owners are likely to add substitute human capital to the board. However, Kor and Misangyi (2008) also investigate boards of entrepreneurial firms and find differing results. Boards are used for access to industry-related experience when top management teams are lacking in industry experience, suggesting that boards may be used to access complementary human capital. Regardless of type, this research suggests that boards are utilized to add human capital to the firm.

In sum, the composition of a board for entrepreneurial firms presents several dilemmas for founders. Entrepreneurs may face threats from some resource providers attempting to procure the firm’s valuable business assets (Katila et al., 2008), and owners may appoint dependent board members in order to protect the owner’s control of the firm (Fiegener et al., 2000). Despite these potential pitfalls, many boards of entrepreneurial firms are not entirely composed of insiders. Boards of venture-backed firms typically have one or more members appointed by the venture capitalist, as entrepreneurs are required to provide board seats in exchange for financial resources (Kaplan \& Stromberg, 2004). Board members appointed in this way and possessing valuable human and social capital are more likely to bring benefits to the firm (Hillman \& Dalziel, 2003), rather than constraints. Indeed, human capital in entrepreneurial settings has a positive relationship with firm performance (Unger et al., 2011). Overall, resource provision by the board of directors is shown to have a positive relationship with firm performance (Westphal, 1999; Carpenter \& Westphal, 2001). Thus: 
H6: Board capital in outside board members will moderate the relationship between financial autonomy and sales growth, such that higher levels of board capital will lead to greater sales growth.

\section{Complementary Human Capital and Autonomy}

Firms engaged in IORs face the possibility of opportunistic behavior from their relationship partner (Teece, 1986), but may also receive positive benefits due to trust and joint action or actively working together (Gulati \& Sytch, 2007). Firms seeking to avoid the creation of new sets of dependencies that may exist after the remedy of one dependency (Pfeffer \& Salancik, 1978) may do so when IOR partners bring synergistic or complementary attributes to the table, creating the best incentive to work together for mutual benefit. Evidence suggests that firms do seek this mutual benefit.

Firms with complementary resources and partner-specific knowledge are shown to enter into alliances (Wang \& Zajac, 2007), suggesting that firms are seeking synergy or other positive outcomes that may prevent new dependencies from forming. That is, the existence of complementary resources suggests that each firm possesses a resource that its partner requires but does not have, and also receives added benefit from working together and sharing such resources. Firms in such relationships are likely to retain autonomy, as each firm benefits from freely providing its resource (Das \& Teng, 2000), and abstaining from any coercion or use of power that creates a disincentive for the partner firm (Gulati \& Sytch, 2007).

While many resources can be complementary, human capital is perhaps the most valuable resource a firm possesses, and its inimitable nature suggests that it is difficult to acquire (Coff, 
1997; 1999; Crook et al., 2011). Accessing complementary human capital resources may thus be better accomplished by engaging in alliances as opposed to acquisitions (Wang \& Zajac, 2007) or intra-industry recruitment (Hatch \& Dyer, 2004). While alliance outcomes are largely positive when post-alliance actions such as learning by doing or joint action (Gulati \& Sytch, 2007) are present, firms seeking to avoid the exchange of one dependency for another (Pfeffer, 1987) must know prior to alliance formation if synergistic opportunities exist. Thus, the existence of complementary human capital provides firms with the knowledge that such opportunities are likely to exist. While the mere existence of complementary human capital does not guarantee access to or benefits from an IOR, a known lack of complementary human capital does guarantee that benefits will not accrue. Firms entering into IORs with complementary human capital are then more likely to obtain synergistic benefits from doing so (Harrison et al., 2001), and to improve performance (Hatch \& Dyer, 2004). Such IORs are likely to be long-lasting due to low coordination costs and increased efficiencies (Humphreys, Lei, and Chan 2004), suggesting that firms maintain their own decision-making ability and autonomy. Long-lasting alliances built on successful IORs are also shown to lead to traditional financial measures of firm performance (Adams, Khoja, \& Kauffman, 2012). Thus:

H7a (7b): Complementary human capital between the alliance partner and management team of the focal firm will moderate the relationship between high (low) commitment complementary resource autonomy and sales growth, such that higher levels of complementary human capital will lead to greater sales growth. 


\section{CHAPTER IV: METHODS}

\section{Data and Methods}

\section{Sample}

To test the above hypotheses data will be collected form a sample of private firms that publicly announce agreements to secure financial and complementary resources. Data is collected from 2008-2017, avoiding the biggest disruptions of the financial crisis while still allowing for a longitudinal approach in analysis. In order to appropriately capture the entrepreneurial context described earlier in this paper, data will be gathered from firms six years old or less (Zahra, Ireland, \& Hitt, 2000).

Data is collected from multiple sources. First, firm-specific data are provided by PrivCo. PrivCo is a database of private company financial information containing financial performance data, venture capital transactions, and executive and investor profiles. PrivCo sources information from regulatory filings, news sources, and industry resources. Data is available on over 850,000 private companies and 112,000 private market deals (PrivCo, 2016). A total of 3,783 firm-years containing at least some of the required data were found. A total of 3,058 firmyears are found with observations for company revenue, leading to a total of 2,140 observations for the dependent variable, sales growth. After other missing data was removed from the analysis, a total of 921 firm-years offered complete data for analysis.

Second, IORs are collected from company websites, PrivCo, and the Factiva database. Company names as well as keywords such as alliance, joint venture, acquisition, and partner were used in the search. Third, additional information regarding firm executive profiles, board member profiles and investor profiles are collected from multiple sources where necessary. 
These sources include, LinkedIn, Relationship Science, and company websites. LinkedIn is used to capture data related to human capital and board capital. Relationship Science (relsci.com) is used to identify board members and board interlocks. Relationship Science provides information on corporate executives and board members, including work history and personal networks, for thousands of public and private firms. The service is designed to identify relationships between individuals, making it appropriate for identifying specific firms’ members and their relationships.

\section{Dependent Variable}

Sales growth. Based on previously reviewed literature, financial and complementary remedies are most likely to be successful when firms seek growth as an outcome (Rosenbusch et al., 2013). Sales growth will be measured as the percent change in year-over-year sales (Columbo \& Grilli, 2010) using the following equation:

$$
\text { Sales Growth }=\frac{\text { Sales }_{t}-\text { Sales }_{t-1}}{\text { Sales }_{t-1}}
$$

\section{Independent Variables}

Firms are shown to engage in IORs when facing resource dependence situations (Finkelstein, 1997). As such, a firm-level view of all such remedies best captures the actions of a firm seeking to remedy resource dependence. A total count of IORs in each year that seek to remedy dependence will be created. IORs will be separately examined according to the nature of the dependence a firm is attempting to remedy using the following constructs.

Financial resource dependence remedy. Financial remedies will be measured by an agreement to secure funding between a focal firm and an individual angel investor, venture capitalist firm, or private equity firm. Firms are incentivized to seek funding that is appropriate for their needs, as seeking too little funding will fail to produce needed benefits, and too much 
funding can cause the firm to exchange more equity than necessary for such funding (Katila et al., 2008). As firms may have more than one financial remedy, the total of all such agreements in each year will be counted.

\section{High and low commitment complementary resource dependence remedies.}

Complementary resource dependence remedies will be measured by an agreement to secure a complementary resource (e.g., manufacturing, marketing, R\&D). Katila et al. (2008) find that firms enter into IORs to remedy complementary dependencies differently based on scarcity. In order to capture high and low commitment complementary resource dependence remedies, the type of alliance activity will be examined. Following the findings and explanation by Katila et al. (2008), agreements considered to grant access to high commitment resources include: exclusive licensing agreements, exploration agreements, manufacturing agreements, and R\&D agreements. Agreements considered to grant access to low commitment include: non-exclusive licensing agreements, marketing agreements, and supply agreements. A count of each type of remedy within each year will be taken. Other types of agreements are coded high or low based on their similarity to these specifically named types.

IOR data is collected from company websites. Many firms publicly announce IOR activity, including the activity that partners will engage in as well as the structure of the IOR. For example, a firm may announce that they have created an independent joint venture to conduct R\&D. Firm IOR activity is also double-checked using Factiva.

\section{Mediating Variables}

Financial autonomy. Financial autonomy is measured as the log of total revenue divided by venture capital funding. Large amounts of cash provide firms with the best opportunity to retain autonomy when facing contingencies (Oliver, 1991a; Peng\& Luo, 2000). Entrepreneurial 
firms typically have two options for access to cash. They can produce their own via revenue, or they can secure venture capital funding. Firms earning enough revenue to operate and grow are unlikely to seek venture capital, as doing so requires a costly grant of equity (Rosenstein, 1988) as well as influence that is attached to the equity. However, outside funding is often required to grow the firm. Entrepreneurs are thus incentivized to accept an appropriate amount of venture capital. That is, enough capital to meet the strategic needs of firm, but not an access amount that comes with high costs (Wang \& Zhou, 2004). Firms accepting venture capital are dependent on that capital to the extent that they are able to operate without it. Thus, the ratio of revenue to funding represents how well a firm is capable of meeting its financial requirements without outside capital.

Complementary resource autonomy. Complementary resource autonomy measures the level of control over resources that firms have when securing such resources through IORs. In order to capture complementary resource autonomy for both high and low commitment resources as described above, multiple steps will be taken. First, alliances will be coded using the alliance intensity scale developed by Contractor and Lorange (1988) and Nohria and Garcia-Pont (1991). The scale rates alliances from 1-9 based on the level of commitment required between alliance partners as follows: 1. Distribution agreements. 2. Know-how and patent-licensing agreements. 3. Component sourcing agreements. 4. Second source agreements. 5. Broad R\&D Agreements. 6. Minority Equity. 7. Limited Cross Equity Ownership. 8. Independent Joint Ventures. 9. Mergers and acquisitions. Relative to lower ratings on the scale, higher ratings represent longer-term and more permanent solutions for access to resources. Firms with higher ratings on the alliance intensity scale should, all else equal, have higher autonomy due to having stronger control over the resource accessed in the alliance. Other factors may clearly influence control over resources 
beyond the commitment-level of the alliance. Such factors are discussed and measured as control variables below.

To code alliances I will first coded 100 alliances from the sample. Second, a second coder coded the same alliances. Coding matched on 82 of 100 alliances. Discrepancies were discussed until coding agreements were made. Third, I coded all alliances used in the sample based on the coding scheme. Lastly, an equation is developed based on the alliance intensity scale and the alliance concentration measure developed by Ahuja (2000). Whereas Ahuja (2000) calculates the level of concentration based on specific alliance partners, complementary resource autonomy intends to capture the overall commitment of a firm based on alliance intensity across alliance partners. The following equation will be calculated:

$$
\text { Complementary Autonomy }=\sum \frac{\frac{A I_{1}}{9}+\frac{A I_{2}}{9}+\frac{A I_{3}}{9}+\frac{A I_{4}}{9}+\cdots \frac{A I_{n}}{9}}{n}
$$

Where $A I$ represents the coded value of alliance intensity and $n$ represents the total number of alliances.

\section{Moderating Variables}

Board capital. Members of boards of directors are identified through PrivCo, company websites, and Relationship Science. Board members LinkedIn profiles are used to gather information about their occupational characteristics. Occupations are then coded according to the typology put forth by (Hillman et al., 2000). Board interlocks are counted using Relationship Science, which provides a thorough list of director positions held. Board capital is a multidimensional measure of the human and social capital of firm directors (Hillman \& Dalziel, 2003). As firms are often required to appoint board members as part of an agreement to secure venture capital (Park \& Steensma, 2014), the board capital of these members will be examined. More specifically, the social capital aspect of board capital is measured as a count of director 
interlocks (Dalziel, Gentry, \& Bowerman, 2011). The human capital aspect of board capital is measured using a heterogeneity index (Blau, 1977) of the board's occupational characteristics (Hillman et al., 2000). Occupational background categories include: “...general management, finance/accounting, sales/marketing, legal, information systems, operations, engineering, human resources, military/government, and real estate” (Haynes \& Hillman, 2010 p. 1154). This is calculated using the following equation:

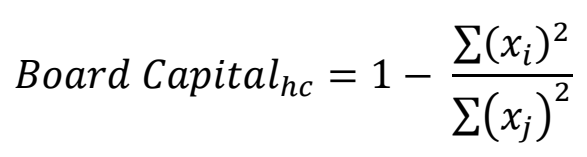

Where $\mathrm{x}_{\mathrm{i}}$ represents number of individuals with each occupational background and $\mathrm{x}_{\mathrm{j}}$ represents the total of all occupational backgrounds present on the board (Blau, 1977).

Complementary human capital. Firm TMTs are first identified through multiple sources, including PrivCo, company websites, and LinkedIn. Human capital data from firm TMTs was collected from LinkedIn. The previous firms of the TMT as well as whether a TMT member previously founded a firm was captured. NAIC codes for each firm were then sourced from Mergent Online and Manta.com. Mergent and Manta were also used to locate NAIC codes for firm alliance partners.

Drawing on the measure of complementary resources used by Lin, Yang, and Arya (2009), complementary human capital will be measured using the industry-specific human capital of the focal firm management team and the industry in which the alliance partner resides. The following equation will be calculated:

$$
\text { Complementary Human Capital }=\frac{\sum T M T H C_{i}+\sum A P_{i}-\sum M_{i}}{T M T H C_{i}+A P_{i}}
$$

Where $T M T H C_{i}$ represents the two-digit NAIC code of each industry in which a top management team member has experience, $A P_{i}$ represents the two-digit NAIC codes of alliance 
partners, and $M_{i}$ represents a two-digit NAIC codes present for both the top management team and alliance partner. Each of these terms is represented as a count. For example, if a management team has experience in industries with four different NAIC codes, an alliance partner has one NAIC code, and it matches the NAIC code of the alliance partner, the calculation is: $(4+1-1) / 5$ $=0.8$. Thus, higher numbers represent a higher level of complementary human capital. Additionally, firms may have more than one NAIC code (Wang \& Zajac, 2007), which theoretically allows for the calculation to be negative. In such instances, it will be assumed that no complementary human capital is present and the variable will be set to zero (Lin et al., 2009).

\section{Control Variables}

Industry. Industry will be controlled for using a dummy variable for each two-digit NAIC code (Robb \& Seamans, 2014).

Size. Firm size will be measured as the total employees of the firm (Lu \& Beamish, 2006).

Age. Firm age will be measured as the number of years since the founding of the firm (Fink \& Harris, 2012).

Year. The calendar year will be included to control for year-to-year differences (Beckman et al., 2004).

Board size. The total number of members on the board of directors (Beckman et al., 2004).

Entrepreneurial human capital. Entrepreneurial human capital will be captured using two measures. First, the number of years of industry experience of the founder(s) will be 
gathered. Second, the number of previous start-ups by the founder(s) will be counted (Unger et al., 2011).

Top management team size. A count of the management team size will be gathered (Baum \& Silverman, 2004).

Total number of alliances. A total count of current firm alliances will be gathered (Ozmel et al., 2013).

Venture capital reputation. Prior research shows that the VC firms possessing strong reputations select investment targets with higher potential (Sorensen, 2007). To control for these possible effects VC reputation is controlled for. As IPOs are typically the most successful venture exit for VC firms, the cumulative market capitalization of IPOs backed by the VC is used to capture reputation (Nahata, 2008). Following Nahata (2008), these measures will be collected over a 10-year period from 2006-2015. Thus, firms in my sample that were founded in 2010 have at least four years of IPO data from which to draw reputation measures, and firms founded in 2015 have ten years. Venture capital reputation is captured using the VentureXpert database within SDC Platinum. All publicly traded firms that completed an IPO between the years 2005 and 2015 are identified, as well as all investors in the firm, and the market capitalization at the end of the first day of trading. The overall market share capitalization of IPOs is then calculated for each investor (Nahata, 2008)

Board monitoring and opportunism. Unlike public firm that have requirements to appoint independent directors, private firms do not face the same obligations. Instead, founders and VC investors are expected to carry out monitoring of the firm through the board of directors (Garg, 2013). However, VCs and funded firms may have differing goals, causing owners to 
monitor in ways that VCs may not. Thus, board monitoring is thus measured as the ratio of firm insiders to board outsiders. To prevent division by zero, 1 is added to the denominator.

To capture the possibility of opportunistic behavior by firm outsiders, a count of the total outsiders is used. Outsider board members are typically appointed by the VC firm (Kaplan \& Stromberg, 2004). Having more board members gives the VC firm leverage to pursue an exit or an early push to profitability when doing so may not be wise (Cumming, 2008). As VCs must often return capital to their limited partners, pressures to act opportunistically exist, and firms with higher representations of outsiders are thus more likely to face opportunism.

\section{Analysis}

Data will be collected that represents different periods of time. This creates nonindependent nested data that requires a mixed-effects model. Mixed-effects models allow for analysis of fixed-effects that include all variables regardless of time as well as random-effects that include all variables that differ across time in order to capture variables that apply to all observations as well as those that change depending on time or other changing effects. To perform such analysis the xtmixed command in stata is utilized. This command allows for analysis over time as well as multilevel analysis, which in this case involves grouping at the industry-level.

Examination of the data shows that the dependent variable, firm performance measured as revenue growth, has several substantial outliers that are likely to skew results. This is not surprising given the nature of the firms in the sample, as young firms are more likely to grow at a faster rate (Markman \& Gartner, 2002). As firms move from very little revenue to substantial revenue in a short period of time firms may occasionally experience revenue growth figures in the thousands of percent. Indeed, 24 observations in the data show firms with over 20,000\% 
growth. As such large numbers can substantially effect results, observations greater than two standard deviations above the mean were trimmed from the analysis. This resulted in 28 observations being trimmed. Additionally, robust standard errors are used in the analysis to avoid issues related to heteroskedasticity.

Hypotheses 1-3 test the direct effect of each type of resource dependence remedy on firm performance. Hypotheses 6, 7a, and 7b examine moderation effects. These hypotheses are tested using the xtmixed command as described above. Hypotheses 4, 5a, and 5b test mediation. Analysis is performed using the sgmediation command in Stata, which performs Sobel-Goodman mediation tests. Sobel-Goodman tests can determine the amount, if any, of influence that a mediating variable carries from an independent variable to a dependent variable. This test is necessary to test mediation, as xtmixed can only examine the relationship between independent variables and moderators and a dependent variable. Results can indicate the proportion of the total effect that is mediated as well as the significance of each path in the mediation. Model fit is assessed using Akaike information criterion (AIC). 


\section{CHAPTER V: RESULTS}

Correlations are presented in table 5.1. Board size and board opportunism are found to be highly correlated (0.91). To check for multicollinearity a Tolerance level and VIF are calculated. The Tolerance level is found to be .997 and the VIF is found to be 1.0. These results fall substantially below suggested levels of Tolerance greater than 0.2 and VIF less than 10.0 (Hair et al., 2010). $=1.00$. No other variables are found to be highly correlated such that multicollinearity may be an issue.

Descriptive statistics are presented in table 5.2. Firm performance, measured as revenue growth, is present for 2,140 observations out of a possible 3,783. Given that at least two years of revenue must be available to calculate growth, this is a reasonable ratio of available observations. All other variables have at least as many observations. However, as missing data throughout the sample appears to be random, the number of complete observations available for testing is reduced to 921. Descriptive statistics also show that the mean of firm performance is equal to 2.09, but the standard deviation is 7.41, with a maximum value of 200.1. As firm performance is measured as a percentage, this means that one firm grew revenue by just over $20,000 \%$ percent in one year. Growth rates of this magnitude are more than likely due to the timing of when a firm begins to earn revenue in a calendar year, or a complete change in the attempt to earn revenue at all, rather than the outcome of a strategic decision. As such, observations of firm performance greater than two standard deviations above the mean are excluded from analysis as described above.

Hypotheses 1-3 test the direct effect of financial dependence remedies, high commitment complementary remedies and low commitment complementary remedies on firm performance. Multiple control variables are also used in the analysis, including board size, board opportunism, 
board monitoring, entrepreneurial human capital, firm age, firm size, TMT size, and VC reputation. Results of H1-H3, as well as the control model, are shown in Table 5.3. Hypothesis 1 states that financial resource dependence remedies will have a positive relationship with firm performance. Results show a positive and significant relationship $(B=0.458, \mathrm{p}<.01)$, thus supporting Hypothesis 1 . Hypothesis 2 states that high commitment complementary resource dependence remedies will have a positive relationship with firm performance. Results fail to find support for Hypothesis $2(B=0.185, \mathrm{p}=.18)$. Hypothesis 3 states that low commitment complementary resource dependence remedies will have a positive relationship with firm performance. Results show a significant but negative effect $(B=-0.099, \mathrm{p}<.01)$, thus failing to find support for Hypothesis 3.

Hypotheses 4, 5a, and 5b all test mediation between each of previously tested resource dependence remedies and firm performance. Mediation is tested using Sobel-Goodman mediation. Results of each mediation are shown in Table 5.4. Hypothesis 4 states that financial autonomy will mediate the relationship between financial resource dependence remedies and firm performance. While financial dependence remedies are shown to have a positive and significant relationship with firm performance $(B=0.572, \mathrm{p}<.01)$ and financial autonomy $(B=$ 10.507, $\mathrm{p}<.01$ ), no relationship was found between financial autonomy and firm performance ( $B$ $=-0.014, \mathrm{p}=.41)$. Further, none of the Sobel-Goodman Mediation tests are significant. Thus, Hypothesis 4 is not supported.

Hypothesis 5a states that complementary resource autonomy will mediate the relationship between high commitment resource dependence remedies and firm performance. Results show that high commitment remedies have a negative and significant effect on firm performance ( $B=$ $-0.398, \mathrm{p}<.05)$ and that complementary autonomy has a positive and significant $(B=4.77, \mathrm{p}$ 
$<.01$ ) effect on firm performance. Sobel-Goodman tests are also significant $(B=0.58, \mathrm{p}<.01)$.

These results show that mediation is present, however, the negative coefficient of high commitment complementary autonomy is counter to the hypothesized relationship. Thus, Hypothesis 5 a is not supported.

Hypothesis 5b states that complementary resource autonomy will mediate the relationship between low commitment resource dependence remedies and firm performance. Results show that low commitment remedies have a positive and significant relationship with low commitment complementary autonomy ( $B=0.04, \mathrm{p}<.01$ ), but no relationship is found between low commitment remedies and firm performance $(B=-0.029, \mathrm{p}=.87)$ or between low commitment complementary autonomy and firm performance $(B=-0.7, \mathrm{p}=.44)$. Sobel-Goodman mediation tests are also non-significant. Thus, Hypothesis $5 \mathrm{~b}$ is not supported.

Hypotheses 6, 7a, and 7b test moderation between each of the mediators and firm performance. Results are shown in Table 5.7. Hypothesis 6 states that board capital will moderate the relationship between financial autonomy and firm performance, such that higher levels of board capital will lead to higher levels of firm performance. Board capital is comprised of the human and social capital of board members (Hillman et al., 2009), so each aspect of tested separately. Board (human) capital is shown to have a negative and significant direct relationship with firm performance $(B=-0.95, \mathrm{p}<.01)$. As lower values in the measure of board capital represent higher amounts of board capital, this result is expected. However, the moderating effect of board (human) capital on firm performance is non-significant ( $B=0.03, \mathrm{p}=.22)$. Board (social) capital is also proposed to moderate the relationship between financial autonomy and firm performance. No result is found $(B=-0.0001, \mathrm{p}=.85)$. As neither component of board 
capital is found to moderate the relationship between financial autonomy and firm performance, Hypothesis 6 is not supported.

Hypothesis 7a examines the moderation of complementary human capital on the relationship between high commitment complementary autonomy and firm performance. Results show a negative but not significant relationship between the interaction term and firm performance $(B=-6.51, \mathrm{p}=.07)$. Hypothesis $7 \mathrm{~b}$ examines the moderation between low commitment complementary autonomy and firm performance. A significant relationship is not found ( $B=2.29, \mathrm{p}=.39$ ). Thus, Hypothesis $7 \mathrm{~b}$ is not supported.

Table 5.3 also present the full model with all direct effects and moderators. Interestingly, Hypothesis 7a finds support in this model $(B=-7.093, \mathrm{p}<.05)$. This and other hypotheses are further explored with post-hoc analysis.

\section{Post-Hoc Analysis}

Sobel-Goodman mediation tests are only capable of examining one mediating relationship of interest at a time. To further explore the mediating relationships proposed structural equation modeling (SEM) is used. SEM allows for full and simultaneous estimation of the mediation and moderation effects, as compared to the combination of xtmixed and sgmediation commands described above. Results are similar to the Sobel-Goodman mediation

test for Hypotheses 4 and 5a. However, differences arise when testing Hypothesis 5b. Hypothesis 5b states that complementary autonomy will mediate the relationship between low commitment remedies and firm performance. This hypothesis is not supported using the Sobel-Goodman method. However, structural equation modeling finds a significant relationship between low commitment remedies and complementary autonomy $(B=.08, \mathrm{p}<.01)$, as well as between low 
commitment complementary autonomy and firm performance $(B=-2.71, \mathrm{p}<.05)$. As lower commitment levels are represented by lower numbers, this lends support to Hypothesis 5b.

Hypothesis 7a examines the moderating effect of complementary human capital on the relationship between complementary autonomy and firm performance. While regression analysis did not find support, the p-value of .07 suggests a relationship may be present. Indeed, SEM finds a significant effect $(B=-7.15, \mathrm{p}<.05)$. As lower levels signify less commitment and less commitment is proposed to increase firm performance, this lends support to Hypothesis 7a. The result is graphed in Figure 5.1.

Given non-significant and counter-findings to many of the hypotheses relating to complementary resource dependence remedies, further post-hoc analysis is conducted. Research shows that venture-backed firms tend to enter more alliances than non-venture-backed firms, and but that alliance formation can be a substitute for venture capital (Wang et al., 2012). Thus, entering into venture capital funding agreements should have a positive relationship with future alliance formation, and alliance formation should have a negative relationship with future venture capital funding. These relationships are tested using negative binomial regression, which is appropriate for dependent variables made up of counts. Results are shown in Table 5.5. While results do find a positive and significant relationship between venture capital funding and future IORs ( $B=.15, \mathrm{p}<0.01)$, a positive and significant relationship is also found between IORs and future venture capital funding $(B=.032, \mathrm{p}<.01)$. The latter result runs counter to the anticipated finding that IORs would reduce the need for future venture capital and thus have a negative relationship with future funding.

It should be noted that Wang et al. (2012) use a sample dating from 1992 to 2004, well before the beginning of the sample used in this dissertation. Additionally, only venture-backed 
companies were used by Wang et al. (2012), whereas this sample utilizes both venture-back and non-venture backed firms. Given the differences in both sample characteristics and empirical findings, further research in this area is warranted. Possible avenues for such research are discussed in the next chapter. 


\section{CHAPTER VI: DISCUSSION}

This dissertation broadly seeks to contribute to literature in resource dependence and firm performance. More specifically, the nature of autonomy is examined in terms of the relationship between resource dependence remedies and firm growth. Additionally, the human and board capital of the TMT and venture board is examined in terms of how it may contribute to growth with IORs. Each of these contributions is described below in greater detail.

\section{Specific Findings}

Hypothesis 1 proposes that financial resource dependence remedies, in the form of venture capital, will lead to sales growth. Similar findings hold in numerous studies (e.g., Rosenbusch et al., 2013). This result thus further solidifies the relationship and provides a starting point for mediating and moderating hypotheses. Hypotheses 2 and 3 examine the relationship between high and low commitment complementary remedies, in the form of IORs, and sales growth. Previous research examines the relationship between IORs and performance (e.g., Lunnan \& Haugland, 2008), typically finding positive outcomes stemming from IOR formation. However, few studies consider the commitment level of the IOR in addition to the type of resource gained (e.g., Katila et al., 2008). Hypothesis 2 predicts a positive relationship between high commitment complementary dependence remedies and sales growth, but is not supported. Hypothesis 3 predicts a positive relationship between low commitment complementary dependence remedies, but instead finds a significant negative relationship. A negative relationship is somewhat surprising. It is certainly possible that such IORs may not lead to increased sales growth, but it seems counter-intuitive for an IOR to prevent a firm from growing. For such a relationship to hold beyond this sample it would seem that forming such

IORs would have to be a poor strategic choice that is unrealized by firm owners and managers, 
or that the goal of such IORs is something considered to be more important than growth. A more likely explanation may be the nature of the resource sought. As these are low commitment resources, some firms may be able to easily develop such resources internally at a relatively low cost. Firms that must seek these resources externally may be expending additional resources to do so, causing lower levels of growth.

Hypotheses 4, 5a, and 5b test the mediation of types of autonomy between their respective resource dependence remedies and growth. Hypothesis 4 examines the relationship between financial autonomy and growth. Unfortunately, no result was found. As firms must eventually stand on their own via the creation of revenue or additional access to capital through an IPO, it seems unlikely that a mediating, or perhaps moderating, effect is not present in the relationship, despite this non-finding. The measurement of financial autonomy may be preventing an effect from being found. This possibility is further discussed in the limitations section.

Hypothesis 5a tests the relationship between high commitment resource dependence remedies and high commitment complementary autonomy. While a significant result is found in post-hoc analysis, the coefficient is opposite of the predicted direction. Lower levels of commitment, represented by lower values in the complementary autonomy variable, would produce a negative coefficient if the hypothesis was supported. The positive coefficient instead means that within high commitment complementary remedies, higher commitment levels lead to firm growth. One possible explanation is that the highest level of commitment, an acquisition, may also bring added revenue to the firm. While any type of growth clearly shows up the same in measures of revenue, other measures of efficiency or profitability may suffer, causing medium and long-term issues for the firm. Further, as high commitment resources are by definition more 
difficult to obtain, having a higher commitment level may reduce uncertainty in the firm, allowing for strategic decisions that better promote growth. High commitment levels may also simply give permanent access to a needed resource, compared to the possible temporary access of a lower commitment level.

Hypothesis $5 b$ tests the relationship between low commitment resource dependence remedies and low commitment complementary autonomy. Sobel-Goodman mediation tests fail to find a significant result. However, SEM finds that low commitment complementary autonomy negatively mediates the relationship between low commitment remedies and sales growth. This is an interesting finding compared to the Sobel-Goodman result and the finding of H3, which identifies a negative relationship between low commitment remedies and sales growth. SEM instead identified no direct relationship between low commitment remedies and sales growth, but instead a positive relationship between low commitment remedies and low commitment complementary autonomy, followed by a negative relationship between such autonomy and sales growth. This result supports H5b, as lower commitment levels lead to higher growth. This is the logical result, as firms seeking low commitment resources externally should not have to make a large commitment to secure such resources. Firms able to do this are likely acquiring resources needed for further commercial development of their product or service (Teece, 1986) at a low cost, whereas firm that must make a large commitment then suffer lower performance.

Hypotheses 6, 7a, and 7b examine moderation between each of the mediating variables and growth. Board capital is examined separately in terms of the human and social capital of the board. No result is found for either measure. As with financial autonomy itself, the issue may be due to the measurement of the mediating variable. Hypothesis 7a tests complementary human capital as a moderator between high commitment complementary autonomy and sales growth. 
Results show that higher levels of complementary human capital increase sales growth. While the result of Hypothesis 5a is counter to the expected result, results of this moderation appear to give further credence to the explanation that higher levels of commitment are preferred when dealing with high commitment resources. As both parties are firmly committed, the presence of complementary human capital creates additional benefits that are more likely to be leveraged than if commitment levels were lower.

Hypothesis 7b tests complementary human capital as a moderator between low commitment complementary autonomy and sales growth. No effect is found. While complementary human capital is shown to be useful in high commitment contexts, it does not appear to be effective in these situations. The result of Hypothesis $5 \mathrm{~b}$ from the SEM analysis may shed light on this non-finding. If firms are indeed securing resources with low levels of commitment and experiencing sales growth from doing so, they effect of complementary human capital in such situations may be irrelevant. Firms may be securing a resource in a straightforward and agreed-upon manner, and then continuing with their strategic plan without the need to work together with the IOR partner for additional success.

Post-hoc analysis also finds an interesting relationship between IORs and funding. Firms with more funding rounds are more likely to engage in IORs after acquiring funding. Taken together with the non-finding between IORs and growth, an interesting plausible story emerges. It may be the case that firms seek funding for growth, but engage in IORs for other purposes. For example, firms may seek a resource that is not available internally, but be doing so as a strategic choice. It may be less costly to engage in an IOR to secure that resource than to develop it internally. As such, an IOR meeting this criterion may be more likely to lead to profitability than growth. 


\section{Contributions}

This dissertation makes several contributions to extant literature. First, results of the literature review demonstrate that autonomy is an overlooked aspect of IORs, despite being central to RDT (Pfeffer \& Salancik, 1978), and being a key mediator in the relationship between IORs and firm performance (Drees \& Huegens, 2013). The lack of attention directly relating to autonomy is even more pronounced given that many studies claimed to study autonomy do not actually use the term (Drees \& Huegens, 2013). Further, autonomy is often measured in very different ways, such as access to financial resources (e.g., Honig et al., 2006), acquisitions (e.g., Teerikangas, 2012) or CEO succession (e.g., Eklund et al., 2013). By examining key theoretical arguments surrounding autonomy (Pfeffer, 1987; Oliver, 1991a), this dissertation proposes that autonomy has three distinct mechanisms: the ability to respond to contingencies, the ability to avoid opportunistic behavior, and the ability to meet multiple demands. Recognizing these mechanisms of autonomy can future researchers distinguish what, exactly, firms are trying to accomplish in a quest for autonomy. They may also provide a foundation for building additional theory and empirical research seeking to identify the antecedents and outcomes of each specific mechanism.

A second contribution of this dissertation involves the nature of resources being sought in IORs. Firms engaging in IORs are seeking resources, but the nature of the resource being sought is also frequently overlooked or only casually examined. This dissertation contributes by developing theory about the nature of the resources sought by the firm. Firms enter IORs ultimately seeking remedies for dependence, but little research asks the question "dependence on what?’. By distinguishing between financial and complementary resources a greater ability to explain and predict outcomes is gained. For example, a firm seeking capital to pursue expansion 
of retail locations may be seeking to remedy this dependence through a venture capital arrangement. However, venture capital funding alone is unlikely to remedy dependence if a firm is seeking to develop a new pharmaceutical drug and lacks technical expertise, or cannot successfully develop cloud technology needed for their software. Further, all complementary resources are not the same. Some resources, such as manufacturing, require higher levels of commitment than others, such as marketing (Katila et al., 2008). This dissertation recognizes this distinction by dividing complementary resources into high and low commitment complementary resources (Katila et al., 2008; Das et al., 1998).

A third contribution is found in the empirical results of $\mathrm{H} 5 \mathrm{a}$ and $\mathrm{H} 5 \mathrm{~b}$. While neither hypothesis is supported in the initial analysis, H5a is significant in the opposite direction and post-hoc SEM analysis finds support for H5b. These findings support the notion that autonomy mediates the relationship between resource dependence remedies and firm performance (Drees \& Huegens, 2013). Perhaps more importantly, they do so in a theoretically grounded manner. As the majority of studies focusing on resource dependence only casually mention autonomy, or ignore it entirely, questions remain regarding what constitutes autonomy and how it relates to various outcomes. This dissertation begins to answer these questions by distinguishing three separate mechanisms of autonomy and finding empirical support for how two of those mechanisms, the ability to avoid opportunistic behavior and the ability to meet multiple demands simultaneously, relate to firm performance.

Further, high and low commitment complementary autonomy are found to have differing relationships with firm performance. High commitment complementary autonomy is hypothesized to lead to higher growth at lower commitment levels. However, higher commitment levels are found to lead to higher growth. While this is not the expected 
relationship, it is also not illogical. As high commitment resources are rarer and more difficult to access, securing them at a high commitment level may allow firms long-term stability that more easily leads to firm growth. Conversely, as low commitment complementary resources are more common and easier to access, firms should not have to undertake a large commitment to access these resources. Overall, these findings suggest that not all IORs lead to firm performance equally, and that both the nature of the resource and the commitment required to secure the resource should be considered when evaluating firm performance.

A fourth contribution involves the human capital of a firm’s TMT. Human capital is shown to have numerous positive outcomes (e.g., Unger at al., 2011) for individuals and firms. This dissertation extends these findings by examining how the human capital of a TMT can benefit the firm in a presence of specific IORs. Results of Hypothesis 7a show that complementary human capital moderates the relationship between high commitment complementary autonomy and revenue growth. This result seems especially important given the unexpected finding in Hypothesis 5a. Pfeffer (1987) states that remedies for dependence are likely to cause new dependencies, making any remedy less than fully effective. Hypothesis 7a argues that complementary human capital can instead create the opportunity for both IOR partners to work together for mutual benefit, rather than working to create a situation of dependence that may not result in higher performance (Gulati \& Sytch, 2007). As higher commitment levels are shown to mediate the relationship between high commitment complementary remedies and firm performance, and higher commitment levels may create dependent situations, complementary human capital may play a very critical role in such relationships. 
Finally, results of post-hoc analysis may shed light on the relationship between funding and alliances and how each effect firm performance. Research suggests that venture capital funding and alliances may be substitutes for each other (Wang et al., 2012). However, this dissertation finds no relationship or a negative relationship between complementary resource dependence remedies and revenue growth, but does find a significant relationship between funding and growth. Further, results of negative binomial regression suggest that venture capital funding leads to future IORs. As young firms have few resources of their own, this result makes logical sense. Firms may be unable to enter into IORs due to a lack of resources available to offer an IOR partner in exchange for other resources. However, firms that first obtain venture capital funding are more likely to build valuable resources that can then be utilized in IORs, allowing them greater access to such opportunities.

\section{Limitations}

Like all studies, this dissertation has limitations. First, using private companies for the sample is less reliable than using public firms. Private firms are not legally required to announce financial results or other activities in the same manner as public firms, creating the possibility that available data consists more of data that firms want released, rather than a complete picture. However, the sources used here are typically reliable, and such data is becoming more readily available as firms are emerging to capture and sell such data (e.g., PrivCo, Pitchbook, etc.).

One specific issue with related to the use of private firms is the number of observations present for IORs. Just over 2,000 observations of the dependent variable, revenue growth, are present. Over 3,000 financial resource dependence remedies are also captured. However, only 152 high commitment complementary resource dependence remedies and 382 low commitment complementary resource dependence remedies are found. Given that these observations are 
captured via firm websites and the Factiva database, it is unlikely that substantial observations for these variables are both present and available to be collected. Firms may of course enter into IORs without media coverage or making an announcement, but the extent to which this may be occurring is unknown. However, given that significant effects are found with only a small number of observations, it seems likely that any missing observations would only shed additional light on what appears to be a significant relationship.

Second, some variables are not able to be measured in the preferred way. Financial autonomy, measured here as the ratio of revenue to funding, is conceptualized as how well a firm can handle unforeseen contingencies that may arise. As such, a ratio of cash to total annual expenses would more accurately indicate how well a firm can meet its expected obligations (George, 2005) while also having a cushion for unforeseen expenses that extend beyond the short term. While this ratio is preferred, the measure used in this dissertation is not without merit. The ratio of revenue to funding captures the ability of a firm to stand on its own to operate. Firms seeking venture capital are typically focused on growth (Zacharakis et al., 2012) and are less concerned about profitability. It is thus likely that a large percentage of funds that are available are used for the operation and growth of the firm. Additionally, owners are incentivized to accept venture capital in the amount required, as accepting additional capital results in costly equity payments and accepting less may result the need to simply raise more capital soon or make suboptimal strategic decisions. As firms sell larger equity stakes for funding, future funding opportunities will eventually dissipate. Therefore, firms with higher ratios of revenue to funding are expected to have greater access to future funding and thus greater financial autonomy. Future research examining financial autonomy in the context of entrepreneurial firms should consider survey research or other creative measures, as data pertaining to cash positions and annual 
expenses are unlikely to be widely available. Indeed, this data was sought from numerous sources that collect information on private companies, including PrivCo, Mergent, ReferenceUSA, and Pitchbook, without success.

Board opportunism, measured as the number of outsiders on the board of directors, may also be best measured in a different manner. Venture capital firms may have dozens or even hundreds of firms in their investment portfolio. The mean number of interlocks present on boards in this sample is 16.44 , the majority of which are due to board members placed by venture capital firms. While their presence, as compared to absence, certainly increases the likelihood of opportunistic behavior taking place, the number of board members spend with the firm may be a better indicator of opportunism (Gabrielsson \& Huse, 2002). Again, exploring such a concept in entrepreneurial firms may be best done via survey research. However, given that opportunism is used as a control variable rather than an independent variable of primary interest, the measurement of outsiders likely suffices.

Board monitoring, measured as the ratio of insiders to outsiders plus one, also suffers from limitations. Adding one to the denominator of the ratio prevents divisions by zero and the creation of missing data, but also creates a non-linear transformation. For example, a firm with one insider and zero outsiders has a ratio of 1.0, a firm with one insider and one outsider has a ratio of 0.5 , and a firm with one insider and two outsiders has a ratio of 0.33 . The inverse of this ratio, outsiders divided by insiders, may prevent the majority of data from being lost while not causing this issue, as most firms have at least one insider on the board. However, in instances where there are no insiders, data would be missing when it is actually a situation ripe for heavy monitoring. This causes the removal of what would otherwise by the maximum values for monitoring in the sample. 
Another limitation deals with the names of high and low complementary remedies and autonomy. This dissertation builds on existing research by Katila et al. (2008) by using the concepts of high and low commitment complementary resources and then naming them accordingly. Further, high and low complementary autonomy are proposed to mediate the relationship between each remedy and performance, matching the names of the resources. While these labels are based on descriptions from established literature (Katila et al., 2008), they may also be potentially misleading. This is due to the predictions made in hypotheses $5 \mathrm{a}$ and $5 \mathrm{~b}$, which state that lower commitment levels will positively mediate the relationship between remedies and performance. The hypotheses are discussing the commitment level of the remedy based on its structure (e.g., distribution agreement, independent joint venture, etc.), while high and low commitment remedies are labels assigned based on the specific resource sought in the IOR (e.g., advertising, manufacturing, etc.). The use of high and low commitment as descriptors for both the type and structure of the remedy may create unnecessary difficulty in explaining the concepts, regardless of their previous establishment in the literature.

Going forward, it is likely wise to relabel high and low commitment complementary remedies as well as high and low commitment autonomy. Relabeling all of these constructs can create a clearer distinction between the remedies, the mechanism driving each type of autonomy, and also allow the stated hypotheses to continue using the accurate description of lower commitment levels being required for mediation. Further, the theoretical foundations for each construct will remain unchanged.

First, high commitment complementary resources could be renamed direct resources. High commitment complementary resources grant access to rarer, scarce, resources that are likely to require fixed costs (Katila et al., 2008). An examination of IORs in this sample suggests 
that these resources are likely to be directly linked to the development or sale of a firm's products or services. For example, multiple firms in the sample entered into IORs with other firms with the intent to integrate their respective software products to offer a superior product to specific customers or create additional benefits for existing customers. Thus, the label direct resources clearly describes how the resource will be used and distinguishes it from low commitment complementary resources, which could be renamed indirect resources. Examination of the IORs in the sample suggests that low commitment complementary resources grant access to resources such as advertising, marketing, and distribution. These are clearly indirect resources. This label may be superior to low commitment complementary resources, as it more precisely describes the nature of the resources and offers a clear distinction from direct resources.

Finally, high and low commitment complementary autonomy, which are named to match the resource that they mediate, should also thus be renamed. One contribution of this dissertation is recognition of the need for theoretical development of autonomy and the proposal of three mechanisms of autonomy each working in conjunction with a specific resource. High and low complementary autonomy, which accurate descriptions, do not refer to the theoretical mechanism that drives each type of autonomy. High commitment complementary autonomy is defined as the ability to avoid opportunistic behavior, and could thus be renamed opportunistic autonomy. Low commitment complementary autonomy is defined as the ability to meet multiple demands simultaneously, suggesting a choice from multiple options, and could thus be renamed matrix autonomy. 


\section{Future Research}

Results suggest several possible avenues for future research that may be fruitful. First, the relationship between low commitment complementary resource dependence remedies and growth is shown to be negative, counter to what is hypothesized. Logically, such IORs should help a firm continue to grow, or at least not hinder growth. A negative relationship may suggest that firms unable to internally develop resources needed for the continued development of the firm (Das et al., 1998). Future research could further explore the link between such IORs and firm performance while also examining the resource capabilities of the firm.

Next, the theoretical arguments described in Chapter III merit further investigation, especially given the limitations outlined above. While financial autonomy in private firms is unlikely to be captured using a measure of cash/total expenses, other options may exist. Firms that acquire funding do so in exchange for a percentage of equity. The percentage of equity is sometimes, but not always, available. This percentage may also be derived if the overall valuation of the firm during a particular funding event is known, as it could simply be used in a ratio of funds given to valuation. Obtaining such a measure and using it in conjunction with the ratio of revenue to funding used here can provide a more detailed look at financial autonomy. Specifically, researchers would know how well the firm is currently standing on its own via the ratio of revenue to funding, and have some indication of how much external funding may still be available. Firms highly dependent on outside funding that have only sold a small percentage of equity should have, all else equal, greater financial autonomy than firms that have sold a higher percentage of equity.

Results of Hypotheses 5a, 5b, 7a, and 7b also suggest avenues for future research. As different types of analyses find different results, and some results are counter to those 
hypothesized, future research should reconsider the theoretical argument presented here, carefully select appropriate analysis for the sample that is collected, and work to further support these relationships or identify potential weaknesses in them.

Next, while the moderating effect of board capital on financial autonomy is not significant, the non-finding could be due to the previously mentioned issues with the measurement of financial autonomy. Further, results point to a potentially promising avenue of investigation. Results show that the direct effect between the human capital aspect of board capital and revenue growth is negative and significant. As lower numbers represent higher amounts of board capital, this suggests that board capital positively influences revenue growth and is worthy of future investigation as both a direct effect and a moderator.

Next, while autonomy is established as a mediator between remedies and performance (Drees \& Huegens, 2013), there may be other important relationships. For example, autonomy is measured at a point in time in this dissertation. However, it changes over time and that change may also be relevant to firm performance or other outcomes of interest. Another possibility is that autonomy may have a non-linear effect. It seems reasonable that some lower levels of autonomy, such as those involving distribution or licensing agreements, may not produce a significantly different effect from each other. At higher levels, though, there is a clearer difference between an independent joint venture and an acquisition. Mathematically, these differences are much closer than they may be in practice. Future research could further develop this logic and propose non-linear effects.

Finally, future research could propose a finer-grained measure of complementary resources. While some resources are clearly high commitment (e.g., manufacturing) and some are clearly low commitment (e.g., advertising), some are not so clear (e.g., technology). Drawing 
on the arguments outlined above for possible renaming of high and low complementary resources, the level of commitment could perhaps instead be measured by how necessary the resource is for the primary operations of the firm. For example, a company that sells products is clearly highly dependent on manufacturing to produce the product, but likely less dependent on a supplier of food for the company cafeteria. Conversely, a restaurant that specializes in a certain cuisine may be dependent on the supplier of the ingredients, but not dependent on the manufacturer used to create products for customers to purchase and take home. This relatedness to core business operations may perhaps be measured using the industries of the partners. Firms in the same industry would be more likely to indicate a resource necessary for the core business that carry higher commitments, while firms in different industries may be more likely to indicate resources that are not directly related to the core business. 


\section{CHAPTER VII: CONCLUSION}

The overall goal of this dissertation is to expand and examine concepts surrounding interorganizational relationships. Findings suggest that the theoretical distinctions made between different types of resources and different mechanisms of autonomy likely have merit. Specifically, the nature of resources being accessed through an IOR are shown to be a critical component of the relationship between IORs and firm performance, and that the level of commitment that firms should undertake when entering into IORs should vary depending on the resource sought. Further, additional factors beyond the resource sought and the commitment level present in securing that resource are also considered. Results suggest that the potential for IOR partners to work together for mutual gain is important in high commitment situations, but not a factor in low commitment situations.

The broad topics related to resource dependence explored in this dissertation have been examined for decades with many advances. However, the specific questions asked here have yet to be answered, despite acknowledgements that resource dependence theory is often used as a metaphor rather than a theoretical foundation (Wry et al., 2011), and that remedies for dependence lead to firm performance in different ways that are currently unknown (Drees \& Huegens, 2013). This dissertation attempts to advance resource dependence theory and its related concepts by studying these questions. Overall, the theory presented and empirical results found begin to shed light on these areas and lays a path for future research to make additional advances. 


\section{References}

Adams, J. H., Khoja, F. M., \& Kauffman, R. (2012). An empirical study of buyer-supplier relationships within small business organizations. Journal of Small Business Management, 50(1), 20-40.

Aharoni, Y., Maimon, Z., \& Segev, E. (1981). Interrelationships between environmental dependencies: A basis for tradeoffs to increase autonomy. Strategic Management Journal, 2(2), 197-208.

Ahlers, G. K., Cumming, D., Günther, C., \& Schweizer, D. (2015). Signaling in equity crowdfunding. Entrepreneurship Theory and Practice, 39(4), 955-980.

Ahuja, G. (2000). The duality of collaboration: Inducements and opportunities in the formation of interfirm linkages. Strategic Management Journal, 21(3), 317-343.

Aldrich, H. E., \& Auster, E. (1986). Even dwarfs started small: Liabilities of age and size and their strategic implications. Research in Organizational Behavior, 8(1986), 165-198.

Alvarez, S. A., \& Barney, J. B. (2001). How entrepreneurial firms can benefit from alliances with large partners. The Academy of Management Executive, 15(1), 139-148.

Alvarez, S. A., \& Busenitz, L. W. (2001). The entrepreneurship of resource-based theory. Journal of Management, 27(6), 755-775.

Arregle, J. L., Naldi, L., Nordqvist, M., \& Hitt, M. A. (2012). Internationalization of familycontrolled firms: A study of the effects of external involvement in governance. Entrepreneurship Theory and Practice, 36(6), 1115-1143.

Artisien, P. F., \& Buckley, P. J. (1985). Western Investment and the New Law in Yugoslavia. Journal of World Trade, 19(5), 522-536.

Bae, J., \& Gargiulo, M. (2004). Partner substitutability, alliance network structure, and firm profitability in the telecommunications industry. Academy of Management Journal, 47(6), 843-859.

Bantel, K. A. (1998). Technology-based, “adolescent” firm configurations: strategy identification, context, and performance. Journal of Business Venturing, 13(3), 205-230.

Barney, J. (1991). Firm resources and sustained competitive advantage. Journal of Management, 17(1), 99-120.

Barringer, B. R., \& Harrison, J. S. (2000). Walking a tightrope: Creating value through interorganizational relationships. Journal of Management, 26(3), 367-403. 
Baum, J. A., Calabrese, T., \& Silverman, B. S. (2000). Don't go it alone: Alliance network composition and startups' performance in Canadian biotechnology. Strategic Management Journal, 21(3), 267-294.

Baum, J. A., \& Silverman, B. S. (2004). Picking winners or building them? Alliance, intellectual, and human capital as selection criteria in venture financing and performance of biotechnology startups. Journal of Business Venturing, 19(3), 411-436.

Beckman, C. M., Haunschild, P. R., \& Phillips, D. J. (2004). Friends or strangers? Firm-specific uncertainty, market uncertainty, and network partner selection. Organization Science, 15(3), 259-275.

Beekun, R. I., \& Ginn, G. O. (1993). Business strategy and interorganizational linkages within the acute care hospital industry: an expansion of the Miles and Snow typology. Human Relations, 46(11), 1291-1318.

Bell, R. G., Moore, C. B., \& Filatotchev, I. (2012). Strategic and institutional effects on foreign IPO performance: Examining the impact of country of origin, corporate governance, and host country effects. Journal of Business Venturing, 27(2), 197-216.

Benghozi, P. J., \& Salvador, E. (2014). Are traditional industrial partnerships so strategic for research spin-off development? Some evidence from the Italian case. Entrepreneurship \& Regional Development, 26(1-2), 47-79.

Blau, P. M. (1977). A macrosociological theory of social structure. American Journal of Sociology 83(1), 26-54.

Bromiley P. (1991). Testing a causal model of corporate risk taking and performance. Academy of Management Journal 34(1), 37-59.

Brush, T. H. (1996). Predicted change in operational synergy and post-acquisition performance of acquired businesses. Strategic Management Journal, 17(1), 1-24.

Bruton, G. D., Chahine, S., \& Filatotchev, I. (2009). Founders, private equity investors, and underpricing in entrepreneurial IPOs. Entrepreneurship Theory and Practice, 33(4), 909928.

Burt, R. S. (1997). The contingent value of social capital. Administrative Science Quarterly, 42(2), 339-365.

Burt, R. S. (1979). A structural theory of interlocking corporate directorates. Social Networks, 1(4), 415-435.

Burt, R. S. (1980). Models of network structure. Annual Review of Sociology, 6, 79-141.

Burt, R. S. (1983). Corporate profits and cooptation: Networks of market constraints and directorate ties in the American economy. Academic Press. 
Burt, R. S. (2000). The network structure of social capital. Research in Organizational Behavior, 22, 345-423.

Busenitz, L. W., West, G. P., Shepherd, D., Nelson, T., Chandler, G. N., \& Zacharakis, A. (2003). Entrepreneurship research in emergence: Past trends and future directions. Journal of Management, 29(3), 285-308.

Busenitz, L. W., Fiet, J. O., \& Moesel, D. D. (2004). Reconsidering the venture capitalists “value added" proposition: An interorganizational learning perspective. Journal of Business Venturing, 19(6), 787-807.

Cai, L., Hughes, M., \& Yin, M. (2014). The relationship between resource acquisition methods and firm performance in Chinese new ventures: the intermediate effect of learning capability. Journal of Small Business Management, 52(3), 365-389.

Carlsson, B. (2002). Institutions, entrepreneurship, and growth: Biomedicine and polymers in Sweden and Ohio. Small Business Economics, 19(2), 105-121.

Carpenter, M. A., \& Westphal, J. D. (2001). The strategic context of external network ties: Examining the impact of director appointments on board involvement in strategic decision making. Academy of Management Journal, 44(4), 639-660.

Casciaro, T., \& Piskorski, M. J. (2005). Power imbalance, mutual dependence, and constraint absorption: A closer look at resource dependence theory. Administrative Science Quarterly, 50(2), 167-199.

Certo, S. T. (2003). Influencing initial public offering investors with prestige: Signaling with board structures. Academy of Management Review, 28(3), 432-446.

Certo, S. T., Daily, C. M., \& Dalton, D. R. (2001). Signaling firm value through board structure: An investigation of initial public offerings. Entrepreneurship Theory and Practice, 26(2), 33-50.

Chang, S. J. (2004). Venture capital financing, strategic alliances, and the initial public offerings of Internet startups. Journal of Business Venturing, 19(5), 721-741.

Chatterjee, P. (2004). Interfirm alliances in online retailing. Journal of Business Research, 57(7), 714-723.

Clarysse, B., Knockaert, M., \& Lockett, A. (2007). Outside board members in high tech startups. Small Business Economics, 29(3), 243-259.

Coff, R. W. (1997). Human assets and management dilemmas: Coping with hazards on the road to resource-based theory. Academy of Management Review, 22(2), 374-402.

Coff, R. W. (1999). How buyers cope with uncertainty when acquiring firms in knowledgeintensive industries: Caveat emptor. Organization Science, 10(2), 144-161. 
Coleman, J. S. (1988). Social capital in the creation of human capital. American Journal of Sociology 94(S1), S95-S120.

Colombo, M. G., \& Grilli, L. (2010). On growth drivers of high-tech start-ups: Exploring the role of founders' human capital and venture capital. Journal of Business Venturing, 25(6), 610-626.

Contractor, F. J., \& Lorange, P. (1988). Why should firms cooperate? The strategy and economics basis for cooperative ventures. Cooperative strategies in international business, 3-30.

Coombes, S. M., Morris, M. H., Allen, J. A., \& Webb, J. W. (2011). Behavioural Orientations of Non-Profit Boards as a Factor in Entrepreneurial Performance: Does Governance Matter? Journal of Management Studies, 48(4), 829-856.

Core, J. E., Holthausen, R. W., \& Larcker, D. F. (1999). Corporate governance, chief executive officer compensation, and firm performance. Journal of Financial Economics, 51(3), 371-406.

Crook, T. R., Todd, S. Y., Combs, J. G., Woehr, D. J., \& Ketchen Jr, D. J. (2011). Does human capital matter? A meta-analysis of the relationship between human capital and firm performance. Journal of Applied Psychology, 96(3), 443.

Cumming, D. (2008). Contracts and exits in venture capital finance. The Review of Financial Studies, 21(5), 1947-1982.

Daily, C. M., \& Dalton, D. R. (1993). Board of directors leadership and structure: Control and performance implications. Entrepreneurship Theory and Practice, 17(3), 65-65.

Daily, C. M., McDougall, P. P., Covin, J. G., \& Dalton, D. R. 2002. Governance and strategic leadership in entrepreneurial firms. Journal of Management, 28(3), 387-412.

Daily, C. M., \& Schwenk, C. (1996). Chief executive officers, top management teams, and boards of directors: congruent or countervailing forces? Journal of Management, 22(2), 185-208.

Dalton, D. R., Daily, C. M., Johnson, J. L., \& Ellstrand, A. E. (1999). Number of directors and financial performance: A meta-analysis. Academy of Management Journal, 42(6), 674686.

Dalziel, T., Gentry, R. J., \& Bowerman, M. (2011). An integrated agency-resource dependence view of the influence of directors' human and relational capital on firms' R\&D spending. Journal of Management Studies, 48(6), 1217-1242.

Das, S., Sen, P. K., \& Sengupta, S. (1998). Impact of strategic alliances on firm valuation. Academy of Management Journal, 41(1), 27-41.

Das, T. K., \& Teng, B. S. (2000). A resource-based theory of strategic alliances. Journal of Management, 26(1), 31-61. 
David, P., Bloom, M., \& Hillman, A. J. (2007). Investor activism, managerial responsiveness, and corporate social performance. Strategic Management Journal, 28(1), 91-100.

Davis, G. F. (1996). The significance of board interlocks for corporate governance. Corporate Governance: An International Review, 4(3), 154-159.

Davis, G. F., \& Cobb, J. A. (2010). Resource dependence theory: Past and future. Research in the Sociology of Organizations, 28(1), 21-42.

Derfus, P. J., Maggitti, P. G., Grimm, C. M., \& Smith, K. G. (2008). The Red Queen effect: Competitive actions and firm performance. Academy of Management Journal, 51(1), 6180.

Deutsch, Y., \& Ross, T. W. (2003). You are known by the directors you keep: Reputable directors as a signaling mechanism for young firms. Management Science, 49(8), 10031017.

de Villiers, C., Naiker, V., \& van Staden, C. J. (2011). The effect of board characteristics on firm environmental performance. Journal of Management, 37(6), 1636-1663.

DeTienne, D. R., \& Cardon, M. S. (2012). Impact of founder experience on exit intentions. Small Business Economics, 38(4), 351-374.

Dimov, D. P., \& Shepherd, D. A. (2005). Human capital theory and venture capital firms: exploring "home runs” and “strike outs”. Journal of Business Venturing, 20(1), 1-21.

Dimov, D., Shepherd, D. A., \& Sutcliffe, K. M. (2007). Requisite expertise, firm reputation, and status in venture capital investment allocation decisions. Journal of Business Venturing, 22(4), 481-502.

Drees, J. M., \& Heugens, P. P. (2013). Synthesizing and Extending Resource Dependence Theory: A Meta-Analysis. Journal of Management, 39(6), 1666-1698.

D'Souza, D. E., \& McDougall, P. P. (1989). Third world joint venturing: a strategic option for the smaller firm. Entrepreneurship Theory and Practice, 13(4), 19-33.

Dyer, J. H., \& Singh, H. (1998). The relational view: Cooperative strategy and sources of interorganizational competitive advantage. Academy of Management Review, 23(4), 660679.

Ehrhardt, O., \& Nowak, E. (2003). The Effect of IPOs on German Family-Owned Firms: Governance Changes, Ownership Structure, and Performance. Journal of Small Business Management, 41(2), 222-232.

Emerson, R. M. (1962). Power-dependence relations. American Sociological Review, 27(1) 3141. 
Fesser, H. R., \& Willard, G. E. (1990). Founding strategy and performance: a comparison of high and low growth high tech forms. Strategic Management Journal, 11(2), 87-98.

Fiegener, M. K., Brown, B. M., Dreux, D. R., \& Dennis, W. J. (2000). CEO stakes and board composition in small private firms. Entrepreneurship Theory and Practice, 24(4), 5-24.

Finkelstein, S. (1997). Interindustry merger patterns and resource dependence: A replication and extension of Pfeffer (1972). Strategic Management Journal, 18(10), 787-810.

Folta, T. B. (1998). Governance and uncertainty: The tradeoff between administrative control and commitment. Strategic Management Journal, 19(11), 1007-1028.

Fried, V. H., Bruton, G. D., \& Hisrich, R. D. (1998). Strategy and the board of directors in venture capital-backed firms. Journal of Business Venturing, 13(6), 493-503.

Gabrielsson, J. (2007). Correlates of board empowerment in small companies. Entrepreneurship Theory and Practice, 31(5), 687-711.

Gabrielsson, J., \& Huse, M. (2002). The venture capitalist and the board of directors in SMEs: roles and processes. Venture Capital: An International Journal of Entrepreneurial Finance, 4(2), 125-146.

Galang, M. C., \& Ferris, G. R. (1997). Human resource department power and influence through symbolic action. Human Relations, 50(11), 1403-1426.

Gales, L. M., \& Blackburn, R. S. (1990). An analysis of the impact of supplier strategies and relationships on small retailer actions, perceptions, and performance. Entrepreneurship Theory and Practice, 15(1), 7-21.

Garg, S. (2013). Venture boards: Distinctive monitoring and implications for firm performance. Academy of Management Review, 38(1), 90-108.

Gargiulo, M. (1993). Two-step leverage: Managing constraint in organizational politics. Administrative Science Quarterly, 38(1), 1-19.

Geletkanycz, M. A., \& Hambrick, D. C. (1997). The external ties of top executives: Implications for strategic choice and performance. Administrative Science Quarterly, 42(4), 654-681.

George, G. (2005). Slack resources and the performance of privately held firms. Academy of Management Journal, 48(4), 661-676.

Grewal, D., Iyer, G. R., Javalgi, R. R. G., \& Radulovich, L. (2011). Franchise partnership and international expansion: a conceptual framework and research propositions. Entrepreneurship Theory and Practice, 35(3), 533-557.

Gerwin, D. (1993). Manufacturing flexibility: a strategic perspective. Management Science, 39(4), 395-410. 
Goes, J. B., \& Park, S. H. (1997). Interorganizational links and innovation: The case of hospital services. Academy of Management Journal, 40(3), 673-696.

Golden, P. A., \& Dollinger, M. (1993). Cooperative alliances and competitive strategies in small manufacturing firms. Entrepreneurship: Theory and Practice, 17(4), 43-57.

Gompers, P. A. (1995). Optimal investment, monitoring, and the staging of venture capital. Journal of Finance, 50(5), 1461-1489.

Gompers, P., \& Lerner, J. (2001). The venture capital revolution. Journal of Economic Perspectives, (15)2, 145-168.

Gulati, R. (1995). Social structure and alliance formation patterns: A longitudinal analysis. Administrative Science Quarterly, 40(4) 619-652.

Gulati, R., \& Gargiulo, M. (1999). Where do interorganizational networks come from? American Journal of Sociology, 104(5), 1439-1493.

Gulati, R., \& Sytch, M. (2007). Dependence asymmetry and joint dependence in interorganizational relationships: Effects of embeddedness on a manufacturer's performance in procurement relationships. Administrative Science Quarterly, 52(1), 3269.

Hair, J. F., Black, W. C., Babin, B. J., \& Anderson, R. E. 2010. Multivariate data analysis: A global perspective. Upper Saddle River, NJ: Pearson.

Hallen, B. L., Katila, R., \& Rosenberger, J. D. (2014). How do social defenses work? A resource-dependence lens on technology ventures, venture capital investors, and corporate relationships. Academy of Management Journal, 57(4), 1078-1101.

Harrison, J. S., Hitt, M. A., Hoskisson, R. E., \& Ireland, R. D. (2001). Resource complementarity in business combinations: Extending the logic to organizational alliances. Journal of Management, 27(6), 679-690.

Harrison, J. R., Torres, D. L., \& Kukalis, S. (1988). The changing of the guard: Turnover and structural change in the top-management positions. Administrative Science Quarterly, 33(2), 211-232.

Hambrick, D. C., Finkelstein, S., Cho, T. S., \& Jackson, E. M. (2004). Isomorphism in reverse: Institutional theory as an explanation for recent increases in intraindustry heterogeneity and managerial discretion. Research in Organizational Behavior, 26, 307-350.

Hatch, N. W., \& Dyer, J. H. (2004). Human capital and learning as a source of sustainable competitive advantage. Strategic Management Journal, 25(12), 1155-1178.

Haynes, K. T., \& Hillman, A. (2010). The effect of board capital and CEO power on strategic change. Strategic Management Journal, 31(11), 1145-1163. 
Hegde, D., \& Tumlinson, J. (2014). Does social proximity enhance business partnerships? Theory and evidence from ethnicity's role in US venture capital. Management Science, 60(9), 2355-2380.

Hillman, A. J. (2005). Politicians on the board of directors: Do connections affect the bottom line? Journal of Management, 31(3), 464-481.

Hillman, A. J., Cannella, A. A., \& Paetzold, R. L. (2000). The resource dependence role of corporate directors: Strategic adaptation of board composition in response to environmental change. Journal of Management Studies, 37(2), 235-256.

Hillman, A. J., \& Dalziel, T. (2003). Boards of directors and firm performance: Integrating agency and resource dependence perspectives. Academy of Management Review, 28(3), 383-396.

Hillman, A. J., Withers, M. C., \& Collins, B. J. (2009). Resource dependence theory: A review. Journal of Management, 35(6), 1404-1427.

Hoehn-Weiss, M. N., \& Barden, J. Q. (2014). The influences of capital market munificence on new-venture alliance formation in emerging industries. Strategic Organization, 12(4), 225-243.

Honig, B., Lerner, M., \& Raban, Y. (2006). Social capital and the linkages of high-tech companies to the military defense system: Is there a signaling mechanism? Small Business Economics, 27(4-5), 419-437.

Humphreys, P. K., Li, W. L., \& Chan, L. Y. (2004). The impact of supplier development on buyer-supplier performance. Omega, 32(2), 131-143.

Hustedde, R. J., \& Pulver, G. C. (1992). Factors affecting equity capital acquisition: The demand side. Journal of Business Venturing, 7(5), 363-374.

Ingram, P., \& Simons, T. (1995). Institutional and resource dependence determinants of responsiveness to work-family issues. Academy of Management Journal, 38(5), 14661482.

Inkpen, A. C. (2001). Strategic alliances. The Blackwell Handbook of Strategic Management, 409-432.

Inkpen, A. C., \& Crossan, M. M. (1995). Believing is seeing: Joint ventures and organization learning. Journal of Management Studies, 32(5), 595-618.

Jain, B. A., Jayaraman, N., \& Kini, O. (2008). The Path-to-profitability of Internet IPO firms. Journal of Business Venturing, 23(2), 165-194.

Jensen, M. C., \& Meckling, W. H. (1976). Theory of the firm: Managerial behavior, agency costs and ownership structure. Journal of Financial Economics, 3(4), 305-360. 
Joshi, A. W., \& Stump, R. L. (1999). The contingent effect of specific asset investments on joint action in manufacturer-supplier relationships: An empirical test of the moderating role of reciprocal asset investments, uncertainty, and trust. Journal of the Academy of Marketing Science, 27(3), 291-305.

Kalaignanam, K., Shankar, V., \& Varadarajan, R. (2007). Asymmetric new product development alliances: Win-win or win-lose partnerships? Management Science, 53(3), 357-374.

Kale, P., Singh, H., \& Perlmutter, H. (2000). Learning and protection of proprietary assets in strategic alliances: Building relational capital. Strategic Management Journal, 21(3), 217-237.

Kale, P., Dyer, J. H., \& Singh, H. (2002). Alliance capability, stock market response, and longterm alliance success: the role of the alliance function. Strategic Management Journal, 23(8), 747-767.

Kanter, R. M., Richardson, L., North, J., \& Morgan, E. (1991). Engines of progress: designing and running entrepreneurial vehicles in established companies; the new venture process at Eastman Kodak, 1983-1989. Journal of Business Venturing, 6(1), 63-82.

Kaplan, S. N., \& Strömberg, P. E. (2004). Characteristics, contracts, and actions: Evidence from venture capitalist analyses. The Journal of Finance, 59(5), 2177-2210.

Katila, R., Rosenberger, J. D., \& Eisenhardt, K. M. (2008). Swimming with sharks: Technology ventures, defense mechanisms and corporate relationships. Administrative Science Quarterly, 53(2), 295-332.

Ketchen, D. J., \& Hult, G. T. M. (2007). Bridging organization theory and supply chain management: The case of best value supply chains. Journal of Operations Management, 25(2), 573-580.

Koka, B. R., \& Prescott, J. E. (2008). Designing alliance networks: the influence of network position, environmental change, and strategy on firm performance. Strategic Management Journal, 29(6), 639-661.

Kor, Y. Y., \& Misangyi, V. F. (2008). Outside directors' industry-specific experience and firms' liability of newness. Strategic Management Journal, 29(12), 1345-1355.

Kostova, T., \& Zaheer, S. (1999). Organizational legitimacy under conditions of complexity: The case of the multinational enterprise. Academy of Management Review, 24(1), 64-81.

Kroll, M., Walters, B. A., \& Le, S. A. (2007). The impact of board composition and top management team ownership structure on post-IPO performance in young entrepreneurial firms. Academy of Management Journal, 50(5), 1198-1216.

Lang, J. R., \& Lockhart, D. E. (1990). Increased environmental uncertainty and changes in board linkage patterns. Academy of Management Journal, 33(1), 106-128. 
Larson, A. (1991). Partner networks: Leveraging external ties to improve entrepreneurial performance. Journal of Business Venturing, 6(3), 173-188.

Lavie, D. (2006). The competitive advantage of interconnected firms: An extension of the resource-based view. Academy of Management Review, 31(3), 638-658.

Lechner, C., \& Leyronas, C. (2012). The competitive advantage of cluster firms: the priority of regional network position over extra-regional networks-a study of a French high-tech cluster. Entrepreneurship \& Regional Development, 24(5-6), 457-473

Levitas, E., \& McFadyen, M. (2009). Managing liquidity in research-intensive firms: signaling and cash flow effects of patents and alliance activities. Strategic Management Journal, 30(6), 659-678.

Lester, R. H., Hillman, A., Zardkoohi, A., \& Cannella, A. A. (2008). Former government officials as outside directors: The role of human and social capital. Academy of Management Journal, 51(5), 999-1013.

Li, H., \& Atuahene-Gima, K. (2001). Product innovation strategy and the performance of new technology ventures in China. Academy of Management Journal, 44(6), 1123-1134.

Li, Y., Wei, Z., \& Liu, Y. (2010). Strategic Orientations, Knowledge Acquisition, and Firm Performance: The Perspective of the Vendor in Cross-Border Outsourcing. Journal of Management Studies, 47(8), 1457-1482.

Lichtenstein, B. M. B., \& Brush, C. G. (2001). How do" resource bundles" develop and change in new ventures? A dynamic model and longitudinal exploration. Entrepreneurship: Theory and Practice, 25(3), 37-37.

Lin, Z. J., Yang, H., \& Arya, B. (2009). Alliance partners and firm performance: resource complementarity and status association. Strategic Management Journal, 30(9), 921-940.

Lu, J. W., \& Beamish, P. W. (2006). Partnering strategies and performance of SMEs' international joint ventures. Journal of Business Venturing, 21(4), 461-486.

Lunnan, R., \& Haugland, S. A. (2008). Predicting and measuring alliance performance: A multidimensional analysis. Strategic Management Journal, 29(5), 545-556.

Lynall, M. D., Golden, B. R., \& Hillman, A. J. (2003). Board composition from adolescence to maturity: A multitheoretic view. Academy of Management Review, 28(3), 416-431.

Madhok, A., \& Tallman, S. B. (1998). Resources, transactions and rents: Managing value through interfirm collaborative relationships. Organization Science, 9(3), 326-339.

Malo, S., \& Norus, J. (2009). Growth dynamics of dedicated biotechnology firms in transition economies. Evidence from the Baltic countries and Poland. Entrepreneurship \& Regional Development, 21(5-6), 481-502. 
Marion, T. J., Eddleston, K. A., Friar, J. H., \& Deeds, D. (2015). The evolution of interorganizational relationships in emerging ventures: An ethnographic study within the new product development process. Journal of Business Venturing, 30(1), 167-184.

Marvel, M. R., Davis, J. L., \& Sproul, C. R. (2016). Human Capital and Entrepreneurship Research: A Critical Review and Future Directions. Entrepreneurship Theory and Practice, 40(3), 599-626.

McCann, J. E. (1991). Patterns of growth, competitive technology, and financial strategies in young ventures. Journal of Business Venturing, 6(3), 189-208.

McGee, J. E., Dowling, M. J., \& Megginson, W. L. (1995). Cooperative strategy and new venture performance: The role of business strategy and management experience. Strategic Management Journal, 16(7), 565-580.

Meyer, J. W., \& Rowan, B. (1977). Institutionalized organizations: Formal structure as myth and ceremony. American Journal of Sociology, 83(2), 340-363.

Mincer, J. (1958). Investment in human capital and personal income distribution. The Journal of Political Economy, 66(4), 281-302.

Mizruchi, M. S. (1996). What do interlocks do? An analysis, critique, and assessment of research on interlocking directorates. Annual Review of Sociology, 22, 271-298.

Mizruchi, M. S., \& Stearns, L. B. (1994). A longitudinal study of borrowing by large American corporations. Administrative Science Quarterly, 39(1), 118-140.

Nahata, R. (2008). Venture capital reputation and investment performance. Journal of Financial Economics, 90(2), 127-151.

Nelson, T. (2003). The persistence of founder influence: Management, ownership, and performance effects at initial public offering. Strategic Management Journal, 24(8), 707724.

Nohria, N., \& Garcia-Pont, C. (1991). Global strategic linkages and industry structure. Strategic Management Journal, 12(S1), 105-124.

Oliver, C. (1990). Determinants of interorganizational relationships: Integration and future directions. Academy of Management Review, 15(2), 241-265.

Oliver, C. (1991a). Network relations and loss of organizational autonomy. Human Relations, 44(9), 943-961.

Oliver, C. (1991b). Strategic responses to institutional processes. Academy of Management Review, 16(1), 145-179.

Ozcan, P., \& Eisenhardt, K. M. (2009). Origin of alliance portfolios: Entrepreneurs, network strategies, and firm performance. Academy of Management Journal, 52(2), 246-279. 
Ozmel, U., Robinson, D. T., \& Stuart, T. E. (2013). Strategic alliances, venture capital, and exit decisions in early stage high-tech firms. Journal of Financial Economics, 107(3), 655670.

Pangarkar, N., \& Wu, J. (2013). Alliance formation, partner diversity, and performance of Singapore startups. Asia Pacific Journal of Management, 30(3), 791-807.

Park, S. H., Chen, R. R., \& Gallagher, S. (2002). Firm resources as moderators of the relationship between market growth and strategic alliances in semiconductor startups. Academy of Management Journal, 45(3), 527-545.

Park, N. K., \& Mezias, J. M. (2005). Before and after the technology sector crash: the effect of environmental munificence on stock market response to alliances of e-commerce firms. Strategic Management Journal, 26(11), 987.

Park, H. D., \& Steensma, H. K. (2014). When Do Venture Capitalists Become Board Members in New Ventures? Finance and Strategy, 231-251. Emerald Group Publishing Limited.

Patzelt, H., Shepherd, D. A., Deeds, D., \& Bradley, S. W. (2008). Financial slack and venture managers' decisions to seek a new alliance. Journal of Business Venturing, 23(4), 465481.

Peng, M. W., \& Luo, Y. (2000). Managerial ties and firm performance in a transition economy: The nature of a micro-macro link. Academy of Management Journal, 43(3), 486-501.

Peteraf, M. A. (1993). The cornerstones of competitive advantage: a resource-based view. Strategic Management Journal, 14(3), 179-191.

Peteraf, M. A. (1994). Commentary: the two schools of thought in resource-based theory: definitions and implications for research. Advances in strategic management, 10, 153158.

Pisano, G. P. (1990). The R\&D boundaries of the firm: an empirical analysis. Administrative Science Quarterly, 1990(S1), 153-176.

Pfeffer, J. (1987). A resource dependence perspective on interorganizational relations. In M. S. Mizruchi, \& M. Schwartz (Eds.), Intercorporate relations: The structural analysis of business: 22-55. Cambridge, UK: Cambridge University Press

Pfeffer, J. (1972a). Interorganizational influence and managerial attitudes. Academy of Management Journal, 15(3), 317-330.

Pfeffer, J. (1972b). Merger as a response to organizational interdependence. Administrative Science Quarterly, 17(3), 382-394.

Pfeffer, J. (1972c). Size and composition of corporate boards of directors: The organization and its environment. Administrative Science Quarterly, 17(2), 218-228.

Pfeffer, J. (1981). Power in organizations (Vol. 33). Marshfield, MA: Pitman. 
Pfeffer, J., \& Nowak, P. (1976). Joint ventures and interorganizational interdependence. Administrative Science Quarterly, 21(3), 398-418.

Pfeffer, J., \& Salancik, G. R. (1978). The external control of organizations: A resource dependence approach. NY: Harper and Row Publishers.

PrivCo. PrivCo Private Company Financial Intelligence. (2016). Available at http://www.privco.com/marketing/about-us (4, January, 2016).

Provan, K. G. (1980). Board power and organizational effectiveness among human service agencies. Academy of Management Journal, 23(2), 221-236.

Provan, K. G., Beyer, J. M., \& Kruytbosch, C. (1980). Environmental linkages and power in resource-dependence relations between organizations. Administrative Science Quarterly, 25(2), 200-225.

Puri, M., \& Zarutskie, R. (2012). On the life cycle dynamics of venture-capital-and non-venturecapital-financed firms. The Journal of Finance, 67(6), 2247-2293.

Raymond, L., Marchand, M., St-Pierre, J., Cadieux, L., \& Labelle, F. (2013). Dimensions of small business performance from the owner-manager's perspective: a reconceptualization and empirical validation. Entrepreneurship \& Regional Development, 25(5-6), 468-499.

Rindfleisch, A., \& Heide, J. B. (1997). Transaction cost analysis: Past, present, and future applications. The Journal of Marketing, 61(4), 30-54.

Robb, A. and Seamans, R. (2014) The role of R\&D in entrepreneurial finance and performance. In Villalonga, B. (Ed.) Advances in Strategic Management, 341-373. Emerald Group Publishing Limited.

Rosenbusch, N., Rauch, A., \& Bausch, A. (2013). The Mediating Role of Entrepreneurial Orientation in the Task Environment-Performance Relationship A MetaAnalysis. Journal of Management, 39(3), 633-659.

Rosenbusch, N., Brinckmann, J., \& Müller, V. (2013). Does acquiring venture capital pay off for the funded firms? A meta-analysis on the relationship between venture capital investment and funded firm financial performance. Journal of Business Venturing, 28(3), 335-353.

Rosenstein, J. (1988). The board and strategy: Venture capital and high technology. Journal of Business Venturing, 3(2), 159-170.

Sahlman, W. A. (1990). The structure and governance of venture-capital organizations. Journal of Financial Economics, 27(2), 473-521.

Santos, F. M., \& Eisenhardt, K. M. (2005). Organizational boundaries and theories of organization. Organization Science, 16(5), 491-508. 
Sarkar, M. B., Echambadi, R. A. J., \& Harrison, J. S. (2001). Alliance entrepreneurship and firm market performance. Strategic Management Journal, 22(6-7), 701-711.

Shane, S., \& Venkataraman, S. (2000). The promise of entrepreneurship as a field of research. Academy of Management Review, 25(1), 217-226.

Shepherd, D. A., Williams, T. A., \& Patzelt, H. (2015). Thinking about entrepreneurial decision making review and research agenda. Journal of Management, 41(1), 11-46.

Shu, C., Liu, C., Gao, S., \& Shanley, M. (2014). The knowledge spillover theory of entrepreneurship in alliances. Entrepreneurship Theory and Practice, 38(4), 913-940.

Sleesman, D. J., Conlon, D. E., McNamara, G., \& Miles, J. E. (2012). Cleaning up the big muddy: A meta-analytic review of the determinants of escalation of commitment. Academy of Management Journal, 55(3), 541-562.

Soh, P. H. (2003). The role of networking alliances in information acquisition and its implications for new product performance. Journal of Business Venturing, 18(6), 727744.

Sørensen, M. (2007). How smart is smart money? A two-sided matching model of Venture Capital. The Journal of Finance, 62(6), 2725-2762.

Spence, A. M. (1974). Market signaling: Informational transfer in hiring and related screening processes (Vol. 143). Harvard University Press.

Spence, M. (2002). Signaling in retrospect and the informational structure of markets. The American Economic Review, 92(3), 434-459.

Stam, W. (2010). Industry event participation and network brokerage among entrepreneurial ventures. Journal of Management Studies, 47(4), 625-653.

Stam, W., \& Elfring, T. (2008). Entrepreneurial orientation and new venture performance: The moderating role of intra-and extraindustry social capital. Academy of Management Journal, 51(1), 97-111.

Stearns, L. B., \& Mizruchi, M. S. (1986). Broken-tie reconstitution and the functions of interorganizational interlocks: A reexamination. Administrative Science Quarterly, (31)4, 522-538.

Steensma, H. K., Marino, L., Weaver, K. M., \& Dickson, P. H. (2000). The influence of national culture on the formation of technology alliances by entrepreneurial firms. Academy of Management Journal, 43(5), 951-973.

Stinchcombe, A. L. (1965). Organizations and social structure. Handbook of Organizations, 44(2), 142-193. 
Sullivan, D. M., \& Ford, C. M. (2014). How entrepreneurs use networks to address changing resource requirements during early venture development. Entrepreneurship Theory and Practice, 38(3), 551-574.

Swaminathan, V., \& Moorman, C. (2009). Marketing alliances, firm networks, and firm value creation. Journal of Marketing, 73(5), 52-69.

Teece, D. J. (1986). Transactions cost economics and the multinational enterprise: An Assessment. Journal of Economic Behavior \& Organization, 7(1), 21-45.

Thompson, J. D. (1967). Organizations in action: Social science bases of administration. Transaction publishers.

Unger, J. M., Rauch, A., Frese, M., \& Rosenbusch, N. (2011). Human capital and entrepreneurial success: A meta-analytical review. Journal of Business Venturing, 26(3), 341-358.

Uzzi, B. (1999). Embeddedness in the making of financial capital: How social relations and networks benefit firms seeking financing. American Sociological Review, 64(4), 481-505.

Villalonga, B., \& McGahan, A. M. (2005). The choice among acquisitions, alliances, and divestitures. Strategic Management Journal, 26(13), 1183-1208.

Vissa, B., \& Chacar, A. S. (2009). Leveraging ties: the contingent value of entrepreneurial teams' external advice networks on Indian software venture performance. Strategic Management Journal, 30(11), 1179-1191.

Walters, B. A., Kroll, M., \& Wright, P. (2010). The impact of TMT board member control and environment on post-IPO performance. Academy of Management Journal, 53(3), 572595.

Wang, H., Wuebker, R. J., Han, S., \& Ensley, M. D. (2012). Strategic alliances by venture capital backed firms: an empirical examination. Small Business Economics, 38(2), 179196.

Wang, L., \& Zajac, E. J. (2007). Alliance or acquisition? A dyadic perspective on interfirm resource combinations. Strategic Management Journal, 28(13), 1291-1317.

Wang, S., \& Zhou, H. (2004). Staged financing in venture capital: moral hazard and risks. Journal of Corporate Finance, 10(1), 131-155.

Wasti, S. N., \& Liker, J. K. (1999). Collaborating with suppliers in product development: a US and Japan comparative study. Engineering Management, IEEE Transactions on, 46(4), 444-460.

Weitz, E., \& Shenhaav, Y. (2000). A longitudinal analysis of technical and organizational uncertainty in management theory. Organization Studies, 21(1), 243-266.

Westphal, J. D. (1999). Collaboration in the boardroom: Behavioral and performance consequences of CEO-board social ties. Academy of Management Journal, 42(1), 7-24. 
Wijbenga, F. H., Postma, T. J., \& Stratling, R. (2007). The influence of the venture capitalist's governance activities on the entrepreneurial firm's control systems and performance. Entrepreneurship Theory and Practice, 31(2), 257-277.

Williamson, O. E. (1975). Markets and hierarchies. New York, 26-30.

Williamson, O. E. (1985). The economic institutions of capitalism. Simon and Schuster.

Williamson, O.E. (1991). Comparative economic organization: the analysis of discrete structural alternatives. Administrative Science Quarterly, 36(3): 269-296.

Wittmann, C. M., Hunt, S. D., \& Arnett, D. B. (2009). Explaining alliance success: Competences, resources, relational factors, and resource-advantage theory. Industrial Marketing Management, 38(7), 743-756.

Woodcock, C. P., Beamish, P. W., \& Makino, S. (1994). Ownership-based entry mode strategies and international performance. Journal of International Business Studies, 25(2), 253-273.

Wry, T., Cobb, J. A., \& Aldrich, H. E. (2013). More than a metaphor: Assessing the historical legacy of resource dependence and its contemporary promise as a theory of environmental complexity. The Academy of Management Annals, 7(1), 441-488.

Xia, J. (2011). Mutual dependence, partner substitutability, and repeated partnership: the survival of cross-border alliances. Strategic Management Journal, 32(3), 229-253.

Xia, J., \& Li, S. (2013). The divestiture of acquired subunits: a resource dependence approach. Strategic Management Journal, 34(2), 131-148.

Yoo, S. S., Schenkel, M. T., \& Kim, J. (2014). Examining the impact of inherited succession identity on family firm performance. Journal of Small Business Management, 52(2), 246-265.

Zacharakis, A. L., McMullen, J. S., \& Shepherd, D. A. (2007). Venture capitalists' decision policies across three countries: an institutional theory perspective. Journal of International Business Studies, 38(5), 691-708.

Zacharakis, A. L., \& Meyer, G. D. (2000). The potential of actuarial decision models: can they improve the venture capital investment decision? Journal of Business Venturing, 15(4), 323-346.

Zaheer, S. (1995). Overcoming the liability of foreignness. Academy of Management Journal, 38(2), 341-363.

Zahra, S. A. (1995). Corporate entrepreneurship and financial performance: The case of management leveraged buyouts. Journal of Business Venturing, 10(3), 225-247.

Zahra, S. A., \& George, G. (1999). Manufacturing strategy and new venture performance: A comparison of independent and corporate ventures in the biotechnology industry. The Journal of High Technology Management Research, 10(2), 313-345. 
Zahra, S. A., \& Hayton, J. C. (2008). The effect of international venturing on firm performance: The moderating influence of absorptive capacity. Journal of Business Venturing, 23(2), 195-220.

Zahra, S. A., Ireland, R. D., \& Hitt, M. A. (2000). International expansion by new venture firms: International diversity, mode of market entry, technological learning, and performance. Academy of Management Journal, 43(5), 925-950.

Zahra, S. A., \& Pearce, J. A. (1989). Boards of directors and corporate financial performance: A review and integrative model. Journal of Management, 15(2), 291-334. 
Table 2.1. Literature Review Results.

\begin{tabular}{|c|c|c|c|c|c|}
\hline Manuscript & Journal & $\begin{array}{l}\text { Basis for } \\
\text { Remedy }\end{array}$ & $\begin{array}{l}\text { Structure of } \\
\text { Remedy }\end{array}$ & $\begin{array}{c}\text { Theoretica } \\
\mathrm{l} \\
\text { Explanatio } \\
\mathrm{n}\end{array}$ & $\begin{array}{l}\text { Nature of } \\
\text { Autonomy }\end{array}$ \\
\hline $\begin{array}{c}\text { Ahlers, } \\
\text { Cumming, } \\
\text { Gunther, \& } \\
\text { Schweizer, } \\
2015 \\
\end{array}$ & $E T \& P$ & Complementary & $\begin{array}{l}\text { Venture Capital } \\
\text { Funding }\end{array}$ & $\begin{array}{l}\text { Resource } \\
\text { dependenc } \\
\text { e theory }\end{array}$ & N/A \\
\hline $\begin{array}{c}\text { Arend \& } \\
\text { Seale, } 2005\end{array}$ & $S M J$ & Complementary & Alliances & $\begin{array}{l}\text { Game } \\
\text { theory }\end{array}$ & Both \\
\hline $\begin{array}{c}\text { Arregle, } \\
\text { Naldi, } \\
\text { Nordqvist, } \\
\text { \& Hitt, } 2012 \\
\end{array}$ & $E T \& P$ & Complementary & $\begin{array}{l}\text { Board of } \\
\text { Directors }\end{array}$ & $\begin{array}{l}\text { Resource } \\
\text { dependenc } \\
\text { e theory }\end{array}$ & Power Balance \\
\hline $\begin{array}{c}\text { Artisien \& } \\
\text { Buckley, } \\
1985\end{array}$ & JIBS & Complementary & Joint Ventures & $\begin{array}{l}\text { Phenomen } \\
\text { on driven }\end{array}$ & $\begin{array}{l}\text { Resource } \\
\text { Stability }\end{array}$ \\
\hline $\begin{array}{l}\text { Audretsch, } \\
\text { Lehmann, \& } \\
\text { Plummer, } \\
2009 \\
\end{array}$ & $E T \& P$ & Complementary & CEO Resources & $\begin{array}{l}\text { Agency } \\
\text { theory }\end{array}$ & Power Balance \\
\hline Bantel, 1998 & $J B V$ & Complementary & Alliances & $\begin{array}{l}\text { Contingen } \\
\text { cy theory }\end{array}$ & Power Balance \\
\hline $\begin{array}{c}\text { Baum, } \\
\text { Calabrese, \& } \\
\text { Silverman, } \\
2000\end{array}$ & $S M J$ & Complementary & Alliance Network & $\begin{array}{l}\text { Network } \\
\text { theory }\end{array}$ & $\begin{array}{l}\text { Resource } \\
\text { Stability }\end{array}$ \\
\hline $\begin{array}{l}\text { Baum \& } \\
\text { Silverman, } \\
2004\end{array}$ & $J B V$ & Financial & $\begin{array}{l}\text { Venture Capital } \\
\text { Funding }\end{array}$ & $\begin{array}{l}\text { Phenomen } \\
\text { on driven }\end{array}$ & $\begin{array}{c}\text { Resource } \\
\text { Stability }\end{array}$ \\
\hline $\begin{array}{c}\text { Bell, Moore, } \\
\& \\
\text { Filatotchev, } \\
2012\end{array}$ & $J B V$ & Financial & IPO & $\begin{array}{l}\text { Signaling } \\
\text { theory; } \\
\text { Institution } \\
\text { al theory }\end{array}$ & $\begin{array}{l}\text { Resource } \\
\text { Stability }\end{array}$ \\
\hline $\begin{array}{l}\text { Benghozi \& } \\
\text { Salvador, } \\
2014\end{array}$ & $E R D$ & Complementary & Spin-offs & RBV & $\begin{array}{l}\text { Power Balance: } \\
\text { Autonomy is } \\
\text { lost when spin- } \\
\text { offs also use a } \\
\text { traditional } \\
\text { partnership }\end{array}$ \\
\hline $\begin{array}{c}\text { Benson \& } \\
\text { Ziedonis, } \\
2009\end{array}$ & OS & Financial & $\begin{array}{l}\text { External } \\
\text { corporate } \\
\text { venturing }\end{array}$ & $\begin{array}{l}\text { Absorptive } \\
\text { Capacity }\end{array}$ & $\begin{array}{l}\text { Resource } \\
\text { Stability }\end{array}$ \\
\hline
\end{tabular}




\begin{tabular}{|c|c|c|c|c|c|}
\hline $\begin{array}{c}\text { Brouthers, } \\
\text { Nakos, \& } \\
\text { Dimitratos, } \\
2015\end{array}$ & $E T \& P$ & Complementary & Alliances & $\begin{array}{l}\text { Resource } \\
\text { dependenc } \\
\text { e theory; } \\
\text { RBV }\end{array}$ & $\begin{array}{c}\text { Resource } \\
\text { Stability }\end{array}$ \\
\hline Brush, 1996 & $S M J$ & Complementary & Acquisitions & $\begin{array}{l}\text { Phenomen } \\
\text { on driven }\end{array}$ & Power Balance \\
\hline $\begin{array}{l}\text { Bruton, } \\
\text { Friend, \& } \\
\text { Hisrich, } \\
1997\end{array}$ & ET\&P & Financial & CEO replacement & $\begin{array}{l}\text { Upper } \\
\text { echelons } \\
\text { theory }\end{array}$ & $\begin{array}{l}\text { Resource } \\
\text { Stability }\end{array}$ \\
\hline $\begin{array}{l}\text { Cai, Hughes, } \\
\text { \& Yin, } 2014\end{array}$ & $J S B M$ & Complementary & $\begin{array}{c}\text { Resource } \\
\text { purchase and } \\
\text { development }\end{array}$ & $\begin{array}{c}\text { RBV; } \\
\text { Organizati } \\
\text { onal } \\
\text { learning }\end{array}$ & $\begin{array}{c}\text { Resource } \\
\text { Stability }\end{array}$ \\
\hline $\begin{array}{l}\text { Carlsson, } \\
2002\end{array}$ & $S B E$ & Financial & $\begin{array}{l}\text { Venture Capital } \\
\text { Financing }\end{array}$ & $\begin{array}{l}\text { Phenomen } \\
\text { on driven }\end{array}$ & $\begin{array}{l}\text { Resource } \\
\text { Stability }\end{array}$ \\
\hline $\begin{array}{l}\text { Certo, Daily, } \\
\text { \& Dalton, } \\
2001\end{array}$ & ET\&P & Financial & $\begin{array}{l}\text { Board size, } \\
\text { reputation, } \\
\text { composition, and } \\
\text { structure }\end{array}$ & $\begin{array}{l}\text { Signaling } \\
\text { theory }\end{array}$ & $\begin{array}{c}\text { Resource } \\
\text { Stability }\end{array}$ \\
\hline $\begin{array}{c}\text { Chakravarty } \\
\text { \& Shahriar, } \\
2015\end{array}$ & $E T \& P$ & Financial & $\begin{array}{l}\text { Microcredit } \\
\text { borrowing }\end{array}$ & $\begin{array}{l}\text { Phenomen } \\
\text { on driven }\end{array}$ & $\begin{array}{l}\text { Resource } \\
\text { Stability }\end{array}$ \\
\hline $\begin{array}{l}\text { Chandler \& } \\
\text { Lyon, } 2009 \\
\end{array}$ & $E T \& P$ & Financial & $\begin{array}{l}\text { New management } \\
\text { team installation }\end{array}$ & $\begin{array}{c}\text { Phenomen } \\
\text { on driven }\end{array}$ & $\begin{array}{l}\text { Resource } \\
\text { Stability }\end{array}$ \\
\hline Chang, 2004 & $J B V$ & Financial & Alliance networks & $\begin{array}{l}\text { Phenomen } \\
\text { on driven }\end{array}$ & $\begin{array}{l}\text { Resource } \\
\text { Stability }\end{array}$ \\
\hline $\begin{array}{c}\text { Channon, } \\
1979 \\
\end{array}$ & $J M S$ & Complementary & Board of directors & $\begin{array}{c}\text { Phenomen } \\
\text { on driven }\end{array}$ & Power Balance \\
\hline $\begin{array}{c}\text { Coombes, } \\
\text { Morris, } \\
\text { Allen, \& } \\
\text { Webb, } 2011 \\
\end{array}$ & $J M S$ & Complementary & Board of directors & RBV & $\begin{array}{c}\text { Resource } \\
\text { Stability }\end{array}$ \\
\hline $\begin{array}{c}\text { Daily \& } \\
\text { Dalton, } 1993\end{array}$ & ET\&P & Financial & Board of directors & $\begin{array}{l}\text { Resource } \\
\text { dependenc } \\
\text { e theory }\end{array}$ & $\begin{array}{l}\text { Resource } \\
\text { Stability }\end{array}$ \\
\hline $\begin{array}{c}\text { Daily \& } \\
\text { Dalton, } 1992\end{array}$ & $J S B M$ & Financial & CEO replacement & $\begin{array}{l}\text { Phenomen } \\
\text { on driven }\end{array}$ & $\begin{array}{l}\text { Resource } \\
\text { Stability }\end{array}$ \\
\hline $\begin{array}{c}\text { Daily \& } \\
\text { Dalton, } 1992 \\
\end{array}$ & $J B V$ & Financial & Board of directors & $\begin{array}{c}\text { Phenomen } \\
\text { on driven }\end{array}$ & Both \\
\hline $\begin{array}{c}\text { De Clercq \& } \\
\text { Voronov, } \\
2009 \\
\end{array}$ & $J S B M$ & Complementary & $\begin{array}{c}\text { Resource } \\
\text { Acquisition }\end{array}$ & $\begin{array}{l}\text { Theory of } \\
\text { practice }\end{array}$ & $\begin{array}{c}\text { Resource } \\
\text { Stability }\end{array}$ \\
\hline $\begin{array}{l}\text { de Villiers, } \\
\text { Naiker, \& }\end{array}$ & $J O M$ & Complementary & Board of directors & $\begin{array}{l}\text { Agency } \\
\text { theory }\end{array}$ & $\begin{array}{l}\text { Resource } \\
\text { Stability }\end{array}$ \\
\hline
\end{tabular}




\begin{tabular}{|c|c|c|c|c|c|}
\hline $\begin{array}{c}\text { van Staden, } \\
2011\end{array}$ & & & & & \\
\hline $\begin{array}{l}\text { DeTienne \& } \\
\text { Cardon, } \\
2012\end{array}$ & $S B E$ & Financial & Exit & $\begin{array}{c}\text { Threshold } \\
\text { theory }\end{array}$ & $\begin{array}{l}\text { Resource } \\
\text { Stability }\end{array}$ \\
\hline $\begin{array}{c}\text { D’Souza \& } \\
\text { McDougall, } \\
1989\end{array}$ & ET\&P & Complementary & Joint Ventures & $\begin{array}{c}\text { I/O theory, } \\
\text { location } \\
\text { theory }\end{array}$ & $\begin{array}{l}\text { Resource } \\
\text { Stability }\end{array}$ \\
\hline $\begin{array}{l}\text { Ehrhardt \& } \\
\text { Nowak, } \\
2003\end{array}$ & $J S B M$ & Financial & IPO & $\begin{array}{l}\text { Phenomen } \\
\text { on driven }\end{array}$ & Both \\
\hline $\begin{array}{l}\text { Eklund, } \\
\text { Palmberg, \& } \\
\text { Wiberg, } \\
2013 \\
\end{array}$ & $S B E$ & Complementary & CEO succession & $\begin{array}{l}\text { Agency } \\
\text { theory }\end{array}$ & Power Balance \\
\hline $\begin{array}{c}\text { Feeser \& } \\
\text { Willard, } \\
1990\end{array}$ & SMJ & Complementary & $\begin{array}{l}\text { Acquisitions; } \\
\text { Business } \\
\text { incubator } \\
\text { origination } \\
\end{array}$ & $\begin{array}{l}\text { Phenomen } \\
\text { on driven }\end{array}$ & $\begin{array}{l}\text { Resource } \\
\text { Stability }\end{array}$ \\
\hline $\begin{array}{c}\text { Feldman, } \\
\text { Amit, \& } \\
\text { Villalonga, } \\
2016 \\
\end{array}$ & $S M J$ & Financial & Divestitures & $\begin{array}{l}\text { Agency } \\
\text { theory }\end{array}$ & $\begin{array}{l}\text { Resource } \\
\text { Stability }\end{array}$ \\
\hline $\begin{array}{c}\text { Fink \& } \\
\text { Harms, } 2012\end{array}$ & $E R D$ & Complementary & Alliances & $\begin{array}{c}\text { Theory of } \\
\text { cooperatio } \\
\mathrm{n} \text { based on } \\
\text { self- } \\
\text { commitme } \\
\mathrm{nt}\end{array}$ & $\begin{array}{c}\text { Power Balance: } \\
\text { Firms remain } \\
\text { legally } \\
\text { independent }\end{array}$ \\
\hline $\begin{array}{c}\text { Fried, } \\
\text { Bruton, \& } \\
\text { Hisrich, } \\
1998 \\
\end{array}$ & $J B V$ & Complementary & Board of directors & $\begin{array}{l}\text { Agency } \\
\text { theory; } \\
\text { Institution } \\
\text { al theory }\end{array}$ & $\begin{array}{l}\text { Resource } \\
\text { Stability }\end{array}$ \\
\hline $\begin{array}{l}\text { Gabrielsson, } \\
2007\end{array}$ & $E T \& P$ & Complementary & Board of directors & $\begin{array}{l}\text { Agency } \\
\text { theory; } \\
\text { Resource } \\
\text { dependenc } \\
\text { e theory }\end{array}$ & Power Balance \\
\hline $\begin{array}{c}\text { Gales \& } \\
\text { Blackburn, } \\
1990\end{array}$ & $E T \& P$ & N/A & $\begin{array}{l}\text { Buyer-supplier } \\
\text { relationships }\end{array}$ & $\begin{array}{c}\text { Phenomen } \\
\text { on driven }\end{array}$ & $\begin{array}{c}\text { Resource } \\
\text { Stability: } \\
\text { Control over } \\
\text { critical } \\
\text { resources } \\
\end{array}$ \\
\hline
\end{tabular}




\begin{tabular}{|c|c|c|c|c|c|}
\hline Garg, 2013 & $A M R$ & Financial & Board of directors & $\begin{array}{c}\text { Agency } \\
\text { theory; } \\
\text { Resource } \\
\text { dependenc } \\
\text { e theory }\end{array}$ & Power Balance \\
\hline $\begin{array}{c}\text { Goldberg, } \\
\text { Cohen, \& } \\
\text { Fiegenbaum, } \\
2003\end{array}$ & $J S B M$ & Complementary & Alliances & $\begin{array}{c}\text { Strategic } \\
\text { reference } \\
\text { point } \\
\text { theory }\end{array}$ & $\begin{array}{c}\text { Resource } \\
\text { Stability }\end{array}$ \\
\hline $\begin{array}{c}\text { Golden \& } \\
\text { Dollinger, } \\
1993\end{array}$ & ET\&P & Complementary & IORs & $\begin{array}{l}\text { Game } \\
\text { Theory }\end{array}$ & $\begin{array}{c}\text { Resource } \\
\text { Stability }\end{array}$ \\
\hline $\begin{array}{l}\text { Grandi \& } \\
\text { Grimaldi, } \\
2005\end{array}$ & $J B V$ & Complementary & Spin-offs & $\begin{array}{c}\text { Phenomen } \\
\text { on driven }\end{array}$ & $\begin{array}{c}\text { Resource } \\
\text { Stability }\end{array}$ \\
\hline $\begin{array}{c}\text { Greene, } \\
\text { Brush, \& } \\
\text { Hart, } 1999\end{array}$ & $E T \& P$ & Complementary & $\begin{array}{l}\text { Resource } \\
\text { Acquisition }\end{array}$ & RBV & Power Balance \\
\hline $\begin{array}{l}\text { Harrison, } \\
\text { Hitt, } \\
\text { Hoskisson, } \\
\text { \& Ireland, } \\
2001\end{array}$ & $J O M$ & Complementary & Alliances & $\begin{array}{l}\text { Phenomen } \\
\text { on driven }\end{array}$ & $\begin{array}{l}\text { Resource } \\
\text { Stability }\end{array}$ \\
\hline $\begin{array}{c}\text { Hegde \& } \\
\text { Tumlinson, } \\
2014\end{array}$ & MS & Financial & IPO & $\begin{array}{c}\text { Phenomen } \\
\text { on driven }\end{array}$ & $\begin{array}{l}\text { Resource } \\
\text { Stability }\end{array}$ \\
\hline $\begin{array}{c}\text { Honig, } \\
\text { Lerner, \& } \\
\text { Raban, 2006 }\end{array}$ & $S B E$ & Financial & Venture Capital & $\begin{array}{l}\text { Signaling } \\
\text { theory }\end{array}$ & $\begin{array}{c}\text { Resource } \\
\text { Stability }\end{array}$ \\
\hline $\begin{array}{l}\text { Hustedde \& } \\
\text { Pulver, } 1992\end{array}$ & $J B V$ & Financial & Venture Capital & $\begin{array}{l}\text { Phenomen } \\
\text { on driven }\end{array}$ & $\begin{array}{l}\text { Resource } \\
\text { Stability }\end{array}$ \\
\hline $\begin{array}{c}\text { Inkpen \& } \\
\text { Crossan, } \\
1995 \\
\end{array}$ & $J M S$ & Complementary & Joint Ventures & $\begin{array}{c}\text { Organizati } \\
\text { onal } \\
\text { learning } \\
\end{array}$ & $\begin{array}{c}\text { Resource } \\
\text { Stability }\end{array}$ \\
\hline $\begin{array}{c}\text { Izquierdo, } \\
\text { Carrion, \& } \\
\text { Gutierrez, } \\
2008\end{array}$ & $E R D$ & Complementary & $\begin{array}{c}\text { Relational } \\
\text { marketing } \\
\text { partnerships }\end{array}$ & $\begin{array}{l}\text { Relational } \\
\text { contracting } \\
\text { theory }\end{array}$ & Both \\
\hline $\begin{array}{c}\text { Jones, } \\
\text { Lanctot, \& } \\
\text { Teegan, } \\
2001\end{array}$ & $J B V$ & Complementary & $\begin{array}{c}\text { External } \\
\text { technology } \\
\text { acquisition }\end{array}$ & $\begin{array}{c}\text { Phenomen } \\
\text { on driven }\end{array}$ & $\begin{array}{l}\text { Resource } \\
\text { Stability }\end{array}$ \\
\hline
\end{tabular}




\begin{tabular}{|c|c|c|c|c|c|}
\hline $\begin{array}{c}\text { Kanter, } \\
\text { Richardson, } \\
\text { North, \& } \\
\text { Morgan, } \\
1991\end{array}$ & $J B V$ & Complementary & $\begin{array}{l}\text { Corporate } \\
\text { Venturing }\end{array}$ & $\begin{array}{l}\text { Phenomen } \\
\text { on driven }\end{array}$ & $\begin{array}{c}\text { Power Balance: } \\
\text { Decision } \\
\text { making } \\
\text { freedom of } \\
\text { venture } \\
\text { managers }\end{array}$ \\
\hline $\begin{array}{c}\text { Keh, } \\
\text { Nguyen, \& } \\
\text { Ng, } 2007 \\
\end{array}$ & $J B V$ & Complementary & $\begin{array}{l}\text { Information } \\
\text { acquisition }\end{array}$ & $\begin{array}{c}\text { Phenomen } \\
\text { on driven }\end{array}$ & $\begin{array}{l}\text { Resource } \\
\text { Stability }\end{array}$ \\
\hline $\begin{array}{c}\text { Koka \& } \\
\text { Prescott, } \\
2008 \\
\end{array}$ & $S M J$ & Complementary & Alliance networks & $\begin{array}{l}\text { Contingen } \\
\text { cy theory }\end{array}$ & $\begin{array}{l}\text { Resource } \\
\text { Stability }\end{array}$ \\
\hline $\begin{array}{c}\text { Kroll, } \\
\text { Walters, \& } \\
\text { Le, } 2007\end{array}$ & $A M J$ & Complementary & Board of directors & $\begin{array}{l}\text { Agency } \\
\text { theory; } \\
\text { Resource } \\
\text { dependenc } \\
\text { e theory }\end{array}$ & Power Balance \\
\hline $\begin{array}{c}\text { Larson, } \\
1991 \\
\end{array}$ & $J B V$ & Complementary & Alliances & $\begin{array}{c}\text { Phenomen } \\
\text { on driven }\end{array}$ & $\begin{array}{l}\text { Resource } \\
\text { Stability }\end{array}$ \\
\hline $\begin{array}{c}\text { Lechner \& } \\
\text { Leyronas, } \\
2012\end{array}$ & $E R D$ & $\begin{array}{c}\text { Financial and } \\
\text { Complementary }\end{array}$ & $\begin{array}{c}\text { Access to a } \\
\text { cluster's resource } \\
\text { base }\end{array}$ & $\begin{array}{c}\text { Phenomen } \\
\text { on driven }\end{array}$ & $\begin{array}{c}\text { Resource } \\
\text { Stability: } \\
\text { Structural } \\
\text { Holes } \\
\end{array}$ \\
\hline $\begin{array}{c}\text { Levitas \& } \\
\text { McFayden, } \\
2009 \\
\end{array}$ & $S M J$ & Financial & Alliances & $\begin{array}{c}\text { Phenomen } \\
\text { on driven }\end{array}$ & Both \\
\hline $\begin{array}{c}\text { Li \& } \\
\text { Atuahene- } \\
\text { Gima, } 2001\end{array}$ & $A M J$ & Complementary & Alliance & $\begin{array}{c}\text { Resource } \\
\text { dependenc } \\
\text { e theory }\end{array}$ & $\begin{array}{l}\text { Resource } \\
\text { Stability }\end{array}$ \\
\hline $\begin{array}{c}\text { Li \& } \\
\text { Atuahene- } \\
\text { Gima, } 2002\end{array}$ & $S M J$ & Complementary & Alliances & RBV & $\begin{array}{l}\text { Resource } \\
\text { Stability }\end{array}$ \\
\hline $\begin{array}{c}\text { Li, Wei, \& } \\
\text { Liu, } 2010\end{array}$ & $J M S$ & Complementary & Outsourcing & $\begin{array}{l}\text { Phenomen } \\
\text { on driven }\end{array}$ & $\begin{array}{c}\text { Power Balance: } \\
\text { Outsourcing } \\
\text { should lead to } \\
\text { future } \\
\text { autonomy; not } \\
\text { tested or further } \\
\text { discussed } \\
\end{array}$ \\
\hline $\begin{array}{l}\text { Lichtenstein } \\
\text { \& Brush, } \\
2001\end{array}$ & ET\&P & Complementary & $\begin{array}{l}\text { Resource } \\
\text { acquisition }\end{array}$ & $\begin{array}{c}\text { RBV; } \\
\text { Resource } \\
\text { dependenc } \\
\text { e theory }\end{array}$ & $\begin{array}{l}\text { Resource } \\
\text { Stability }\end{array}$ \\
\hline $\begin{array}{c}\text { Lu \& } \\
\text { Beamish, } \\
2006 \\
\end{array}$ & $J B V$ & Complementary & Joint ventures & $\begin{array}{c}\text { RBV; } \\
\text { Institution } \\
\text { al theory }\end{array}$ & Both \\
\hline
\end{tabular}




\begin{tabular}{|c|c|c|c|c|c|}
\hline $\begin{array}{c}\text { Lu \& } \\
\text { Beamish, } \\
2001\end{array}$ & SMJ & Complementary & Alliances & $\begin{array}{l}\text { Phenomen } \\
\text { on driven }\end{array}$ & $\begin{array}{l}\text { Resource } \\
\text { Stability }\end{array}$ \\
\hline $\begin{array}{l}\text { Lynall, } \\
\text { Golden, \& } \\
\text { Hillman, } \\
2003\end{array}$ & $A M J$ & $\begin{array}{l}\text { Complementary } \\
\text { and Financial }\end{array}$ & Board of directors & $\begin{array}{l}\text { Agency } \\
\text { theory; } \\
\text { Resource } \\
\text { dependenc } \\
\text { e theory; } \\
\text { Institution } \\
\text { al theory; } \\
\text { Social } \\
\text { network } \\
\text { theory }\end{array}$ & $\begin{array}{l}\text { Power Balance: } \\
\text { Power of CEO } \\
\text { and external } \\
\text { financiers is } \\
\text { discussed }\end{array}$ \\
\hline $\begin{array}{c}\text { MacMillan, } \\
\text { Block, \& } \\
\text { Narasimha, } \\
1986\end{array}$ & $J B V$ & Financial & Joint ventures & $\begin{array}{l}\text { Phenomen } \\
\text { on driven }\end{array}$ & Power Balance \\
\hline $\begin{array}{c}\text { Malo \& } \\
\text { Norus, 2009 }\end{array}$ & $E R D$ & Complementary & Alliances & $\begin{array}{l}\text { Phenomen } \\
\text { on driven }\end{array}$ & $\begin{array}{l}\text { Resource } \\
\text { Stability }\end{array}$ \\
\hline $\begin{array}{c}\text { Marino, } \\
\text { Strandholm, } \\
\text { Steensma, \& } \\
\text { Weaver, } \\
2002\end{array}$ & $E T \& P$ & Complementary & Alliances & $\begin{array}{l}\text { Phenomen } \\
\text { on driven }\end{array}$ & $\begin{array}{l}\text { Resource } \\
\text { Stability }\end{array}$ \\
\hline $\begin{array}{c}\text { McCann, } \\
1991\end{array}$ & $J B V$ & Complementary & Joint ventures & $\begin{array}{l}\text { Phenomen } \\
\text { on driven }\end{array}$ & $\begin{array}{l}\text { Resource } \\
\text { Stability }\end{array}$ \\
\hline $\begin{array}{c}\text { McGee, } \\
\text { Dowling, \& } \\
\text { Megginson, } \\
1995\end{array}$ & SMJ & Complementary & $\begin{array}{l}\text { Cooperative } \\
\text { agreements }\end{array}$ & $\begin{array}{c}\text { Strategic } \\
\text { behavior } \\
\text { theory }\end{array}$ & $\begin{array}{l}\text { Resource } \\
\text { Stability }\end{array}$ \\
\hline $\begin{array}{l}\text { Meuleman, } \\
\text { Amess, } \\
\text { Wright, \& } \\
\text { Scholes, } \\
2009\end{array}$ & $E T \& P$ & Financial & Buy-outs & $\begin{array}{l}\text { Agency } \\
\text { theory }\end{array}$ & Both \\
\hline $\begin{array}{l}\text { Meyskens \& } \\
\text { Carsrud, } \\
2013\end{array}$ & $S B E$ & Complementary & $\begin{array}{l}\text { Partnership } \\
\text { diversity }\end{array}$ & $\begin{array}{c}\text { Phenomen } \\
\text { on driven }\end{array}$ & $\begin{array}{l}\text { Resource } \\
\text { Stability }\end{array}$ \\
\hline $\begin{array}{c}\text { Niederkofler } \\
, 1991\end{array}$ & $J B V$ & Complementary & Alliances & $\begin{array}{l}\text { Phenomen } \\
\text { on driven }\end{array}$ & $\begin{array}{l}\text { Resource } \\
\text { Stability }\end{array}$ \\
\hline $\begin{array}{c}\text { Ozcan \& } \\
\text { Eisenhardt, } \\
2009\end{array}$ & AMJ & Complementary & $\begin{array}{l}\text { Alliance } \\
\text { portfolios }\end{array}$ & $\begin{array}{l}\text { Network } \\
\text { theory; } \\
\text { Resource } \\
\text { dependenc } \\
\text { e theory } \\
\end{array}$ & $\begin{array}{l}\text { Power Balance: } \\
\text { Discussion of } \\
\text { interdependenc } \\
\text { e between firms } \\
\text { in a network }\end{array}$ \\
\hline
\end{tabular}




\begin{tabular}{|c|c|c|c|c|c|}
\hline $\begin{array}{l}\text { Patzelt, } \\
\text { Shepherd, } \\
\text { Deeds, \& } \\
\text { Bradley, } \\
2008 \\
\end{array}$ & $J B V$ & Financial & Alliances & $\begin{array}{l}\text { Phenomen } \\
\text { on driven }\end{array}$ & $\begin{array}{c}\text { Both: } \\
\text { Managerial } \\
\text { Discretion } \\
\text { (Financial } \\
\text { Slack) } \\
\end{array}$ \\
\hline $\begin{array}{l}\text { Randoy \& } \\
\text { Goel, } 2003\end{array}$ & $J B V$ & Financial & Board of directors & $\begin{array}{l}\text { Agency } \\
\text { theory }\end{array}$ & Power Balance \\
\hline $\begin{array}{c}\text { Rosenstein, } \\
1988 \\
\end{array}$ & $J B V$ & Financial & Board of directors & $\begin{array}{c}\text { Phenomen } \\
\text { on driven }\end{array}$ & Power Balance \\
\hline $\begin{array}{l}\text { Rosenstein, } \\
\text { Bruno, } \\
\text { Bygrave, \& } \\
\text { Taylor, 1993 }\end{array}$ & $J B V$ & Complementary & Board of directors & $\begin{array}{c}\text { Agency } \\
\text { theory; } \\
\text { TCE }\end{array}$ & $\begin{array}{l}\text { Resource } \\
\text { Stability }\end{array}$ \\
\hline $\begin{array}{c}\text { Sarkar, } \\
\text { Echambadi, } \\
\text { \& Harrison, } \\
2001\end{array}$ & $S M J$ & Complementary & Alliances & $\begin{array}{l}\text { Phenomen } \\
\text { on driven }\end{array}$ & $\begin{array}{l}\text { Resource } \\
\text { Stability }\end{array}$ \\
\hline $\begin{array}{c}\text { Sedaitis, } \\
1998 \\
\end{array}$ & OS & Complementary & Alliance networks & $\begin{array}{c}\text { Phenomen } \\
\text { on driven }\end{array}$ & $\begin{array}{c}\text { Resource } \\
\text { Stability }\end{array}$ \\
\hline $\begin{array}{l}\text { Shu, Liu, } \\
\text { Gao, \& } \\
\text { Shanley, } \\
2014\end{array}$ & $E T \& P$ & Complementary & Alliances & $\begin{array}{l}\text { Knowledg } \\
\text { e spillover } \\
\text { theory }\end{array}$ & $\begin{array}{l}\text { Resource } \\
\text { Stability: } \\
\text { Autonomy, as } \\
\text { defined by } \\
\text { Lumpkin and } \\
\text { Dess, is less } \\
\text { important than } \\
\text { competitive } \\
\text { aggressiveness } \\
\text { in alliances }\end{array}$ \\
\hline Soh, 2003 & $J B V$ & Complementary & Alliance networks & $\begin{array}{c}\text { Phenomen } \\
\text { on driven }\end{array}$ & Power Balance \\
\hline Stam, 2010 & $J M S$ & Complementary & $\begin{array}{l}\text { Participation in } \\
\text { industry events }\end{array}$ & $\begin{array}{c}\text { Phenomen } \\
\text { on driven }\end{array}$ & Power Balance \\
\hline $\begin{array}{c}\text { Stam \& } \\
\text { Elfring, } \\
2008\end{array}$ & $A M J$ & Complementary & Bridging ties & $\begin{array}{l}\text { Phenomen } \\
\text { on driven }\end{array}$ & $\begin{array}{l}\text { Resource } \\
\text { Stability }\end{array}$ \\
\hline $\begin{array}{c}\text { Tan, Zhang, } \\
\text { \& Wang, } \\
2015 \\
\end{array}$ & $E T \& P$ & Complementary & Structural holes & $\begin{array}{c}\text { Structural } \\
\text { hole } \\
\text { theory }\end{array}$ & $\begin{array}{l}\text { Resource } \\
\text { Stability }\end{array}$ \\
\hline $\begin{array}{c}\text { Teerikangas, } \\
2012 \\
\end{array}$ & JOM & Complementary & Acquisitions & $\begin{array}{c}\text { Phenomen } \\
\text { on driven }\end{array}$ & Power Balance \\
\hline $\begin{array}{c}\text { Vissa \& } \\
\text { Chacar, } \\
2009 \\
\end{array}$ & $S M J$ & Complementary & Structural holes & $\begin{array}{c}\text { Structural } \\
\text { hole } \\
\text { theory }\end{array}$ & $\begin{array}{l}\text { Resource } \\
\text { Stability }\end{array}$ \\
\hline
\end{tabular}




\begin{tabular}{|c|c|c|c|c|c|}
\hline $\begin{array}{c}\text { Wadhwa \& } \\
\text { Kotha, } 2006\end{array}$ & $A M J$ & Financial & $\begin{array}{c}\text { Corporate venture } \\
\text { capital }\end{array}$ & $\begin{array}{c}\text { Phenomen } \\
\text { on driven }\end{array}$ & $\begin{array}{l}\text { Resource } \\
\text { Stability }\end{array}$ \\
\hline $\begin{array}{c}\text { Walters, } \\
\text { Kroll, \& } \\
\text { Wright, } \\
2010\end{array}$ & $A M J$ & Financial & Board of directors & $\begin{array}{l}\text { Agency } \\
\text { theory; } \\
\text { Stewardshi } \\
\text { p theory }\end{array}$ & Power Balance \\
\hline $\begin{array}{c}\text { Wijbenga, } \\
\text { Postma, \& } \\
\text { Stratling, } \\
2007\end{array}$ & $E T \& P$ & Complementary & $\begin{array}{l}\text { Venture Capital } \\
\text { firm services }\end{array}$ & $\begin{array}{l}\text { Agency } \\
\text { theory; } \\
\text { Resource } \\
\text { dependenc } \\
\text { e theory }\end{array}$ & Power Balance \\
\hline $\begin{array}{c}\text { Woodcock, } \\
\text { Beamish, \& } \\
\text { Makino, } \\
1994\end{array}$ & $J I B S$ & Financial & Market entry & $\begin{array}{l}\text { Contingen } \\
\text { cy theory }\end{array}$ & $\begin{array}{l}\text { Resource } \\
\text { Stability }\end{array}$ \\
\hline $\begin{array}{c}\text { Yoo, } \\
\text { Schenkel, \& } \\
\text { Kim, } 2014\end{array}$ & $J S B M$ & Financial & Board of directors & $\begin{array}{c}\text { Agency } \\
\text { theory; } \\
\text { Stewardshi } \\
\text { p theory; } \\
\text { Identity } \\
\text { theory }\end{array}$ & Power Balance \\
\hline Zahra, 1995 & $J B V$ & Financial & Buyouts & $\begin{array}{l}\text { Agency } \\
\text { theory }\end{array}$ & $\begin{array}{l}\text { Resource } \\
\text { Stability }\end{array}$ \\
\hline $\begin{array}{c}\text { Zahra \& } \\
\text { Hayton, } \\
2008\end{array}$ & $J B V$ & Financial & Alliances & $\begin{array}{l}\text { Organizati } \\
\text { onal } \\
\text { learning } \\
\text { theory }\end{array}$ & $\begin{array}{l}\text { Resource } \\
\text { Stability }\end{array}$ \\
\hline $\begin{array}{c}\text { Zahra, } \\
\text { Neubaum, \& } \\
\text { Huse, } 2000\end{array}$ & JOM & Financial & $\begin{array}{c}\text { Corporate } \\
\text { entrepreneurship }\end{array}$ & $\begin{array}{l}\text { Agency } \\
\text { theory }\end{array}$ & $\begin{array}{l}\text { Resource } \\
\text { Stability }\end{array}$ \\
\hline
\end{tabular}




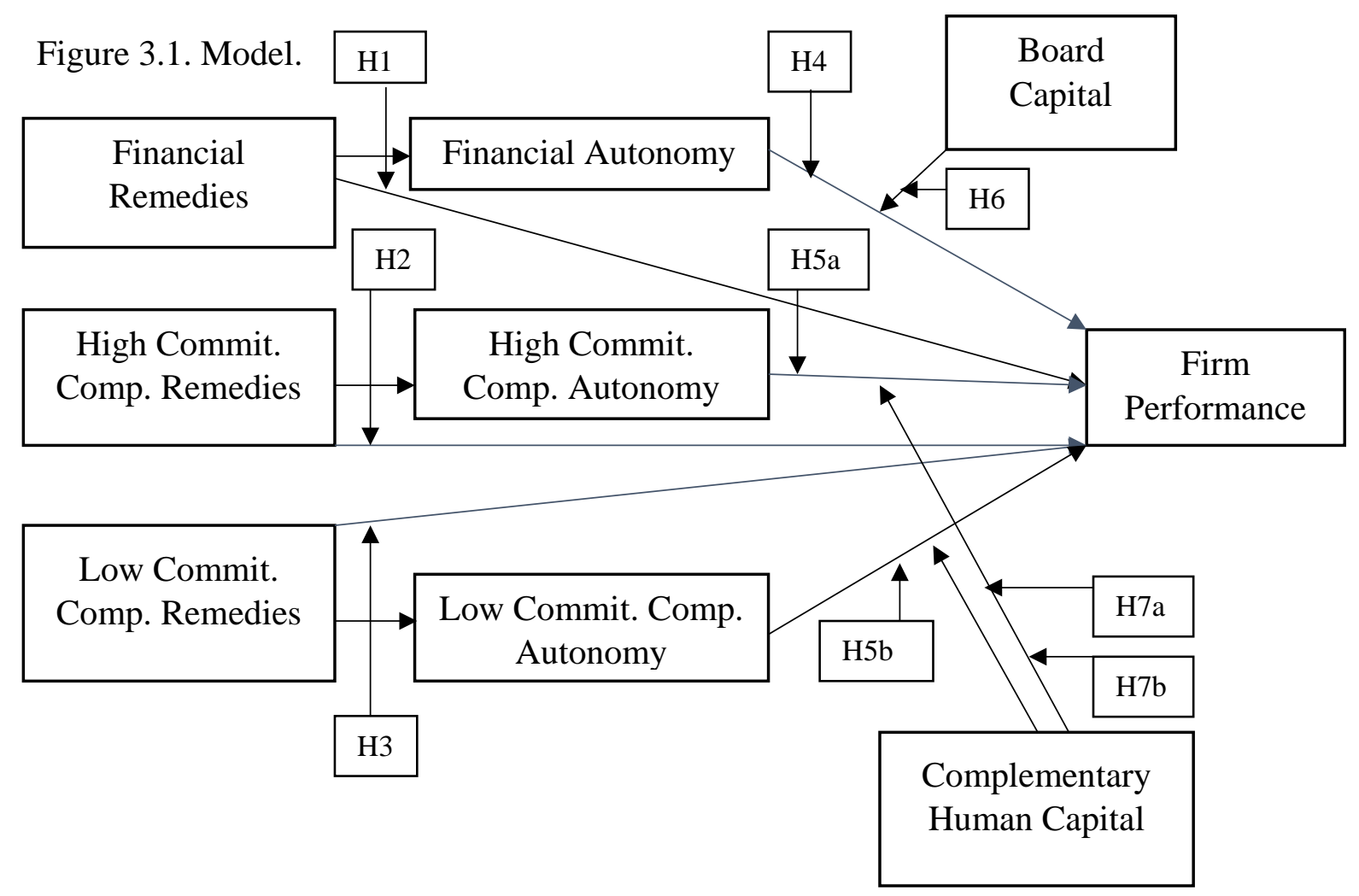


Table 5.1. Summary

Statistics.

\begin{tabular}{|l|c|c|c|c|c|}
\hline Variable & Obs & Mean & $\begin{array}{c}\text { Std. } \\
\text { Dev. }\end{array}$ & Min & Max \\
\hline Firm Performance & 2,140 & 2.09 & 7.41 & -1 & 200.01 \\
\hline Fin. Dependence Remedy & 3,711 & 1.09 & 0.71 & 0 & 5.00 \\
\hline $\begin{array}{l}\text { High Commit. Comp. } \\
\text { Remedy }\end{array}$ & 3,802 & 0.12 & 0.45 & 0 & 5.00 \\
\hline $\begin{array}{l}\text { Low Commit. Comp. } \\
\text { Remedy }\end{array}$ & 3,802 & 0.34 & 1.07 & 0 & 14.00 \\
\hline & & & & & \\
\hline Financial Autonomy & 3,058 & 8.92 & 7.65 & 0 & 22.55 \\
\hline High Commit. Comp. Auto. & 3,800 & 0.03 & 0.08 & 0 & 1.00 \\
\hline Low Commit Comp. Auto. & 3,800 & 0.05 & 0.08 & 0 & 0.56 \\
\hline Firm Size & 2,974 & 117.89 & 556.41 & 0 & 15,000 \\
\hline & & & & & \\
\hline Comp. Human Cap. & 3,802 & 0.10 & 0.18 & 0 & 1.00 \\
\hline Board (Human) Capital & 2,155 & .055 & .294 & .016 & 1 \\
\hline Board (Social) Capital & 3,757 & 16.45 & 27.68 & 0 & 212 \\
\hline & & & & & \\
\hline Board Size & 2,196 & 3.97 & 2.22 & 1 & 12 \\
\hline VC Reputation & 3,775 & 0.00 & 0.01 & 0 & 0.27 \\
\hline Ent. Human Capital & 3,775 & 2.07 & 2.44 & 0 & 18 \\
\hline Board Monitoring & 2,187 & 0.18 & 0.53 & 0 & 6.00 \\
\hline Board Opportunism & 2,187 & 3.53 & 2.19 & 0 & 11.00 \\
\hline Firm Age & 3,776 & 3.11 & 2.08 & 0 & 9.00 \\
\hline TMT Size & 2,934 & 3.50 & 2.35 & 1 & 13.00 \\
\hline
\end{tabular}


Table 5.2. Correlation Matrix.

\begin{tabular}{|c|c|c|c|c|c|c|c|c|c|c|c|c|c|c|c|}
\hline & $\begin{array}{l}\text { Firm } \\
\text { Perf. }\end{array}$ & $\begin{array}{l}\text { Fin. } \\
\text { Dep. } \\
\text { Remedy }\end{array}$ & $\begin{array}{l}\text { High } \\
\text { Commit. } \\
\text { Remedy }\end{array}$ & $\begin{array}{l}\text { Low } \\
\text { Commit. } \\
\text { Remedy }\end{array}$ & $\begin{array}{l}\text { Comp. } \\
\text { Human } \\
\text { Cap. }\end{array}$ & $\begin{array}{l}\text { High } \\
\text { Commit. } \\
\text { Auto. }\end{array}$ & $\begin{array}{l}\text { Low } \\
\text { Commit } \\
\text { Auto. }\end{array}$ & $\begin{array}{l}\text { Firm } \\
\text { Size }\end{array}$ & $\begin{array}{l}\text { TMT } \\
\text { Size }\end{array}$ & $\begin{array}{l}\text { Board } \\
\text { Size }\end{array}$ & $\begin{array}{l}\text { VC } \\
\text { Rep. }\end{array}$ & $\begin{array}{l}\text { Ent } \\
\text { Human } \\
\text { Cap. }\end{array}$ & $\begin{array}{l}\text { Board } \\
\text { Mon. }\end{array}$ & $\begin{array}{l}\text { Board } \\
\text { Opp. }\end{array}$ & $\begin{array}{l}\text { Firm } \\
\text { Age }\end{array}$ \\
\hline $\begin{array}{l}\text { Firm } \\
\text { Performance }\end{array}$ & 1 & & & & & & & & & & & & & & \\
\hline $\begin{array}{l}\text { Fin. Dep. } \\
\text { Remedy }\end{array}$ & 0.04 & 1 & & & & & & & & & & & & & \\
\hline $\begin{array}{l}\text { High } \\
\text { Commit. } \\
\text { Remedy }\end{array}$ & -0.04 & $0.05^{* *}$ & 1 & & & & & & & & & & & & \\
\hline $\begin{array}{l}\text { Low } \\
\text { Commit. } \\
\text { Remedy }\end{array}$ & $-0.05 *$ & $0.04 *$ & $0.47^{* *}$ & 1 & & & & & & & & & & & \\
\hline $\begin{array}{l}\text { Comp. } \\
\text { Human Cap. }\end{array}$ & -0.02 & $0.08^{* *}$ & $0.39 * *$ & $0.58 * *$ & 1 & & & & & & & & & & \\
\hline $\begin{array}{l}\text { High } \\
\text { Commit. } \\
\text { Auto. }\end{array}$ & 0.04 & $0.09 * *$ & $0.59 * *$ & $0.21 * *$ & $0.31^{* *}$ & 1 & & & & & & & & & \\
\hline $\begin{array}{l}\text { Low } \\
\text { Commit } \\
\text { Auto. }\end{array}$ & -0.01 & $0.08^{* *}$ & $0.26 * *$ & $0.48 * *$ & $0.66^{* *}$ & $0.31^{* *}$ & 1 & & & & & & & & \\
\hline Firm Size & -0.03 & -0.01 & $0.07^{* *}$ & $0.07 * *$ & 0.01 & $0.08^{* *}$ & $0.11^{* *}$ & 1 & & & & & & & \\
\hline TMT Size & 0.06 & $-0.07 * *$ & -0.005 & $0.04 *$ & 0.03 & $0.06^{* *}$ & $0.07 * *$ & 0.03 & 1 & & & & & & \\
\hline Board Size & 0.00 & 0.02 & $0.10^{* *}$ & $0.11^{* *}$ & $0.19 * *$ & $0.12^{* *}$ & $0.15^{* *}$ & $0.07 * *$ & $0.08^{* *}$ & 1 & & & & & \\
\hline $\begin{array}{l}\text { VC } \\
\text { Reputation }\end{array}$ & 0 & $0.03 *$ & -0.01 & -0.01 & -0.03 & -0.01 & -0.01 & 0 & 0.02 & -0.03 & 1 & & & & \\
\hline $\begin{array}{l}\text { Ent. Human } \\
\text { Cap. }\end{array}$ & 0.03 & $-0.11^{* *}$ & 0.02 & $0.06^{* *}$ & $0.06 * *$ & $0.05^{* *}$ & $0.08^{* *}$ & -0.01 & $0.36 * *$ & 0.03 & 0.01 & 1 & & & \\
\hline $\begin{array}{l}\text { Board } \\
\text { Monitoring }\end{array}$ & -0.03 & 0 & 0.01 & $0.08 * *$ & $0.08 * *$ & 0.02 & 0.02 & -0.03 & $-0.08 * *$ & $0.05^{*}$ & 0 & $-0.09 * *$ & 1 & & \\
\hline Board Opp. & 0.02 & 0 & $0.07 * *$ & $0.07 * *$ & $0.14^{* *}$ & $0.08^{* *}$ & $0.12 * *$ & $0.07 * *$ & $0.12^{* *}$ & $0.91^{* *}$ & -0.02 & $0.08^{* *}$ & $-0.3 * *$ & 1 & \\
\hline Firm Age & $-0.20 * *$ & $0.10^{* *}$ & $0.25 * *$ & $0.34 * *$ & $0.13^{* *}$ & $0.03 *$ & $0.08 * *$ & $0.11^{* *}$ & $-0.10 * *$ & $0.05^{* *}$ & $-0.06 * *$ & $-0.09 * *$ & 0.02 & 0.04 & 1 \\
\hline
\end{tabular}


Table 5.3. Mixed-Effects Regression Analysis.

Dependent Variables: Firm Performance (Sales Growth)

\begin{tabular}{|c|c|c|c|}
\hline Variable & Model 1: Controls & $\begin{array}{l}\text { Model 2: } \\
\text { Main Effects }\end{array}$ & Model 3: Moderation \\
\hline Financial Remedy & & $0.458^{* *}$ & 0.252 \\
\hline $\begin{array}{l}\text { High Commitment } \\
\text { Complementary }\end{array}$ & & & \\
\hline Remedy & & 0.185 & -0.266 \\
\hline $\begin{array}{l}\text { Low Commitment } \\
\text { Complementary }\end{array}$ & & & \\
\hline Remedy & & $-0.099 * *$ & 0.029 \\
\hline Financial Autonomy & & & -0.033 \\
\hline High Commit. Comp. Auto & & & $6.186^{* *}$ \\
\hline Low Commit. Comp. Auto & & & $-2.383 *$ \\
\hline Comp. Human Capital & & & -0.162 \\
\hline $\begin{array}{l}\text { High Commit. Comp. Auto } \\
\text { * Comp. Human Cap }\end{array}$ & & & $-7.093 *$ \\
\hline $\begin{array}{l}\text { Low Commit. Comp. Auto } \\
\text { * Comp. Human Cap }\end{array}$ & & & 3.472 \\
\hline Board (Human) Capital & & & $-0.98 * *$ \\
\hline Board (Human) Capital & & & 0.024 \\
\hline * Fin. Autonomy & & & \\
\hline Board (Social) Capital & & & 0.002 \\
\hline $\begin{array}{l}\text { Board (Social) Capital } \\
\text { * Fin. Autonomy }\end{array}$ & & & 0 \\
\hline Board Size & 0.079 & 0.029 & 0.026 \\
\hline Board Opportunism & -0.062 & -0.015 & -0.061 \\
\hline Ent. Human Capital & $-0.048^{*}$ & $-0.04 *$ & -0.036 \\
\hline Firm Age & $-0.628 * *$ & $-0.71^{* *}$ & $-0.566 * *$ \\
\hline VC Reputation & $-3.25^{* *}$ & $-5.098^{*}$ & $-6.987 * *$ \\
\hline Firm Size & $-0 * *$ & $-0.00^{* *}$ & $-0.001^{* *}$ \\
\hline TMT Size & -0.03 & -0.144 & $-0.061 * *$ \\
\hline Board Monitoring & $-0.24 *$ & -0.03 & -0.203 \\
\hline Year: & & & \\
\hline 2009 & $3.98 * *$ & $3.84 * *$ & $3.517^{* *}$ \\
\hline 2010 & $3.54 * *$ & $3.48 * *$ & $3.055^{* *}$ \\
\hline 2011 & $3.93 * *$ & $3.97 * *$ & $3.348^{* *}$ \\
\hline 2012 & $3.62 * *$ & $3.75^{* *}$ & $3.013^{* *}$ \\
\hline 2013 & $4.03^{* *}$ & $4.26^{* *}$ & $3.468 * *$ \\
\hline 2014 & $4.3^{* *}$ & $4.58^{* *}$ & $3.635^{* *}$ \\
\hline 2015 & $4.44^{* *}$ & $4.83^{* *}$ & $3.788 * *$ \\
\hline 2016 & $3.28 * *$ & $3.66^{* *}$ & $2.474^{* *}$ \\
\hline 2017 & $2.84 * *$ & $2.83^{* *}$ & $1.667^{* *}$ \\
\hline Intercept & $.12 * *$ & $-0.326^{* *}$ & $1.265^{* *}$ \\
\hline $\mathrm{N}$ & 921 & 921 & 885 \\
\hline Wald $\chi^{2}$ & $164.61 * *$ & $191.47^{* *}$ & $223.96 * *$ \\
\hline Log-Likelihood & -1972.45 & -1961.2 & -1855.81 \\
\hline AIC (df) & $3984.91(20)$ & 3968.39 (23) & \\
\hline
\end{tabular}


Table 5.4. Sobel-Goodman

Mediation - Financial Autonomy

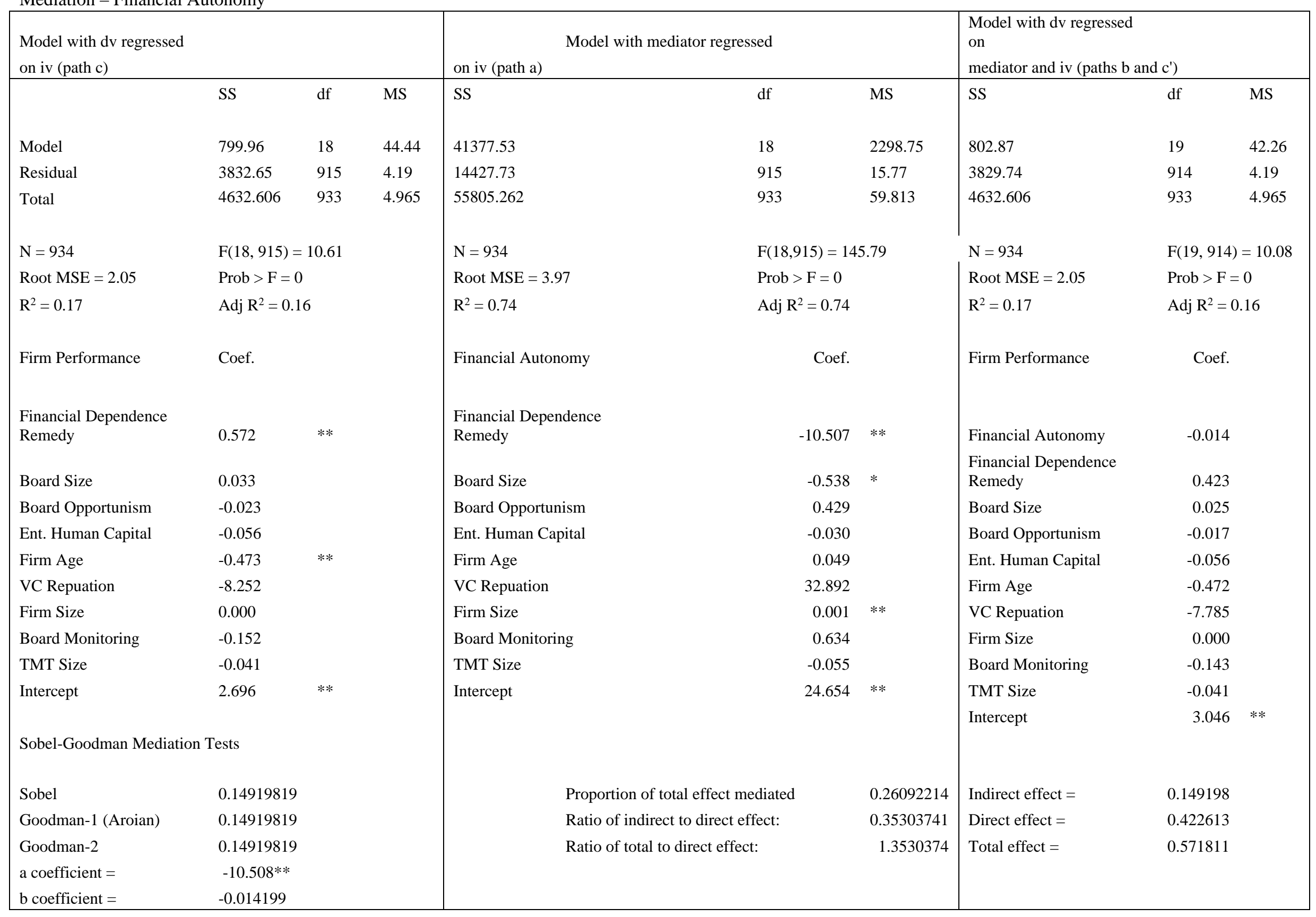


Table 5.5. Sobel-Goodman Mediation -

High Commitment Complementary

Autonomy

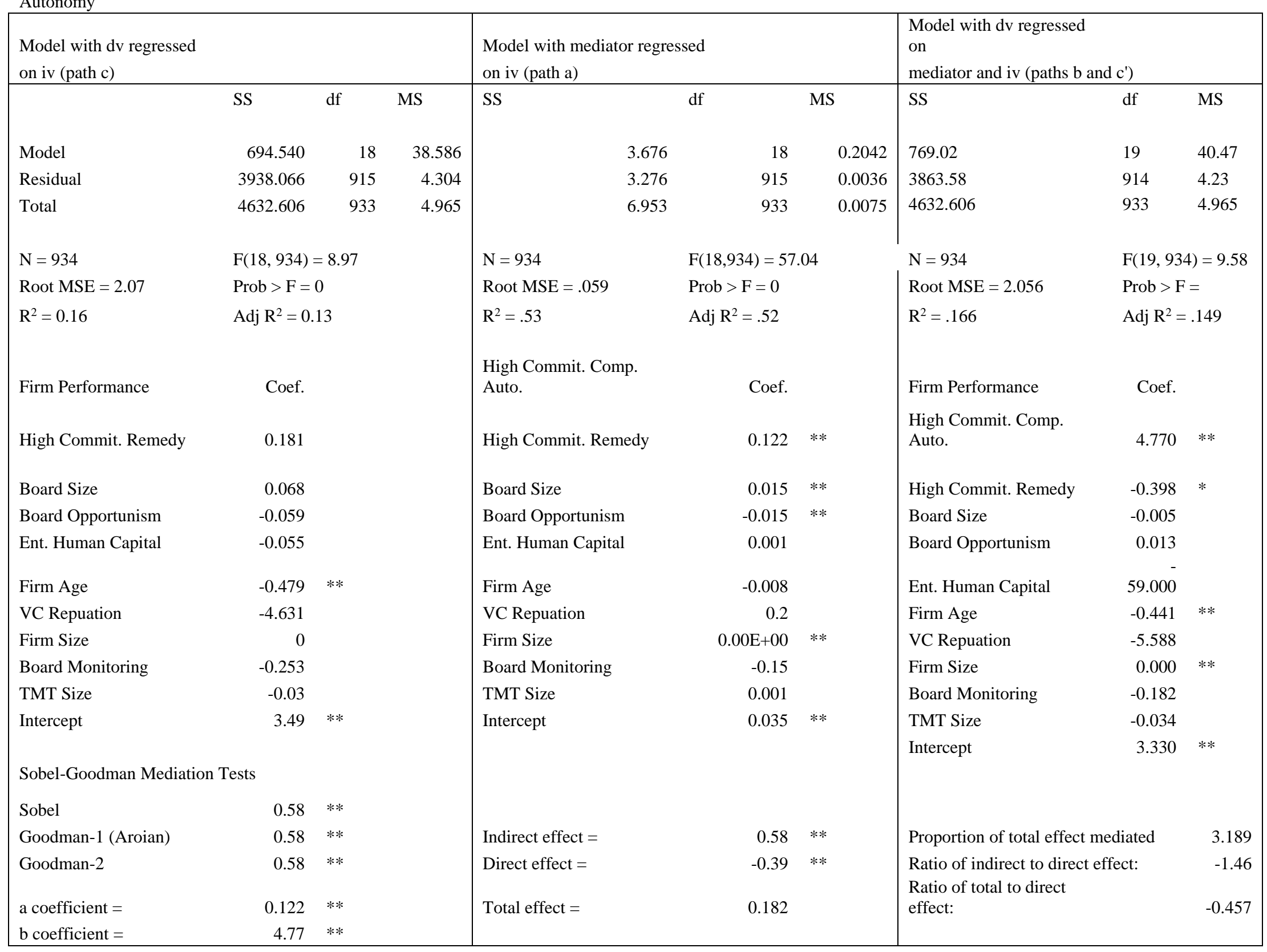


Table 5.6. Sobel-Goodman Mediation - Low Commitment

\begin{tabular}{|c|c|c|c|c|c|c|c|c|c|}
\hline \multirow[t]{2}{*}{$\begin{array}{l}\text { Model with dv regressed } \\
\text { on iv (path c) }\end{array}$} & & & & \multicolumn{3}{|c|}{$\begin{array}{l}\text { Model with mediator regressed } \\
\text { on iv (path a) }\end{array}$} & \multicolumn{3}{|c|}{$\begin{array}{l}\text { Model with dv regressed } \\
\text { on } \\
\text { mediator and iv (paths b and c') }\end{array}$} \\
\hline & SS & $\mathrm{df}$ & MS & SS & df & MS & SS & $\mathrm{df}$ & MS \\
\hline Model & 689.90 & 18 & 38.33 & 2.56 & 18 & 0.14 & 692.50 & 19 & 36.45 \\
\hline Residual & 3942.70 & 915 & 4.31 & 5 & 915 & 0.01 & 3940.10473 & 914 & 4.31 \\
\hline Total & 4632.606 & 933 & 4.965 & 7.868 & 933 & 0.008 & 4632.606 & 933 & 4.965 \\
\hline $\mathrm{N}=934$ & \multicolumn{3}{|c|}{$F(18,934)=8.89$} & $\mathrm{~N}=934$ & \multicolumn{2}{|c|}{$F(18,915)=24.52$} & $\mathrm{~N}=934$ & \multicolumn{2}{|c|}{$\mathrm{F}(19,914)=8.45$} \\
\hline Root MSE $=2.08$ & \multicolumn{3}{|c|}{ Prob $>F=0$} & Root MSE $=.076$ & \multicolumn{2}{|l|}{ Prob $>F=0$} & Root MSE $=2.07$ & \multicolumn{2}{|c|}{ Prob $>F=0$} \\
\hline $\mathrm{R}^{2}=0.15$ & \multicolumn{3}{|c|}{ Adj $R^{2}=0.13$} & $\mathrm{R}^{2}=0.323$ & \multicolumn{2}{|l|}{ Adj $R^{2}=0.31$} & $\mathrm{R}^{2}=0.15$ & \multicolumn{2}{|c|}{ Adj $R^{2}=0.13$} \\
\hline Firm Performance & \multicolumn{2}{|l|}{ Coef. } & & $\begin{array}{l}\text { Low Commit. Comp. } \\
\text { Auto. }\end{array}$ & \multicolumn{2}{|l|}{ Coef. } & Firm Performance & \multicolumn{2}{|l|}{ Coef. } \\
\hline $\begin{array}{l}\text { Low Commit. Comp. } \\
\text { Remedy. }\end{array}$ & \multicolumn{2}{|l|}{-0.039} & & $\begin{array}{l}\text { Low Commit. Comp. } \\
\text { Remedy. }\end{array}$ & 0.040 & ** & $\begin{array}{l}\text { Low Commit. Comp. } \\
\text { Auto. }\end{array}$ & \multicolumn{2}{|l|}{-0.700} \\
\hline Board Size & \multicolumn{2}{|l|}{0.093} & & Board Size & 0.021 & $* *$ & $\begin{array}{l}\text { Low Commit. Comp. } \\
\text { Remedy. }\end{array}$ & \multicolumn{2}{|l|}{-0.011} \\
\hline Board Opportunism & \multicolumn{2}{|l|}{-0.079} & & Board Opportunism & -0.020 & ** & Board Size & \multicolumn{2}{|l|}{0.109} \\
\hline Ent. Human Capital & \multicolumn{2}{|l|}{-0.050} & & Ent. Human Capital & 0.001 & & Board Opportunism & \multicolumn{2}{|l|}{-0.094} \\
\hline Firm Age & -0.465 & $* *$ & & Firm Age & -0.005 & $*$ & Ent. Human Capital & -0.050 & \\
\hline VC Repuation & \multicolumn{2}{|l|}{-4.540} & & VC Repuation & 0.798 & $*$ & Firm Age & -0.469 & $* *$ \\
\hline Firm Size & 0.000 & $* *$ & & Firm Size & 0.000 & ** & VC Repuation & -3.975 & \\
\hline Board Monitoring & -0.279 & & & Board Monitoring & -0.032 & ** & Firm Size & 0.000 & * \\
\hline TMT Size & -0.290 & & & TMT Size & 0.000 & & Board Monitoring & -0.301 & \\
\hline Intercept & 3.450 & $* *$ & & Intercept & 0.050 & $* *$ & $\begin{array}{l}\text { TMT Size } \\
\text { Intercept }\end{array}$ & $\begin{array}{r}-0.029 \\
3.76\end{array}$ & $* *$ \\
\hline Sobel-Goodman Mediati & ests & & & & & & & & \\
\hline Sobel & 0.028 & & & Indirect effect $=$ & -0.028 & & Proportion of total effect $m$ & diated & 0.711 \\
\hline Goodman-1 (Aroian) & 0.028 & & & Direct effect $=$ & -0.011 & & $\begin{array}{l}\text { Ratio of indirect to direct ef } \\
\text { Ratio of total to direct }\end{array}$ & & 2.46 \\
\hline Goodman-2 & 0.028 & & & Total effect $=$ & -0.039 & & effect: & & 3.46 \\
\hline a coefficient $=$ & 0.039 & $* *$ & & & & & & & \\
\hline $\mathrm{b}$ coefficient $=$ & -0.699 & & & & & & & & \\
\hline
\end{tabular}


Table 5.7. Mixed-Effects Regression Analysis. DV: Firm Performance (Sales Growth)

Variable

Financial Autonomy

High Commit. Comp. Auto

Low Commit. Comp. Auto

Comp. Human Capital

High Commit. Comp. Auto

* Comp. Human Cap

Low Commit. Comp. Auto

* Comp. Human Cap

Board (Human) Capital

Board (H) Capital * Fin. Auto.

Board (S) Capital

Board (S) Capital * Fin. Auto.

Board Size

Board Opportunism

Ent. Human Capital

Firm Age

VC Reputation

Firm Size

TMT Size

Board Monitoring

Year:

2009

2010

2011

2012

2013

2014

2015

2016

2017

Intercept

$\mathrm{N}$

Log-Likelihood

AIC (df)

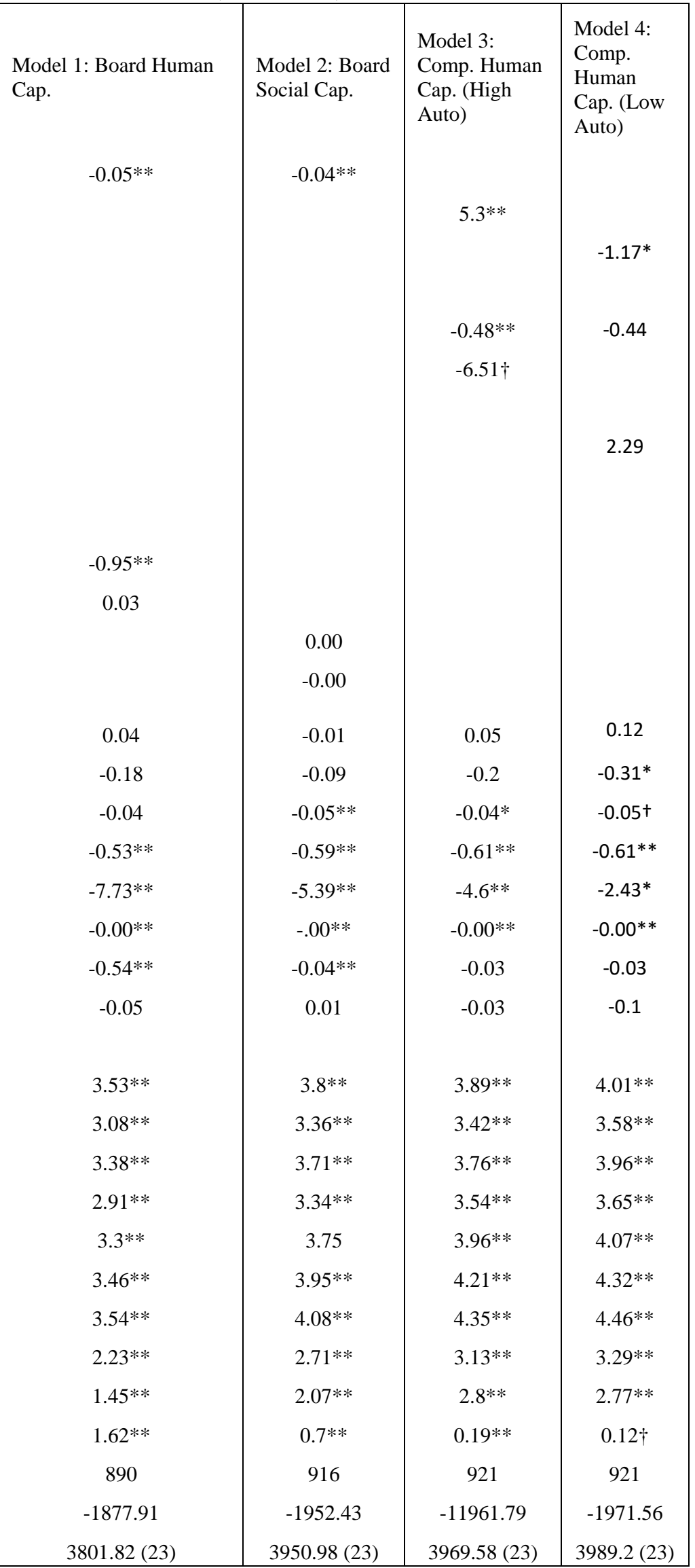


Table 5.8. Mixed-effects negative binomial regression

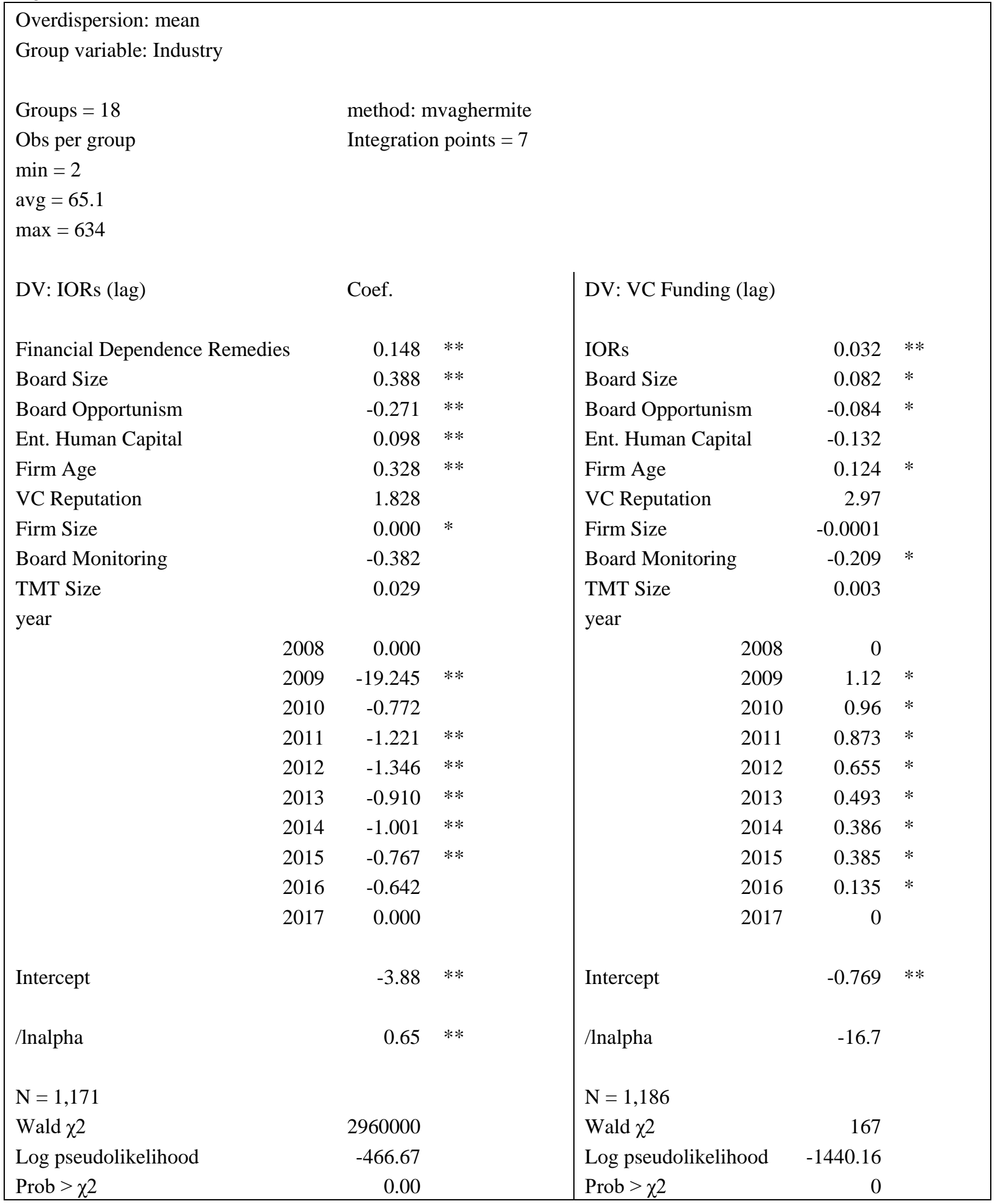


Figure 5.1. Structural Equation Modeling.

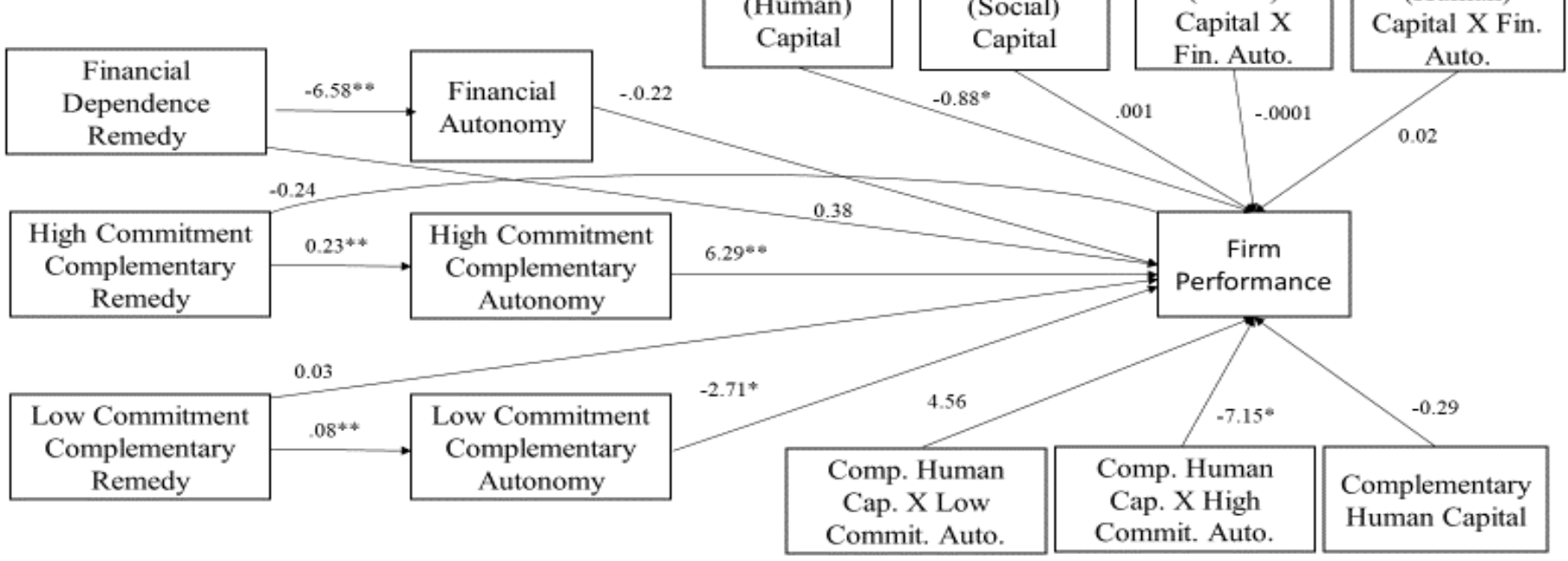

Industry latent and control variables are included in the model but not shown bere. 
Figure 5.2. Moderation Plot.

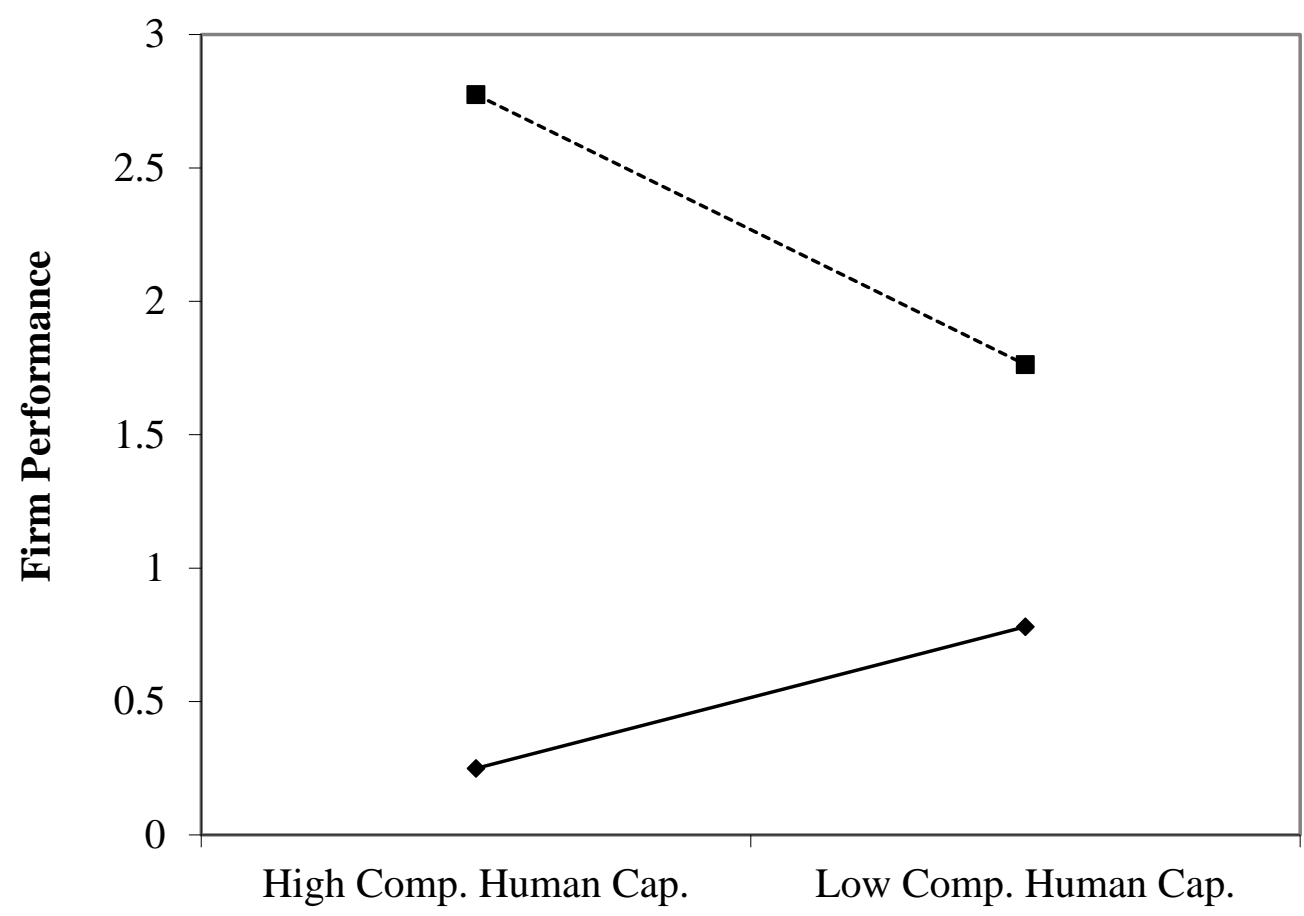

$\longrightarrow$ Low High Commit. Auto.

---n--- High High Commit. Auto. 